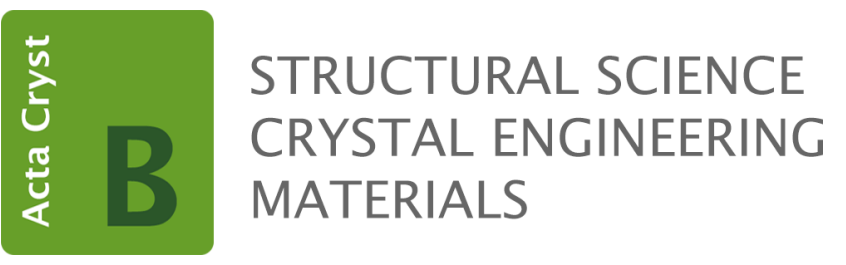

Volume $76(2020)$

Supporting information for article:

Identifying and characterizing translationally modulated molecular crystal structures

Carolyn Pratt Brock and Robin Taylor 
Supplementary Material for

\title{
Identifying and characterizing translationally modulated molecular crystal structures
}

\author{
BY CAROLYN PRATT BROCK* \\ Department of Chemistry, University of Kentucky, Lexington, KY 40506-0055, USA \\ EMAIL address: cpbrock@uky.edu \\ AND ROBIN TAYLOR \\ Cambridge Crystallographic Data Centre, 12 Union Road, Cambridge CB2 1EZ, UK \\ EMAIL address: ROBIN@JUSTMAGNOLIA.CO.UK
}

\begin{abstract}
Most structural (i.e., displacive) modulations make molecules independent that had been related by translation in a phase having a smaller or centered unit cell. In the modulated structure the independent molecules are differentiated by small translations, rotations, and/or conformational changes but an approximate translational relationship is normally retained. A program has been written to identify such pseudotranslations because they can be difficult to find by eye and because they combine with each other and with lattice translations in ways that can be confusing. To characterize the pseudotranslations the program calculates their fractional translational, orientational, and conformational components as well as several quality indicators. While many pseudotranslations are obvious, others are borderline; setting tolerances for identifying a pseudotranslation proved difficult. Default were chosen to reproduce experience-based judgement but they can be varied in the program input. The program was run for organic and for metallo-organic structures with $R \leq 0.075$ in the 2019 release of the Cambridge Structural Database. The frequency of pseudotranslations increases with $Z$ ' and is approximately $50 \%$ for $Z>4$. Some structures were found in which an identified pseudotranslation cannot correspond to a modulation. These include structures in which some but not all of the molecules are related by pseudotranslations and structures in which pseudotranslations in different parts of the unit cell have different directions.
\end{abstract}

1. Extra text and tables (pp. 2-43)

2. Extra figures (pp. $44-65)$

3. References for structures mentioned in the supplementary material (pp. 66-78) 
The Supplementary Material includes additional information for many sections of the paper. In most cases the list of additional structures discussed is not exhaustive.

For all sections below except 3 (Methodology) the subsections are numbered as in the paper. In Section 3 the sections are numbered sequentially.

\section{Material related to paper section}

\section{Introduction}

\section{$P 1, Z=Z^{\prime}=2$ structures that are approximately $P \overline{1}$ or $P 2_{1}$ with $Z^{\prime}=1$}

A transition in which a screw operation becomes approximate while $Z$ remains constant is not expected to generate a pseudotranslation. Molecules related by an approximate $2{ }_{1}$ axis are seldom also related by approximate translation because the molecule would have to have an approximate twofold axis that is approximately parallel to that screw axis.

(Examples of $P 1, Z=Z^{\prime}=2$ structures that seem to be distorted $P 21, Z=2, Z^{\prime}=1$ structures, none of which have approximate translations: CUHZAH, EGOZIK, JETYOZ, MEZQIU, OFANIV, YARZAV.)

In a $P 1$ structure derived from a $P \overline{1}$ structure only molecules that are approximately centrosymmetric can be related by a pseudotranslation; if the molecules are not approximately centrosymmetric then the modulated structure has no pseudotranslation.

(Examples of $P 1, Z=Z^{\prime}=2$ structures that seem to be distorted $P \overline{1}, Z=2, Z^{\prime}=1$ structures are OVAPEI, RIDFOA01, RIGSEF, SEVHAD, XEGKIG, XEPHUX. Of those only RIDFOA01 can be seen as modulated. XEGKIG has a pseudotranslation but it relates only one of the two large residues.)

\section{Material related to paper section}

\section{Modulations, pseudotranslations and pseudotranslational columns}

\section{Structures in which $Z$ ' decreases with cooling through a phase transition}

If the crystal goes through a sequence of phases with cooling, and if an intermediate phase has the highest value of $Z$ ', then there is a transition with cooling to a smaller asymmetric unit. Sometimes all three phases are known, e.g. MUFQAH phases There are phase transitions at 163 and $142 \mathrm{~K}$; the axial directions are the same for all three phases. The axis a of the HT cell is doubled in the intermediate cell (where beta $=90.01^{\circ}$ ) and tripled in the LT cell. The LT phase has a larger unit cell but a smaller 
asymmetric unit than does the intermediate- $\mathrm{T}$ phase. The transitions are reported to be singlecrystal-to-single-crystal (hereafter, scsc).

MUFQAH $203 \mathrm{~K} ; P 212121, Z^{\prime}=1(Z=4)$

MUFQAH01 $153 \mathrm{~K} ; P 2{ }_{1}, Z^{\prime}=4(Z=8)$ Pseudotranslation $[100] / 2$

MUFQAH02 $123 \mathrm{~K} ; P 212{ }_{12}, Z^{\prime}=3(Z=12)$ Pseudotranslation [100]/3

XOJYEC phases Formulated as a 1.5:1 co-crystal of 2,6-diisopropylphenol and isonicotinamide; if the co-crystal were formulated as 3:2 then the $Z$ ' values would be halved. The transitions are reported to be scsc.

XOJYEC $273 \mathrm{~K} ; P \overline{1}, Z^{\prime}=2(Z=4)$

XOJYEC01 $218 \mathrm{~K} ; P \overline{1}, Z^{\prime}=6(Z=12)$ Pseudotranslation $[1 \overline{11}] / 3$

XOJYEC02 $123 \mathrm{~K} ; P 2_{1} / c, Z^{\prime}=2(Z=8)$ Pseudotranslation $[111] / 2$ (and $[1 \overline{11}] / 2=[111] / 2-$ $\{011])$. The XOJYEC02 cell has approximate $I 2 / a$ symmetry with $Z^{\prime}=1$; in that group one of the phenol molecules would lie on a twofold rotation axis.

TETBUS phases The phases differ in the conformation of the $\mathrm{Me}\left(\mathrm{CH}_{2}\right)_{4}$ chain of the 2aminoheptanoic acid molecules. The highest-T phase is very disordered. The transitions are reported to be sCSC.

TETBUS04 $399 \mathrm{~K} ; C 2 / c, Z^{\prime}=1(Z=8)$ (but $\left.R=0.149\right)$

TETBUS03 RT; $P 2{ }_{1} / c ; Z^{\prime}=1(Z=4)$

TETBUS $150 \mathrm{~K} ; C 2 / c, Z^{\prime}=1(Z=8)$

TETBUS02 $145 \mathrm{~K} ; C 2, Z^{\prime}=8(Z=32)$. Pseudotranslation $[101] / 4$.

TETBUS01 $70 \mathrm{~K} ; P 2{ }_{1}, Z^{\prime}=6(Z=12)$ (but $\left.R=0.115\right)$

Examples of phase sequences for which the high-Z' phase is at the highest temperature.

JAWQIH phases There is no lower- $Z^{\prime}$ phase known above the $Z^{\prime}=8$ phase determined at $311 \mathrm{~K}$. JAWQIH03 $311 \mathrm{~K} ; B 21, Z^{\prime}=8(Z=32)$ Pseudotranslations [100]/2 and [001]/8 give [401]/8. JAWQIH01 RT; $P 21 / c, Z^{\prime}=3(Z=12)$ Pseudotranslations [100]/2 and [001]/3 give [302]/6 The transition is scsc.

VIVSAV phases There is no lower-Z' phase known above the $Z^{\prime}=6$ phase determined at $350 \mathrm{~K}$ (and no lower- $\mathrm{T}$ phases below the $Z^{\prime}=12$ phase determined at $100 \mathrm{~K}$ ).

VIVSAV03 $350 \mathrm{~K} ; P 2_{1} / a, Z^{\prime}=6(Z=24)$

VIVSAV04 $290 \mathrm{~K} ; P \overline{1}, Z^{\prime}=6(Z=12)$

VIVSAV01 $205 \mathrm{~K} ; P 2{ }_{1} / a, Z^{\prime}=1(Z=4)$

[and then

VIVSAV02 $\left.100 \mathrm{~K} ; P \overline{1}, Z^{\prime}=12(Z=24)\right]$

The transitions are reported to be sCSC.

KUTMAP phases There is no lower- $Z^{\prime}$ phase known above the $Z^{\prime}=6$ phase determined at $187 \mathrm{~K}$. KUTMAP02 $187 \mathrm{~K} ; P \overline{1}, Z^{\prime}=6(Z=12)$ Pseudotranslation $[111] / 6$

KUTMAP01 $85 \mathrm{~K} ; P \overline{1}, Z^{\prime}=1(Z=2)$ (and KUTMAP at $100 \mathrm{~K}$ ) 
There is some uncertainty about the temperatures; the inconsistency between the paper and the Supplementary Material could not be resolved. The temperatures shown above are those in the Supplementary Material and in the CSD entries. The transition is reported to be sCSC.

\section{Structures in which the pseudotranslation does not affect all the residues}

XEGKIG $\left[P 1, Z=Z^{\prime}=2\right.$; L-proline bis(2,4-dichlorobenzoic acid) hemihydrate. i.e., a 1:2:1/2 hydrated co-crystal] The [100]/2 pseudotranslation relates pairs of acid molecules but not the two L-proline zwitterions. These are related by pseudoinversion, as are the two independent columns of acid molecules. The pseudoinversion, rather than the pseudotranslation, makes XEGKIG a modulated form of a $P \overline{1}, Z^{\prime}=1$ structure.

ONANIC01 $\left[P 1, Z=Z^{\prime}=2 ; 2: 1\right.$ salt of $\mathrm{C}_{23} \mathrm{H}_{33} \mathrm{~N}_{2} \mathrm{O}_{6}{ }^{+}$and $\left.\mathrm{C}(\mathrm{OH})(\mathrm{COOH})(\mathrm{COO})^{2-}\right]$ The material is enantiomerically pure but the structure mimics $P \overline{1}$ packing. The protonated amine would be racemic if the $\mathrm{CH}_{2}$ and $\mathrm{O}$ of its THF ring were switched in half the cations. The dianion chirality would be switched by $\mathrm{H}^{+}$migration. There is a $[10 \overline{1}] / 2$ pseudotranslation that relates pairs of the four independent cations but not the two anions.

HUZDOV $\left[P 1, Z=Z^{\prime}=4 ; \mathrm{N}(n-\mathrm{Bu}) 4^{+} \text {(2,6-dihydroxybenzoate) }\right)^{-}$plus an included 2,6dihydroxybenzoic acid molecule] The cations are in layers near $z=1 / 4$ and $3 / 4$; cations within the layers are related by a $[1 \overline{1} 0] / 2$ pseudotranslation. The other residues make layers of H-bonded tetramers near $z=0$ and $1 / 2$. There is no pseudotranslation in the anion layers.

VUZTIU (P21/c, Z'=6; a 1: $2 / 3$ hydrate) The [323]/6, [010]/3, and [101]/2 pseudotranslations describe the main molecules only. There are two water molecules for every three of the larger molecules so the water molecules are occupationally modulated.

XECPON $\left[P \overline{1}, Z^{\prime}=8 ; 2: 1\right.$ co-crystal of an N-substituted bi-imidazole (substituent $=4$-pyridinyl) and 1,2,3,4-tetrafluoro-5,6-diiodobenzene] The [110]/2 pseudotranslation is too perfect; the volume of the unit cell should be halved. The [101]/2 pseudotranslation relates the bi-imidazole molecules but not the $\mathrm{C}_{6} \mathrm{~F}_{4} \mathrm{I}_{2}$ molecules.

The transformation matrix for halving the cell to a conventional triclinic cell is $\left(\overline{1}_{2} 1 /\left.20\right|^{1} / 2 / 20 \mid 00 \overline{1}\right)$. Additional inversion centers are introduced; $Z$ ' is reduced from four 2:1 formula units to two. There are obvious layers (100), $0.0<x<0.5$ in the larger cell; the layers are (110) in the smaller cell, where they are centrosymmetric. The $\mathbf{a}$ and $\mathbf{b}$ axes of the layer are [011] and [011] in the larger cell and [111] and [111] in the smaller cell. In the layers the bi-imidazole molecules are related by an alayer/ $/ 2$ pseudotranslation but the positions of the $\mathrm{F}$ and I substituents on the benzene rings prevent that pseudotranslation from applying to the whole layer or to the 3-D structure.

Both residues are related by approximate $2{ }_{1}$ axes along $\mathbf{a}_{\text {layer }}$ and approximate glides along $\mathbf{b}_{\text {layer }}$, with those two axes making an angle of $89.8^{\circ}$; the overall symmetry of the layer is approximately $p 2_{1} / b 11$ (\#17). The two independent bi-imidazole molecules are related by an approximate twofold axis along $\mathbf{a}_{\text {layer. }}$. In the approximate layer group some of the inversion 
centers of the $P \overline{1}$ cell are retained but others are absorbed into the approximate glide and approximate twofold rotation. If the $\mathrm{C}_{6} \mathrm{~F}_{4} \mathrm{I}_{2}$ molecules are ignored the approximate layer symmetry is $p 2 / b 11$ (\#16) with the alayer vector halved.

\section{Structures in which a pseudotranslation relates only some of the chemically identical molecules}

See the discussion of PIPQUA and UYOPAA below in section 7.4.

\section{Material related to paper section}

\section{Methodology}

\subsection{Definition of some basic terms}

The centroid of a molecule is the unweighted centroid of all its atoms except for terminal hydrogens.

The dissimilarity of two molecules of the same residue is measured by the root-mean-square deviation (rmsd) of the positions of their paired atoms (excluding terminal hydrogens) after the molecules have been overlaid in some way (see next section). Atom pairing is achieved by obtaining all possible graph matches of the two molecular connectivities and selecting the one that yields the lowest rmsd; although the connectivities are identical, there may be more than one match because of topological symmetry. Large molecules with very high topological symmetry (e.g., PINCOO) can very occasionally cause the software to fail tidily. This affects $<0.25 \%$ of organic structures and $<1.5 \%$ of metallo-organics. Element types and hydrogen counts are taken into account in the graph-matching, but not bond types or formal charges.

The algorithm for finding pseudotranslations looks for columns. A column is the repeat unit of a series of molecules related by approximate translation, i.e. $M 1, M 2, \ldots, M n, M 1$ ', where $M 1$ is the first molecule, followed by molecules $M 2$ to $M n$, and terminating in $M 1$ ', the last molecule, which is related to $M 1$ by the [uvw] lattice translation corresponding to the modulation direction. The length of the column, $d$, is therefore the length of this lattice vector. 
The median vector of a column lies along the modulation direction and has length $d$. Specifically, it is the vector $M 1-M 1$ ' after translation in a perpendicular direction such that the vector sum of the perpendicular ("transverse") displacements from the median vector of the molecule centroids is zero (excluding that of the last molecule). A hypothetical example is shown in Fig. S1, the bold arrow representing the median vector, the black circles being the centroids of molecules 1, 2, 3 and 1', and the red arrows being the transverse displacements of these centroids.

\subsection{Quantifying deviations from perfect translational symmetry}

For a molecule pair: Deviations from ideal translational symmetry can be separated into four components:

conformational $(C)$ - the molecules may adopt different shapes;

orientational $(O)$ - a rigid-body rotation may be needed to position one molecule optimally on another;

transverse $(T)$ - the centroids of the molecules may not lie exactly on the median vector; longitudinal $(L)$ - the projections of the centroids on the median vector may not be evenly spaced.

For example, consider molecules 1 and 3 in Fig. S1. Their conformational dissimilarity, $\operatorname{rms} d(C)$, is measured by superimposing their centroids (i.e., applying translation $a$ ) and rotating molecule 3 to obtain the best least-squares fit. The dissimilarity due to both conformational and orientational differences, $\operatorname{rmsd}(\mathrm{CO})$, is measured by applying the same translation but no rotation. The conformational + orientational + transverse dissimilarity, $r m s d(C O T)$, is measured by moving molecule 3 , without rotation, along the modulation direction until its centroid is as close as possible to that of molecule 1 (translation $b$ ). Finally, the dissimilarity due to all four components, $\operatorname{rmsd}(C O T L)$, is measured by moving molecule 3 , without rotation, along the pseudotranslation direction by the distance that would separate the centroids if the translational symmetry were ideal - in this case, $2 d / 3$ (translation $c$ ). The latter rmsd will henceforth be termed rmsd(total) as it measures the total deviation from ideal translational symmetry.

For a column: The overall quality of a column is measured by av_rmsd(total), the average of the rmsd(total) values of all molecule pairs, excluding any involving the end molecule, i.e., the one related to the first molecule by the $[u v w]$ lattice translation. The maximum of these $n(n-1) / 2$ values is termed max_rmsd(total). Quantities such as $a v \_r m s d(C)$ are defined analogously.

For a pseudotranslation (set of columns): Statistics are also useful for a set of columns since they may collectively make up a pseudotranslation, e.g. the GOLGIX [010]/3 modulation consists of two columns since $Z^{\prime}=6$. Clearly, quantities such as av_rmsd(total), etc., can be calculated for a set of columns. The relative proportions of conformational, orientational, transverse and longitudinal deviations in a modulation can then be quantified by: 
$\operatorname{fract}(\operatorname{conf})=a v \_r m s d(C) / a v \_r m s d(t o t a l)$

fract $($ orient $)=\left[a v \_r m s d(C O)-a v \_r m s d(C)\right] / a v \_r m s d(t o t a l)$

fract(trans) $=\left[\right.$ av_rmsd $\left.(C O T)-a v \_r m s d(C O)\right] /$ av_rmsd(total)

fract $(l o n g)=\left[a v \_r m s d(t o t a l)-a v \_r m s d(C O T)\right] / a v \_r m s d(t o t a l)$

The four fract values sum to 1 .

The $a v \_r m s d(t o t a l)$ and max_rmsd(total) values of a pseudotranslation or a pseudotranslational column are used frequently herein as indicators of its quality and will henceforth be simply termed av_rmsd and max_rmsd.

\subsection{Testing against CSD entries}

Throughout the development of the algorithm the output was compared with $c a .300$ organic structures having $Z^{\prime}>4$ and $\mathrm{R}<0.075$. Later on the results for $c a$. 100 organic, $\mathrm{R}<0.075$ structures in $P 1$ that were identified as having pseudotranslations were investigated individually. Finally, a set of 32 organic, $\mathrm{R}<0.075, Z^{\prime}=2-4$ structures identified as having borderline pseudotranslations were examined. ${ }^{1}$

\subsection{Other descriptive statistics}

The average transverse deviation of one or more columns can be measured by av_trans_dev, the mean (unsigned) distance of the molecule centroids (excluding those of end molecules) from their median vector. Similarly, the average longitudinal deviation, av_long_dev, is the mean of $\left|D_{i}-d / n\right|$, where $D_{i}$ is the distance between the projections of the centroids of the $i$ th pair of adjacent molecules onto the median vector, and $d / n$ is the distance expected for ideal translational symmetry.

If the centroid of the ith molecule in a column is termed $C_{i}$ and the projection of that centroid onto the median vector is $P_{i}$, then the absolute value of the torsion angle $\tau_{i j}=C_{i}-P_{i}-P_{j}-C_{j}$ can be defined. $\tau_{i j}$ values are calculated for all pairs of adjacent molecules. For an order 2 column, the two $\tau_{i j}$ values will both be $180^{\circ}$ because of the definition of the median vector (specifically, that it minimizes transverse deviations). However, the angle is rarely $180^{\circ}$ when a column is of higher order. For one or more columns, the maximum and minimum of the $\tau_{i j}$, termed min_trans_tau, max_trans_tau, indicate the variability of the torsions. Also, the crossover statistic \%trans_tau $>90$ is defined as the percentage of $\tau_{i j}$ values that exceed $90^{\circ}$. In qualitative

\footnotetext{
${ }^{1}$ AJEYEU [101], APUNUV [100], BOGPUK [100], EBODOR [211], EZAWAF [001], GASWII [001], HAZDOC [001], HUHMII [010], IFULUQ02 [100], IWUGIS [010], JACVOZ [001], KURHUC [001], LUYPIE [011], MOGJAV [121] , NAJYAB02 [102], OKELEW [201]], PUWRIK [210], QANVUW [101], QUYNUU [100], RAKZUA [100], TIWFAG [231] ], TOXQOO [111], UGOVER [001], VALPOP [110], VETNIR [100], VIVSAV02

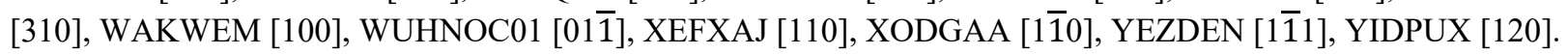


terms this measures the proportion of adjacent molecules that lie on opposite sides of the median vector and therefore helps distinguish between sawtooth and crenel patterns. The former have high crossover values (can be as large as 100\%) and the latter much smaller (though never zero).

The statistics max_ind and min_ind are, respectively, the largest and smallest number of symmetry-independent molecules in any of the columns comprising a pseudotranslation. Both of these quantities will usually be equal to the order $n$, but not always. For example, some of the pseudotranslations in a $C$-centered cell will have max_ind and min_ind equal to $n / 2$. There are several interesting examples, such as the [001]/2 modulation in TARNEG (Fig. S3) - in two of the four columns, the adjacent molecules are related by inversion symmetry. Since these two molecules (but not the other four) almost have inversion symmetry the pseudotranslation is of good quality.

In the event that one or more pseudotranslations in a modulation contain(s) symmetry-related molecules, imposed sym indicates which symmetry operators are involved (e.g., imposed_sym $=i$ means inversion).

Finally, qual_range is the difference in quality between the best and worst columns in a pseudotranslation; incomplete is a label attached to pseudotranslations that appear to occur only in certain layers; and enant is a crude statistic used to indicate whether apparent pseudotranslations might better be described as pseudoglides. These are detailed in Section 3.7.

\subsection{Scope of search}

The algorithm searches for pseudotranslations along all $[u v w]$ directions with $u>0$ and $|u|,|v|$ and $|w| \leq m x$, the maximum allowed index. This was set to 4 throughout this work, which almost always allowed the most important modulations to be found, though there were very occasional exceptions (e.g. SEMPEH [015]/10, Fig. S2.) There is no restriction on the maximum number of molecules in a column. Residues are dealt with in turn, in descending order of size. If a residue is found not to be modulated in a certain direction, no search is performed in that direction for substantially smaller residues $\left(\mathrm{NNONH}_{\text {smaller }}<0.6 \mathrm{NNONH}_{\text {largest }}\right.$ and $\mathrm{NNONH}_{\text {smaller }}<10$, where $\mathrm{NNONH}_{\text {largest }}$ and $\mathrm{NNONH}_{\text {smaller }}$ are the number of non-H atoms in the largest and smaller residue, respectively). To reduce processing time, single-atom residues that occur more than 16 times in the asymmetric unit are ignored (these are invariably water molecules or metal ions). Missing terminal-hydrogen atom coordinates are tolerated, but if bridging-hydrogen or nonhydrogen atom coordinates are missing, the residue to which the errant molecule belongs is omitted from the search.

\subsection{Searching for columns}

In this section, the word "molecule" refers only to molecules (and molecular ions) of a particular residue and the search is for columns along $[u v w]$. The search requires setting two criteria, max_crit and av_crit, the values of which are discussed in Sections 3.9 and 3.10, respectively. 
An array of unit cells is generated of size $(m x+1)$ by $(m x+1)$ by $(m x+1)$ and the atomic coordinates are transformed to an orthogonal coordinate system. The molecular centroids are calculated. The array of centroids is rotated about the origin to make [uvw] coincident with the $z$ axis of the orthogonal system; this is done just to make the arithmetic easier. The average $x$ and $y$ coordinates of the centroids are computed ( $a v x, a v y)$ in the orthogonal system and the point ( $a v x$, $a v y, 0)$ defined as the base centre. Each search for a column starts from a centroid (the start centroid, i.e. the centroid of the first molecule in the putative column) positioned as close as possible to the base centre, so as to minimize the chances that the search will overstep the boundaries of the array. If the coordinates of this centroid are (xstart, ystart, zstart), there will also be a centroid at (xstart, ystart, zstart $+d$ ), where $d$ is the length of [uvw]. This is the centroid of the last molecule, which is added to the putative column. The search then looks for other centroids with $(x, y)$ coordinates within max_crit $\AA$ of (xstart, ystart) and with a $z$ coordinate intermediate between zstart and zstart $+d$. If any are found they are added to the putative column.

The molecules corresponding to the chosen centroids are now inspected. Specifically, the rmsd $(C O)$ values of the first molecule with each of the intermediate molecules in turn are calculated. If any exceeds max_crit, the intermediate molecule is rejected. Optionally, the distance between the start centroid and each intermediate centroid can be compared with all possible expected pseudotranslation distances (e.g., $d / 2, d / 3$ and $d / 6$ if $Z^{\prime}=6$ ) and the molecule discarded if its distance is too far (>max_crit) from any of them (but see Section 3.9). Provided the intermediate centroids have not all been rejected, the max_rmsd value of the column is computed and the column accepted if the value is $\leq$ max_crit.

The column-search procedure is repeated until every molecule in the unit cell has either been found to occur in at least one column or has been unsuccessfully tried as a first molecule of a putative column. The start centroid for each new column corresponds to a molecule that has yet to be assigned to a column and has not already been tried. Columns must all be of the same size. If one is found that is smaller than the preceding columns, it is rejected; if larger, the preceding columns are rejected. The final outcome will be one of the following: (a) every molecule of the residue in the unit cell has been assigned to a column and at least one of the columns contains $\geq$ 2 symmetry-independent molecules; (b) some of the molecules are not in columns but the columns that do exist contain at least one example of each of the symmetry-independent molecules and, again, at least one of the columns contains $\geq 2$ independent molecules; (c) any other result. Result (a) indicates that the residue might be pseudotranslated, (b) indicates that an incomplete pseudotranslation might exist (i.e., pseudotranslation only in certain layers), while (c) shows that the residue is not pseudotranslated. In the latter case, the search has failed and the algorithm turns to the next residue or a new direction. Otherwise, the set of columns is analyzed to determine whether it is a pseudotranslation. 


\subsection{Analyzing a set of columns}

Layered structures: If outcome (b) above occurs, the pseudotranslation is marked as incomplete and the structure is presumably layered. Even if all molecules have been found in columns, i.e. outcome (a), some columns might be much better than others - this is expressed by the qual_range statistic, the difference between the av_rmsd values of the worst and best columns.

Best subset of columns: Once the possibility of layering has been examined, the best subset of columns containing at least one instance of each of the symmetry-independent molecules is found. Further analysis is confined to these columns only. In particular, acceptance of rejection of a pseudotranslation is based on whether the av_rmsd and max_rmsd of this subset of columns satisfy the criteria described in Sections 3.9, 3.10.

Final checks: The columns are rejected if: (a) the combined columns do not contain the correct number of each of the symmetry-independent molecules; (b) the difference between the largest and smallest adjacent-molecule inter-centroid distances exceeds a criterion, set throughout this work to $3.5 \AA$; (c) the overall av_rmsd of the set of columns exceeds av_crit. If these tests are passed the columns are deemed to be a valid pseudotranslation.

Possible pseudoglides: A crude indicator of whether the pseudotranslations might actually be pseudoglides is obtained by calculating enant, the average value over all pairs of adjacent molecules of $r m s d(C)$ - $r m s d(C)^{\prime}$, where $\operatorname{rmsd}(C)$ is the conformational dissimilarity of the pair and $r m s d(C)$ ' is the dissimilarity when one of the molecules is inverted.

The last step before moving to the next residue or direction is to complete the calculation of the statistics defined in Sections 3.2 and 3.4.

\subsection{Presentation of results}

Once the search on a structure is complete, the pseudotranslations - if any - for each residue are reviewed. Firstly, the shortest pseudotranslation with the largest value of $n$ is deemed to be the base pseudotranslation. Usually, all other pseudotranslations found for the residue can be related to the base by addition of one or two lattice vectors or shorter (i.e., lower $d / n$ ) pseudotranslations that have already been related to the base. These relationships are deduced. Very occasionally, no relationship can be found, in which case the pseudotranslation is recorded as none found.

\subsection{The need for iteration}

Unfortunately, no single value of max_crit is suitable for all structures. Problems are caused by

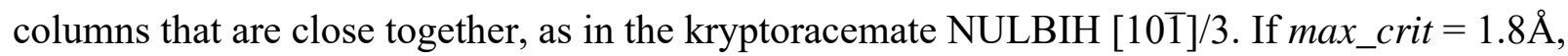
the algorithm will successfully find the columns with the correct order $n=3$, but with max_crit $=$ $3.0 \AA$, enantiomeric columns are incorrectly merged to give a column with $n=6$. On the other hand, a large max_crit is essential for some structures containing large-amplitude modulations, e.g. IGUYOA [001]/7. The problem is solved by searching for columns iteratively, gradually 
increasing max_crit along the sequence 1.0 $1.2, \ldots 2.0,2.25, \ldots 3.25 \AA$ until a modulation is found or all max_crit values have been unsuccessfully tried. (This is for the largest residue; all the values are increased by $0.2 \AA$ for smaller residues.) The sequence is cut down to just two values for very large residues $(1.8,3.25 \AA)$.

VADVIH [010]/2, highlights a clear deficiency in the algorithm. The modulation consists of four columns, three of which are high quality, the fourth very much poorer. The problem is that none of the max_crit values used in the search will simultaneously find all four, though the three good ones and the poor one can be separately found. One might think that a sufficiently large max_crit value would find then all. When the value is large, however, extraneous molecules nearby are erroneously included in at least one of the good columns. The pseudotranslation is then rejected because the columns are not all of the same order. Fortunately this problem occurs only rarely.

A further problem surrounds the optional step described in section 3.6, viz. checking the distances between the projected centroids of a putative column to see if they are close to the distances expected for the likely values of $n$. This step is essential to find some modulations, such as SEMPEH [011]/2, where columns are interleaved and difficult to separate. However, it can sometimes be counter-productive, e.g., on AZADUA [310]/6, which it incorrectly finds as [310]/3. Therefore, the iteration over max_crit is first run with this step switched off and, if no modulations are found, re-run with the step enabled.

Applying both the max_crit iterations and the switching off and on of the optional distance check roughly doubles the search time when the program is run on all the $Z^{\prime}>4$ structures. Compute times are still small enough, however, to allow the algorithm to be run on hundreds of thousands of structures, and our emphasis in this work is on the quality of the results.

\subsection{Selecting av_crit}

The ultimate criterion for deciding that a set of columns is good enough to constitute a pseudotranslation is that its $a v \_r m s d$ is less than the program parameter $a v \_c r i t$. Selecting $a v \_c r i t$ was therefore a very important step in the algorithm development. It was finally decided to calculate the parameter from:

$$
a v \_c r i t=\min (1.15+0.035 \text { non } H, 2.05)
$$

where nonH is the number of atoms in the residue neglecting terminal hydrogens. The coefficients were chosen by one of us (RT) to obtain good agreement between the results from the algorithm and the judgements made manually by the other (CPB). The increase of av_crit with non $H$ was essential to obtain good agreement and reflects the fact that pairs of small molecules can have small rmsds even if oriented randomly, whereas this is highly unlikely for larger molecules (Cole et al., 2005; Maiorov \& Crippen, 1995; Betancourt \& Skolnik, 2001). 


\subsection{Program performance}

The earlier manual study of Z'> 4 structures (Brock, 2016) found 144 of 284 to have pseudotranslations (see spreadsheet in supplementary material of that paper). A simple measure of program performance was obtained by examining how well this result was reproduced. Four of the structures with pseudotranslations were eliminated because there were no coordinates in the CSD for some molecules or there was serious unresolved symmetry-generated disorder (CHOEST21, OGUROZ, XELKAB, AWAKEO). When run on the remaining 280, the program had 14 false positives and 10 false negatives. For 8 of the false positives, however, the program gave clear indications that the pseudotranslations were layered so did not constitute modulated structures (i.e. marked incomplete or with a high qual_range: AGIXIZ, FEHFEF, JATNEX, MAJSOG, NAXDIZ04, QUJSAP, UYOPAA, WOPVOO). Of the others (DEYXOW [010]/2, FULLOP [111]/3, GENLAN [001]/2, PIPQUA [011]/2, TEMBAQ [101]/2, TIWFAG [231] $/ 6$ ) some appeared on visual inspection to have arguable pseudotranslations. Of the false negatives, 4 had marginal pseudotranslations (GIYNAE [012]/2, MERFEU [201] $/ 5$ and [102]/5, RESMUX [010]/6, SUHBIG [201]/18) and one had an ordered fault, one of the molecules in each column being flipped by $180^{\circ}$ with respect to the others (DHXANT13 [100]/4). Another 2 had pseudotranslations that involved only $n-1$ of the $n$ independent molecules, a situation not recognized by the program as a modulation (JOZPIX [111]/5. QADTEW [011]/6). QURQOK $[11 \overline{1}] / 5$ involved molecules in different ionization states (e.g., glycine, glycinium) which is also not recognized by the program. VADVIH [010]/2 was discussed in Section 3.9. DATTAV [100]/2 was probably missed because the transverse deviations are large and the pseudotranslational columns are closely interleaved.

Further program lapses are discussed elsewhere both in the main paper and below.

\subsection{Program timings}

Program timings were analyzed for a run on 49,490 organic structures from the CSD that had $R$ $\leq 0.075$ and might possibly have contained pseudotranslations (i.e. were not eliminated trivially on $Z^{\prime}$ grounds). The median processing time per structure was $0.5 \mathrm{~s}$ on a single Intel ${ }^{\circledR}$ Xeon ${ }^{\circledR}$ E5-2690 v4 $2.60 \mathrm{GHz}$ processor. 458 of the structures took longer than $10 \mathrm{~s}$. Very occasionally a structure will take several minutes, e.g. $210 \mathrm{~s}$ for VANFUO. Appreciably faster times can be achieved by making searches less thorough, with only a small depreciation in results quality.

\section{Material related to paper section}

\section{Parameters used to describe pseudotranslations}

\subsection{Order}

[See Figs. S2 (SEMPEH), S3 (TARNEG), and S4 (ROPJAJ)] 


\section{Structures in which the pseudotranslation is different for different residues}

LOHPON $\left[P 4_{2} / m, Z=2, Z^{\prime}=1 / 4\right.$ for $8\left(\mathrm{C}_{14} \mathrm{H}_{8} \mathrm{~S}_{4}{ }^{+}\right), 3\left(\mathrm{C}_{14} \mathrm{H}_{8} \mathrm{~S}_{4}\right), 4\left(\mathrm{TeCl}_{6}{ }^{2-}\right)$,

$\mathrm{C}_{14} \mathrm{H}_{8} \mathrm{~S}_{4}=$ dibenzotetrathiofulvalene $]$ The pseudotranslations are $[001] / 11, n \_i n d=6$ for the TTF derivative and $[001] / 4, n \_i n d=2$ and 1 for the anion.

OMOBUP $\left(P 2{ }_{1} / c, Z^{\prime}=5\right.$; a 2:1:1.4 hydrated salt of a $\mathrm{C}_{2} \mathrm{H}_{5} \mathrm{~N}_{4}{ }^{+}$cation and a $\mathrm{C}_{2} \mathrm{~N}_{8} \mathrm{O}_{2}{ }^{2-}$ bitetrazole dianion. The dianion nearly has $2 / m$ symmetry.) For every five 2:1 formula units of the salt there are seven water molecules that appear to be ordered in an H-bonded chain. The water chains thread together ion layers (001), which have approximate symmetry pbam (\#44). Along [101] there is an $n=10$ pseudotranslation for the ion layers and an $n=14$ pseudotranslation for the water molecules.

\section{Structures in which two sets of one residue are described by different pseudotranslations}

See discussion of PIPQUA, GENLAN, QUJSAP, and UYOPAA in Section 7.4.

\section{Structures in which the order of the pseudotranslation is not a factor of $Z^{\prime}$}

The following are all self-inclusion complexes, i.e., the included molecule is the same as the host molecules. These structures were not found by the program described in this paper.

JOZPIX $\left[P 1, Z=Z^{\prime}=6=5+1\right.$; bromo-2-(2'-pyridyl)phenyl-tellurium $]$ A sort of channel-inclusion complex in which molecule $\# 5$ fits between columns along $[1 \overline{11}]$ of $\# 3,4,6,1,2, \ldots$, but the orientations of host molecules \#3, 4 differ by ca. $180^{\circ}$ (in-plane rotation) from the orientations of $\# 6,1,2$.

QADTEW $\left[P \overline{1}, Z^{\prime}=7=6+1\right.$; dimethyl (5-chloro-1,3-benzoxazol-2-yl)carbonodithioimidate, $\mathrm{C}_{10} \mathrm{H}_{9} \mathrm{ClN}_{2} \mathrm{OS}_{2}$ ] A sort of channel-inclusion complex in which \#1 fills channels between four columns (each \#5,6,7,2,3,4,5,...) along [011]. The approximate[011]/6 pseudotranslation relating the molecules in the columns has a strong sawtooth character.

OCAZEX ( $P 2{ }_{1}, Z^{\prime}=5=4+1$; 4-pyridone hydrate $\left.\mathrm{C}_{5} \mathrm{H}_{5} \mathrm{NO}, 1.2 \mathrm{H}_{2} \mathrm{O}\right)$ A sort of channel-inclusion complex. Four of the 4-pyridone molecules make up the host lattice $(\# 1,3$ and \#2,4) while \#5 is the guest (as are the six water molecules). A layer of the host has approximate symmetry $p 11 a$ (\#5) with $\mathbf{a}_{\text {layer }}=[101]$ and $\mathbf{b}_{\text {layer }}=\mathbf{- a} / 2$.

\subsection{Number of independent molecules}

[See Figs. S3 (TARNEG) and S4 (ROPJAJ)] 


\section{Material related to paper section}

\section{Other features of pseudotranslations}

\subsection{Combinations with lattice vectors; the base pseudotranslation}

Fig. S5 (SOYKOH) illustrates how pseudotranslations are related by combinations with lattice vectors.

\section{Variation in the relative fractions of the transverse and longitudinal components}

The relative fractions of the transverse and longitudinal components can vary with the addition of lattice vectors. If two $[u v w]+\left[l_{1} l_{2} l_{3}\right]$ pseudotranslations are perpendicular then the magnitudes of the transverse and longitudinal components in one are switched relative to the other. In SECHUG $\left(P 2{ }_{1}{ }_{1} 2_{1}, Z^{\prime}=2\right)$ the program gives $71 \%$ transverse and $1 \%$ longitudinal for $[10 \overline{1}] / 2$ and gives the reverse for [101]/2 (which is listed only in the secondary output of the program). A view along [101] with limits of $0-1.5$ in all three directions shows some molecule columns in which the modulation is primarily transverse and other, symmetry-related columns in which the modulation is primarily longitudinal; the assignment of transverse and longitudinal components can depend on exactly which column is considered.

\section{Examples of structures in which there are two independent pseudotranslations}

AFIYUL $\left(P \overline{1}, Z^{\prime}=4\right)$ The pseudotranslations are $[10 \overline{1}] / 2$ and $[010] / 2$ with $a v \_r m s d s$ of 0.37 and $0.96 \AA$.

CEQKUH $\left(P \overline{1}, Z^{\prime}=4 ; 1: 1\right.$ co-crystal) The pseudotranslations are [100]/2 and $[001] / 2$ with $a v \_r m s d s$ of 0.26 and $0.18 \AA$ for the former and of 0.95 and $0.91 \AA$ for the latter. (There are two $a v \_r m s d$ values for each pseudotranslation because the crystal contains two different residues.)

$\operatorname{EPUQEM}\left(P 1, Z=Z{ }^{\prime}=2\right)[100] / 2$ and $[01 \overline{1}] / 2\left(a v \_r m s d s=0.62\right.$ and $\left.0.39 \AA\right)$

A 2:1 host-guest compound; the two pseudotranslations relate the four 4,4'-bipyridine host molecules only. PLATON recommends adding inversion centers to give a $P \overline{1}$ cell but there is some doubt about this recommendation (see Fig. S18).

KAFDIH $\left(P \overline{1}, Z^{\prime}=4\right)$ The pseudotranslations are $[101] / 2$ and $[010] / 2$ with $a v \_r m s d s$ of 0.77 and $1.05 \AA$.

YERFOT $\left(P \overline{1}, Z^{\prime}=4\right)$ The pseudotranslations are $[010] / 2$ and $[1 \overline{1} 1] / 2$ with $a v \_r m s d s$ of 0.38 and $0.42 \AA$ Their combination, [101]/2, is also listed.

YUVLOS $\left(P \overline{1}, Z^{\prime}=4\right)$ The pseudotranslations are $[010] / 2$ and $[100] / 2$ with $a v \_r m s d s$ of 0.61 and $0.86 \AA$. 
ZITFIT $\left(P \overline{1}, Z^{\prime}=4\right)$ The pseudotranslations are $[001] / 2$ and $[100] / 2$ with $a v \_r m s d s$ of 1.03 and $1.26 \AA$.

A more complicated example is $\operatorname{POLPOX}\left(P 2_{1}, Z=12, Z^{\prime}=6\right)$. Pseudotranslations [010]/3 and [313]/6 point to an $I 2$ basic cell with $Z=4$ and $Z^{\prime}=1=2(1 / 2)$, with the molecules lying on twofold axes. In the $P 2{ }_{1}$ cell there is also a pseudotranslation that relates two independent sets of three molecules each, but it is not clear whether [001]/2, [110]/2 or [100]/2 is the best description of that relationship. Two of those three (i.e., [001]/2 and [110]/2) are listed in the output. In any event, halving any of the $P 21$ cell axes does not lead to a smaller basic cell of the same or higher symmetry so that the additional pseudotranslation is not a modulation.

Structures in which the shortest pseudotranslation for a factor of $n(e . g ., 2$ or 3 for $n=6)$ is collinear with $[u v w] / n$

$\begin{array}{ll}n=4, m=2 & \text { CEJKEI, COCMIR02, HONBIW, HUYBIN, RIWSUL (residue 2) } \\ n=6, m=3 \text { and } 2 & \text { KUTMAP02 } \\ n=6, m=3 & \text { IVUBUY } n=8, m=4 \text { and/or } 2 \text { (none) } \\ n=10, m=5 \text { and } 2 & \text { OMOBUP (residues } 1 \text { and } 2 \text { ) } \\ n=14, m=7 & \text { OMOBUP (residue } 3 \text { ) }\end{array}$

\subsection{Cell centering}

\section{Examples of structures in which a pseudotranslation includes a centering vector}

C2 RIQLUZ [132] ]/6; TAMZIS [132]/6

Cc XIFMOQ and XUYTIW, both [132]/6.

$R \overline{3} \quad$ VANFOI01, VANFOI02, VANFUO=VANFOI0, three phases, all with [11 2$] / 4$ (In their space group $R \overline{3}$ the centering vectors are $\left[2 / 3^{1} 3^{1 / 3}\right],\left[{ }^{1} 3^{1 / 3} 3^{1}\right]$ and $\left[1^{1} 3^{2} 3^{1 / 3}\right]$.)

\subsection{Approximate cell centering}

\section{Structures in primitive cells having a basic cell that seems to be centered}

There are a number of structures in which the basic cell seems to be centered monoclinic (i.e. space group \#5, 9, or 15), with its axis b lengthened by an integral factor and the centering becoming approximate. If the basic cell is $C$-centered these structures have pseudotranslations $[010] / n$ and $[11 / n 0] / 2=[n \quad 10] / 2 n$, i.e., $[010] / 3$ and $[310] / 6$ if $n=3$. If the basic cell is $A-$ or $I-$ centered the second pseudotranslation is $[01 n] / 2 n$ or $[n 1 n] / 2 n$. Examples are:

$n=2 /$ FUFJUL $A$-centered; [010]/2 and [012]/4; the [100]/2 pseudotranslation is a remnant of the $a$ glide in the $A 2 / a$ basic cell.

$n=3$ / AZADUA, GOLGIX, JEDTIY, NAHCOQ. Also DAQYIG, POLPOX and QUCXOD (all $I$-centered), and SILJAB, WAWPES (both $A$-centered). When $n=3$ and the basic cell is $C$ - 
centered $[010] / 3$ and $[310] / 6$ combine to give $[330] / 6=[110] / 2$. Analogous combinations for $I$ and $A$-centered cells are $[111] / 3$ and $[011] / 2$.

$n=4 /$ LANBOS

$n=6 / \operatorname{LUXYOU}[23 \overline{4}] / 12$ in the full cell, where the layers are (101), corresponds to [110]/2 in the $C 2 / c$ basic cell, which is the cell found near $300 \mathrm{~K}$ (LUXYOU01/02). In the $C 2 / c$ cell the layers are (100).

Also,

BOCKEK06 $\left[P 1, Z=Z^{\prime}=4 ;\left(\mathrm{H}_{2} \mathrm{DABCO}^{2+}\right)\left(\mathrm{FHF}^{-}\right)_{2}\right]$ BOCKEK06 is the structure below the sCSC phase transition from the $C m c{ }_{1}, Z=4, Z^{\prime}=1$ phase (BOCKEK - BOCKEK05). The two sets of cell axes point in the same directions and their lengths are very similar. The [110]/2 pseudotranslation in the $P 1$ structure is then a remnant of the centering operation in the orthorhombic phase.

\subsection{Symmetry elements within the pseudotranslation}

\section{Some structures in which all molecules lie on special positions}

KAVLUP $\left[C 2, Z^{\prime}=3=6^{*}(1 / 2)\right]$ All six molecules lie on twofold rotation axes. The $[010] / 3$ pseudotranslation combines with the centering vector $[110] / 2$ to give $[310] / 6, n \_i n d=3$. There is also a $[001] / 2$ pseudotranslation that combines with $\{010] / 3$ to give $[023] / 6, n \_i n d=6$.

FADVOW $\left(C 2 / c, Z^{\prime}=1=2 *(1 / 2) ;[010] / 2\right)$ Both molecules lie on a twofold axis; the pseudotranslation is along that axis.

IHOYOT $\left(P 2, Z^{\prime}=1=2 *(1 / 2) ;[001] / 2\right)$ Both molecules lie on a twofold axis; the pseudotranslation is perpendicular to that axis.

MOBXUW01 $\left(C m c 21, Z^{\prime}=2.5=5 *(1 / 2) ;[010] / 5\right)$ All five molecules lie on a mirror plane. The pseudotranslation lies within that plane.

OMOSAK $\left(P 2 / n, Z^{\prime}=1=2 *(1 / 2) ;[011] / 2\right)$ The two bis(methylsulfamido) sulfone molecules (13 non-H atoms) lie on twofold rotation axes. The identified pseudotranslation, however, looks much more like a glide (enant $=0.95 \AA$ ) than like a pseudotranslation.

Layers (100) have approximate symmetry $p b 2 n$ with axes $\mathbf{a}_{\text {layer }}=\mathbf{c}$ and $\mathbf{b}_{\text {layer }}=\mathbf{b}$, and $z^{\prime}=1 / 2$, Adjacent layers (100) are related by the $n$ glide of $P 2 / n$. There are a number of approximate space groups consistent with those glides and with $p b 2 n$ layer symmetry; the most likely of those groups seems to be Aea2 (\#41)

RIWSUL $\left(P \overline{1}, Z^{\prime}=1=2(1 / 2) ;[100] / 2\right)$ Both molecules lie on inversion centers. The pseudotranslation is excellent except for a $180^{\circ}$ difference in the orientation of the 2-pyridinyl 
rings. There are four independent $\mathrm{H}_{2} \mathrm{O}$ molecules, which have a very good [100]/2 and a less good [100]/4 pseudotranslation. The water molecules lie on general positions.

ZZZVTY12 $\left(P \overline{3}, Z^{\prime}=1=3(1 / 3) ;[\overline{1} 11] / 3\right)$ All three molecules lie on threefold axes. The pseudotranslation suggests an $R \overline{3}$ basic cell. One of the $\mathrm{CPh}_{3} \mathrm{Cl}$ molecules in a column has an inverted conformation.

\section{Some structures in which a pseudotranslation passes through a symmetry element}

\section{Examples in which a molecule lies on the symmetry element}

HEKZOO ( $\mathrm{Cm}, \mathrm{Z}^{\prime}=2.5$ for $\left.2 \mathrm{I}_{2} \cdot \mathrm{DABCO}\right)$ Three sets of five molecules each (one set of DABCO cages and two sets of $\mathrm{I}_{2}$ molecules) line up along [010]; in each set of five one molecule lies on a mirror and two pairs of molecules are related by the mirror.

TAJVIK $\left[R \overline{3}, Z^{\prime}=3(1 / 3)+1 / 6=1.17\right.$ the number of independent molecules $\left(Z^{*}\right)$ is 4$]$;

$\left.\mathrm{Ph}_{3} \mathrm{SiC} \equiv \mathrm{CC} \equiv \mathrm{CSiPH}_{3}\right)$ Three independent molecules lie on threefold axes and a fourth lies on a $\overline{3}$ site. Along [001] seven molecules line up but only four are independent.

TAJVIK01 $\left(P \overline{1}, Z^{\prime}=2.5 ; \mathrm{Ph}_{3} \mathrm{SiC} \equiv \mathrm{CC} \equiv \mathrm{CSiPH}_{3}\right)$ There is a pseudotranslation along [11̄2] that relates five molecules: two pairs of molecules related by an inversion center and one molecule lying on a $\overline{1}$ site.

NB/ TAJVIK at RT and TAJVIK01 at $180 \mathrm{~K}$ may be related by a phase transition.

The structures of FIDJOS $\left(\mathrm{Ph}_{3} \mathrm{CC} \equiv \mathrm{CC} \equiv \mathrm{CCPh}_{3}\right)$ and TPSICI $\left(\mathrm{Ph}_{3} \mathrm{SiN}=\mathrm{C}=\mathrm{NSiPh}_{3}\right)$ are similar to that of TAJVIK; both are $R \overline{3}, Z^{\prime}=1 / 3+2 *(1 / 6)=2 / 3$ at RT and so have three independent molecules rather than four.

THIOUR05 (Pbnm, Z’=4.5). Along [001] nine molecules are lined up; four pairs of molecules are related by the mirror on which molecule \#1 is located.

\section{Examples in which no molecule lies on the symmetry element}

KAYGUO $\left(P \overline{1}, Z^{\prime}=6\right)$. 1:1 N-(Pyridin-2-yl)isonicotinamide succinic acid co-crystal. For the succinic acid, which is nearly centrosymmetric, the pseudotranslation $[3 \overline{2} 1] / 6, n \_i n d=3$ passes through inversion centers; the inversion center relates two groups of three molecules.

(For the larger molecule that is a nicotinamide derivative, which has approximate mirror

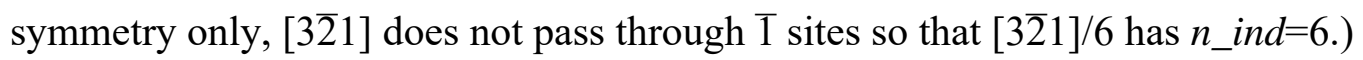

OMOBUP $\left[P 2_{1} / c, Z^{\prime}=5\right]$. For the dianion the pseudotranslation is $[101] / 10, n \_i n d=5$. Inclusion of inversion symmetry within the row is possible because the deviations of the dianion from inversion symmetry are small (its idealized symmetry is $2 / \mathrm{m}$ ). The rows along [101] of the less symmetric monocations (idealized symmetry $m$ ) do not pass through inversion centers; for the cation the pseudotranslation is [101]/10 with $n \_$ind $=10$. 


\section{Material related to paper Section}

\section{Results}

\subsection{Most too-good pseudotranslations are easy to spot}

If the pseudotranslation is suspected of being too perfect then the fraction of superlattice reflections ${ }^{2}$ having $I>3 \sigma(I)$ is the best indicator of its validity. If the pseudotranslation is too good then the least-squares refinement was almost certainly unstable. The presence of any very eccentric atomic displacement ellipsoids (ADPs) is a danger signal, especially if ellipsoids for atoms related by the supposed pseudotranslation are elongated in approximately perpendicular directions. If the ADPs for corresponding atoms in molecules related by the pseudotranslation seem to be the same then there is a good chance that constraints or strong restraints were used to stabilize the refinement. Discussion of some borderline cases follows:

\section{Structures in which a subtle pseudotranslation seems to be real:}

ASATET01 $\left(P 2{ }_{1} 2_{1} 2_{1}, Z^{\prime}=3\right)$ Crystals grown from acetone have a threefold larger cell than do crystals grown from methanol The av_rmsd and max_rmsd values for the [001]/3 pseudotranslation are small $(0.10$ and $0.12 \AA)$ but the authors justified the supercell refinement carefully.

MOVTIB02 $\left(P c, Z^{\prime}=8\right)$ The $[010] / 2$ modulation for the isonicotinamide molecules $\left(\mathrm{C}_{6} \mathrm{H}_{6} \mathrm{~N}_{2} \mathrm{O}\right)$ looks too good ( $a v \_r m s d=0.15 \AA$ ) but $[010] / 2$ is much less good for the included water molecules $\left(a v \_r m s d=0.96 \AA\right)$.

ODUWEQ [P1, Z=Z'=4; $\left(\mathrm{C}_{6} \mathrm{H}_{8} \mathrm{~N}^{+}\right)\left(\mathrm{H}_{4} \mathrm{~B}_{5} \mathrm{O}_{10} 0^{-}\right) \cdot \mathrm{C}_{6} \mathrm{H}_{7} \mathrm{~N}$ at $\left.120 \mathrm{~K}\right]$. The $[011] / 2$ pseudotranslation for the two sets of the two anions has $a v \_r m s d=0.05 \AA$ but no pseudotranslation is identified for the 4-MePy/4-MePyH ${ }^{+}$pairs because the cation and neutral molecule alternate along [011] (see section 7.1).

BOCKEK06 $(P 1, Z=Z$ '=4) The [110]/2 pseudotranslation (av_rmsd and max_rmsd values 0.16, $0.17 \AA$ and $0.22,0.24 \AA$ for the two residues) was found below a phase transition that was studied carefully.

EXEMOJ $\left(C 2 / c, Z^{\prime}=4\right)$. For $[110] / 4$ the $a v \_r m s d$ value is $0.16 \AA$ but the third and fourth molecules along [110] are related to the first and second by the $C$-centering operation so that the $a v \_r m s d$ may be underestimated by a factor of two.

TCLOBQ $\left(P 21 / n, Z^{\prime}=7\right)$ The [201]/7 modulation is subtle ( $a v \_r m s d=0.18 \AA$ although max_rmsd $=0.31 \AA$ ) and little crystallographic information is available, but the spacing along [201] of the centroids of the rigid o-chloranil molecules, $\mathrm{C}_{6} \mathrm{Cl}_{4} \mathrm{O}_{2}$, is convincingly variable $(6.67$

\footnotetext{
${ }^{2}$ Superlattice reflections are those that would be systematically absent if the pseudotranslation were a true (i.e., crystallographic) translation.
} 
$-7.15 \AA$ ). The ADPs are physically reasonable. If strong restraints had been applied during the refinement the principal axes of the ADPs would probably vary less than they do.

ZATLAJ03 ( $P 2_{1}, Z^{\prime}=8$ at $120 \mathrm{~K}$ ) The [001]/2 modulation is very subtle ( $a v \_r m s d=0.18 \AA$ ) for the larger benzene-1,2-diaminium cations but no pseudotranslation at all was found for the included water molecules or the $\mathrm{SO}_{4}{ }^{2-}$ and $\mathrm{HSO}_{4}{ }^{-}$anions, for which the protons were not located definitively and the double-bond assignments are arbitrary. The $P 2{ }_{1}, Z^{\prime}=4$ structure above the phase transition (ZATLAJ01 at $130 \mathrm{~K}$ and ZATLAJ at $144 \mathrm{~K}$ )) was studied carefully, so the pseudotranslation is almost certainly real. When a crystal is cooled through the transition the length of the axis $\mathbf{c}$ is doubled.

\section{Structures in which the pseudotranslation is in doubt:}

$\operatorname{SAXNUD}\left(P 1, Z=Z^{\prime}=4\right)$ For $[100] / 2$ av_rmsd $=0.72 \AA$ but a view along a shows almost perfect overlap of two molecule pairs except for a $180^{\circ}$ rotation of one of the four $\mathrm{C}_{4} \mathrm{H}_{2} \mathrm{~N}_{2}-\mathrm{C}_{5} \mathrm{H}_{4} \mathrm{~N}$ substituents. The ADPs for a number of the atoms are very eccentric, which suggests unrecognized $\mathrm{C} / \mathrm{N}$ disorder and/or misidentification.

WEZBAF $\left(P 21, Z^{\prime}=4\right)$ The pseudotranslation [110]/2 has av_rmsd=0.32 $\AA$ but both PLATON and Marsh (see WEZBAF01) recommend a $C 2$ cell with $Z=4$ and $Z^{\prime}=1$. The somewhat arbitrary choice of the primary $\mathrm{Ph}$ orientation in one $(\# 2)$ of the four disordered molecules [occupancy factors 0.49(1), 0.46(1), 0.49(1), 0.48(1)] accounts for the av_rmsd being large enough to avoid notice.

Marsh (1999) wrote that

There are many examples of superstructures, often forming at low temperature, where small, systematic shifts from a symmetric arrangement are clearly evidenced by weak superlattice reflections or by small violations of space-group absences; in most such cases, I believe, the antisymmetric shifts are $0.5 \AA$ or more for at least some atoms. If the separation between energy minima were appreciably smaller than that, perhaps of the order $0.1-0.2 \AA$, one might well expect a disordered (either static or dynamic) structure; except at low temperatures, such disorder might be adequately modeled with anisotropic displacement parameters and would probably go unnoticed.

It is our experience that Marsh's proposed criterion is too strict.

Hempler et al. (2017) used DFT-D calculations to investigate possible conversion of a pseudotranslation to a true translation for seven structures, three of which were not considered in this project because of an $R$ factor $>0.075$. The DFT-D calculations support the shortened axes for LEPMEZ03 ( $\left.Z^{\prime}=2 ; \mathbf{c} / 2 ; a v \_r m s d=0.04 \AA\right)$ and MOVWIE $\left(Z^{\prime}=3 ;[112] / 3 ; a v \_r m s d=0.04\right.$ $\AA$ ). The DFT-D calculations do support the identification of pseudotranslations $\mathbf{a} / 2$ in JECREO $\left(a v \_r m s d=0.32 \AA\right)$ and $\mathbf{c} / 2$ in GOMKAU (av_rmsd $\left.=0.42 \AA\right)$. These results are in agreement with our findings. 


\subsection{Effect on space-group frequencies}

Fig. S12 is an expanded version of Fig. 5 in the paper (five distributions are shown rather than two). Space group frequencies for the ten most common space groups and for all other groups combined are shown for the organic and for the metallo-organic structures. The distributions were determined for structures in the November 2019 version of the CSD that meet the criteria used in this study (e.g., $R \leq 0.075$ ).

\section{Observations:}

1/ The distributions for the $Z^{\prime}=1$ structures are very like those for all structures because $Z^{\prime}=1$ structures are such a large fraction of all structures. (For metallo-organic structures the $Z^{\prime}=1$ structures are a smaller fraction of all structures because of the larger number $(29 \%$ vs. $13 \%)$ having fractional $Z^{\prime}<2$, i.e., having molecules located on special positions.

2/ All three distributions for the $Z \geq 2$ structures are clearly different than the distributions for all structures and for the $Z^{\prime}=1$ structures.

3/ The distributions for the $Z^{\prime} \geq 2$, no pseudotranslation structures are very like the distributions for all $Z^{\prime} \geq 2$ structures because $c a$. $85 \%$ of the $Z^{\prime} \geq 2$ structures have no pseudotranslation.

4/ The distributions for the $Z^{\prime} \geq 2$, modulated structures are somewhat different (especially for the metallo-organics) than for the $Z^{\prime} \geq 2$, no pseudotranslation structures.

A comparison of the the $Z^{\prime}=1$ and $Z^{\prime} \geq 2$, no pseudotranslation distributions indicates there must be a systematic difference that has not yet been recognized. The increase in the $P 1$ percentage going from $Z^{\prime}=1$ to $Z^{\prime} \geq 2$ may be partly explained by structures in which two molecules in an enantiopure crystal are arranged to mimic an inversion relationship. In any event, whatever the factor(s) may be, they may also affect the distribution of the $Z^{\prime} \geq 2$, modulated structures. 
The graphs were made from the following table:

Percentage occupancy of space groups, organic structures

\begin{tabular}{lllll}
\hline Space group & $Z^{\prime}=1$ & $Z^{\prime} \geq 2$ & $Z^{\prime} \geq 2$, modulated & $\begin{array}{l}Z^{\prime} \geq 2, \text { no } \\
\text { pseudotranslation }\end{array}$ \\
\hline 14 & 38.0 & 24.3 & 31.7 & 22.9 \\
2 & 20.1 & 29.3 & 34.2 & 28.2 \\
19 & 14.5 & 7.7 & 4.8 & 8.4 \\
4 & 8.4 & 17.6 & 16.1 & 18.1 \\
15 & 4.9 & 2.1 & 1.0 & 2.1 \\
61 & 4.4 & 1.3 & 0.4 & 1.5 \\
33 & 1.8 & 2.1 & 0.9 & 2.4 \\
9 & 1.2 & 1.6 & 1.0 & 1.6 \\
5 & 1.0 & 1.6 & 1.7 & 1.5 \\
29 & 0.9 & 2.4 & 0.7 & 2.8 \\
1 & 0.7 & 6.0 & 2.8 & 6.8 \\
7 & 0.4 & 1.3 & 1.8 & 1.2 \\
\hline
\end{tabular}

Percentage occupancy of space groups, metallo-organic structures

\begin{tabular}{lllll}
\hline Space group & $Z^{\prime}=1$ & $Z^{\prime} \geq 2$ & $\begin{array}{l}Z^{\prime} \geq 2, \\
\text { modulated }\end{array}$ & $\begin{array}{l}Z^{\prime} \geq 2, \text { no } \\
\text { pseudotranslation }\end{array}$ \\
\hline 14 & 43.3 & 29.4 & 41.0 & 27.3 \\
2 & 29.4 & 38.6 & 40.2 & 38.0 \\
19 & 6.1 & 3.9 & 2.5 & 4.2 \\
15 & 5.3 & 2.0 & 1.3 & 2.1 \\
61 & 4.0 & 1.6 & 0.3 & 1.9 \\
4 & 3.3 & 9.9 & 6.6 & 10.7 \\
33 & 1.8 & 2.0 & 1.2 & 2.2 \\
9 & 1.5 & 1.7 & 0.7 & 1.9 \\
29 & 0.7 & 2.4 & 0.5 & 2.9 \\
1 & 0.6 & 3.9 & 1.3 & 4.5 \\
7 & 0.4 & 1.6 & 1.4 & 1.6 \\
60 & 0.4 & 0.1 & 0.1 & 0.1 \\
\hline
\end{tabular}




\subsection{Pseudotranslations often have more than one important component}

Distributions of fract(conf), fract(orient), fract(trans) and fract(long)

\begin{tabular}{lllll}
\hline Range & \multicolumn{2}{l}{ Numbers of structures } & & \\
& fract(conf) & fract(orient) & fract(trans) & fract(long) \\
\hline $0.0 \leq$ fract $<0.1$ & 2550 & 2603 & 4781 & 8618 \\
$0.1 \leq$ fract $<0.2$ & 1399 & 1469 & 1613 & 834 \\
$0.2 \leq$ fract $<0.3$ & 917 & 1133 & 1033 & 289 \\
$0.3 \leq$ fract $<0.4$ & 834 & 966 & 657 & 135 \\
$0.4 \leq$ fract $<0.5$ & 755 & 898 & 484 & 61 \\
$0.5 \leq$ fract $<0.6$ & 748 & 740 & 415 & 29 \\
$0.6 \leq$ fract $<0.7$ & 719 & 582 & 310 & 11 \\
$0.7 \leq$ fract $<0.8$ & 736 & 506 & 281 & 1 \\
$0.8 \leq$ fract $<0.9$ & 703 & 505 & 279 & 1 \\
$0.9 \leq$ fract $\leq 1.0$ & 624 & 583 & 132 & 6 \\
\hline
\end{tabular}

The longitudinal component of a pseudotranslation is almost always the smallest because if the molecules are in contact then their spacing should be even unless they have very different conformations or orientations. The [011] $/ 5$ pseudotranslation in XAPKOQ [Fig. 6(d)] is a good example of a pseudotranslation with a significant longitudinal component [fract(long) $=0.28$ ]. In XAPKOQ one molecule (\#3) has a different conformation than the other four; that conformation allows it to be closer to its neighbors along [011] than the other four molecules are to each other. Overall that $[01 \overline{1}] / 5$ pseudotranslation has a sawtooth character.

The component fractions can be restricted by composition or symmetry. The conformational and orientational fractions of a pseudotranslation are necessarily zero in the case of a residue having only one non-H atom. The transverse and longitudinal fractions are zero in the case of all related molecules lying on inversion centers. The transverse fraction is zero in the case of all related molecules being located on a single rotation axis that is parallel to the pseudotranslation (e.g., [010]/3 in KAVLUP).

Some structures in which the important conformational difference between molecules is the orientation of a phenyl ring

Differences in aromatic ring rotations (usually phenyl or naphthyl) are common for molecules related by pseudotranslations. The difference in rotation allows space to be filled more efficiently. Examples include AFOXAW, EZUZEG, FOKROO, IFOCIQ, IHIZIK, JOKNED, KAGVAS, NUVJIZ, OCAZOI, QAVYAO, QIZWIF, QOSTEZ, SIMHUS, TAFLET, VAFHEQ, VAHKIB, WADXAA, XATRAL, YOHKOX01, YUJGOZ. 


\section{Material related to paper section}

\section{Problem structures and interesting outliers}

\subsection{Positioning of $\mathbf{H}$ atoms}

\section{Structures having apparent pseudotranslations that are not identified because the units that would be related have different numbers of $H$ atoms}

KOHRAA [P1, $Z=Z^{\prime}=4$; L-lysinium succinate (a 2:1 salt) plus a neutral molecule of succinic acid] In the CSD the compound is formulated as 1:0.5:0.5; the unit cell contains four cations, two dianions, and two neutral molecules. A [100]/2 pseudotranslation is identified for the cations only but also works well for the succinic acid residues if the difference in protonation is ignored.

(Note/ This 1991 structure does not include any $\mathrm{H}$ atoms. when $\mathrm{H}$ atoms are not located, the database-building software adds them but without 3D coordinates. In KOHRAA the software assigned $\mathrm{H}$-atom positions so that each of the columns along [100] contains one succinic acid molecule and one succinate ion, in which case no pseudotranslation is identified.)

ODUWEQ [P1, Z=Z' $=4 ;\left(\mathrm{C}_{6} \mathrm{H}_{8} \mathrm{~N}^{+}\right)\left(\mathrm{H}_{4} \mathrm{~B}_{5} \mathrm{O}_{10^{-}}\right)^{\cdot} \mathrm{C}_{6} \mathrm{H}_{7} \mathrm{~N}$ at $\left.120 \mathrm{~K}\right]$. A [011]/2 pseudotranslation is identified for two sets of two anions. No pseudotranslation is identified for the four 4-MePy/4$\mathrm{MePyH}^{+}$pairs that are similarly related because molecules and cations alternate along [011] (the proton positions were determined). A phase change to a $P \overline{1}, Z^{\prime}=2$ structure in which the extra protons are disordered seems likely at higher temperatures.

RIDFOA [P $\left.\overline{1}, Z^{\prime}={ }^{1} / 2 ;\left(\mathrm{C}_{12} \mathrm{H}_{13} \mathrm{~N}_{2}{ }^{+}\right)_{2}\left(\mathrm{C}_{6} \mathrm{I}_{2} \mathrm{O}_{4}{ }^{2-}\right) \cdot \mathrm{C}_{6} \mathrm{H}_{2} \mathrm{I}_{2} \mathrm{O}_{4}\right]$ contains a 5,5'-dimethyl-2,2'bipyridinium cation, the dianion of iodanilic acid (3,6-diiodo cyclohexa-2,5-diene-1,4-dione-5ol-2-olate) and an iodanilic acid molecule. The apparent [010]/2 pseudotranslation is not listed for the anion and molecule (i.e., for $\mathrm{C}_{6} \mathrm{I}_{2} \mathrm{O}_{4}{ }^{2-}$ and $\mathrm{C}_{6} \mathrm{H}_{2} \mathrm{I}_{2} \mathrm{O}_{4}$ ) because they have different numbers of $\mathrm{H}$ atoms. (NB/ It is not clear that the $\mathrm{H}$-atom positions in this structure were all assigned correctly.

BUT, pseudotranslations relating TCNQ molecules and TCNQ- anions are found, as are pseudotranslations relating BEDT-TTF molecules and BEDT-TTF ${ }^{+}$ions (e.g., OFAXUP, PEXTER). The two units have different numbers of electrons but the same numbers of the same atoms. 


\subsection{Molecules that are related by symmetry}

\section{Structures having apparent pseudotranslations that are not identified because the molecules in each column are equivalent by symmetry}

This problem arises when (a) the molecule has good enough approximate symmetry that a symmetry relationship of the basic cell can give rise to one or more pseudotranslational columns; and (b) there is no other column that contains two or more symmetry-independent molecules.

POLPOX $\left[P 2{ }_{1}, Z=12, Z^{\prime}=6 ; 1\right.$,3-bis(1-benzyl-4-phenylpyrrolidin-3-yl)urea, $\left.\mathrm{C}_{35} \mathrm{H}_{38} \mathrm{~N}_{4} \mathrm{O}\right]$ has an obvious pseudotranslation [010]/3 with the molecules lying on very good, but approximate, twofold axes. The basic cell has $\mathbf{b}^{\prime}=\mathbf{b} / 3$ and $Z=4$; its symmetry is clearly $I 2$ with $Z^{\prime}=1=2(1 / 2)$. The pseudotranslation corresponding to the approximate $I$ centering is $\left[1 \frac{1}{3} 1\right] / 2$ or $[313] / 6$, which is also listed. The combination of [010]/3 and [313]/6 is [333]/6=[111]/2 but [111]/2 is not listed because molecules adjacent along [111] are related by a 21 axis.

FUGMIF01 ( $P \overline{1}, Z=4, Z$ '=2 at $413 \mathrm{~K}$; piperazin-1-ium perchlorate) The [1111]/2 pseudotranslation is found for the anions but not the cations. Along [111] the two independent cations are in separate columns within which the ions are related by crystallographic inversion. $(\mathrm{NB} /$ the protonated $\mathrm{N}$ atoms could not be identified; the occupancy factors of the extra protons are all given as 0.50 .)

FUGMIF ( $P 1, Z=Z^{\prime}=4$ at $200 \mathrm{~K}$ ) has the same unit cell dimensions as FUGMIF01 but the inversion centers have been lost. The apparent pseudotranslation for the cations is still not listed because the position of the protonated $\mathrm{N}$ atom appears to alternate along [111] even though the occupancy factors for all those protons are given as 0.50 .

\subsection{Pseudoglides and pseudoscrews may be identified as pseudotranslations}

\section{Structures in which a pseudotranslation might be better described as a pseudoscrew or pseudoglide}

Approximate glides and screws are often the result of symmetry lowering associated with a phase transition. Approximate operations that include a translational component can be difficult to distinguish from pure pseudotranslations that include modest orientational and/or conformational changes. When do those changes become so large that the pseudotranslation label is no longer appropriate? If there is a phase transition in which a glide operation becomes approximate and is identified as a pseudotranslation then the situation is clear, but more often it is not.

In a few cases a listed pseudotranslation is actually an overlooked symmetry relationship. 


\section{Structures in which an identified pseudotranslation is an overlooked glide or screw}

FUCTIG03 ( $P 1, Z=Z^{\prime}=2 ; 4,4^{\prime}$-bipyridinium dinitrate) PLATON recommends, at the $100 \%$ level, transformation to $F d d 2, Z^{\prime}=1 / 2$ with the transformation matrix $(021|201| 00 \overline{1})$. FUCTIG03 is therefore the same as FUCTIG01 (also at RT) and FUCTIG02 (at $90 \mathrm{~K}$ ). In the Fdd2 cell there can be no pseudotranslation because the asymmetric unit contains one nitrate ion and one half of a 4,4'-bipyridinium ion, which is located on a twofold axis. The pseudotranslations [1110]/2 and [111]/2 in the $P 1$ cell become [110]/4 and [110]/4 in the F-centered cell; the ions apparently related by a pseudotranslation are actually related by a $d$ glide.

BAZHAM ( $P 1, Z=Z^{\prime}=8$; methoxymethylsilane) PLATON recommends a change to Pna $2_{1}$ with $Z^{\prime}=2$; the transformation matrix, which just rotates the axes, is (001|100|010). Marsh recommended the same transformation in 2005 (see BAZHAM01). The deviations of the cell angles from $90^{\circ}$ are no greater than $0.03^{\circ}$.

The two independent molecules in the revised cell seem to be related by approximate symmetry but it is local and does not lead to any additional symmetry or approximate symmetry.

The $a$ glide of the $P n a 2{ }_{1}$ cell becomes a $c$ glide perpendicular to $\mathbf{a}$ in the $P 1$ cell, which is found as a [001]/2 pseudotranslation. The $n$ glide of the $P n a 2_{1}$ cell would be found as a [110]/2 pseudotranslation in the $P 1$ cell but that glide interchanges the $\mathrm{SiH}_{3}$ and $\mathrm{OMe}$ ends of the molecule so that the [110]/2 pseudotranslation would have a too-large av_rmsd.

The $[02 \overline{1}] / 4$ pseudotranslation that is listed would be [102]/4 in the Pna2 1 cell and would relate the two independent molecules in that cell.

\section{Structures in which a pseudotranslation is clearly an approximate glide}

NAKNEV03/04 $\left[P 1, Z=Z^{\prime}=4 ;\left(\mathrm{H}_{2} \mathrm{DABCO}^{2+}\right)\left(\mathrm{ClO}_{4}^{-}\right)_{2} \cdot \mathrm{H}_{2} \mathrm{O}\right]$ NAKNEV03/04 are structures below the scsc phase transition from the $P c a 2_{1}, Z=4, Z$ ' $=1$ phase (NAKNEV, NAKNEV02). The unit cells for the two space groups have nearly the same dimensions but the axes are labeled differently. The [101]/2 pseudotranslation identified for the $P 1$ structure is a remnant of the $a$ glide of the $P c a 2_{1}$ structure. The shorter $c$ glide of the $P c a 2_{1}$ structure does not appear as a pseudotranslation because the combination of the distance of the ions from the mirror and the differences in their orientations leads to an $a v \_r m s d$ for a pseudotranslation in that direction greater than the tolerance.

The isostructural $\mathrm{BF}_{4}^{-}$salt (NAKNOF02/03/04) has the same phase transition.

FUFJUL $\left(P 2{ }_{1} / n, Z=16, Z^{\prime}=4 ; 2: 1: 3\right.$ hydrated sodium salt of the dianion $\left.\mathrm{C}_{19} \mathrm{H}_{15} \mathrm{NO}_{7}{ }^{2-}\right)$ No higher-symmetry cell has been reported but the basic cell appears to be $C 2 / c, Z=8, Z^{\prime}=1$ after transformation by $\left(001\left|0 \frac{1}{2} 0\right| 100\right)$. The pseudotranslation[100]/2 in FUFJUL would then be the remnant of the $c$ glide of the $C 2 / c$ basic cell. The $n$ glide of the $C 2 / c$ cell is retained in the modulated cell.

LANBOS $\left(P 2{ }_{1} / n, Z=64, Z^{\prime}=16\right.$; sodium saccharinate dihydrate $)$ The basic cell seems to have $C 2 / c$ symmetry with axes $\mathbf{a}, \mathbf{b} / 4$, and $\mathbf{c}$ so that $Z=16$, and $Z^{\prime}=2$. (The two independent anions 
alternate in a column along $\mathbf{b}$.) When $\mathbf{b}$ is lengthened the original centering operation [110]/2 becomes $\left[1 \frac{1}{400}\right] / 2$, which is better written as $[410] / 8$. The listed pseudotranslation $[001] / 2$ (marked none found, i.e. could not be related to the base of other shorter pseudotranslations by addition of lattice vectors) is the remnant of the $c$ glide, which is lost when the centering is lost. \{The $c$ glide can be written as a combination the $n$ glide plus the centering operation $[(1 / 2+x, 1 / 2-y$, $1 / 2+z)-(1 / 2,1 / 2,0)=(x, y, 1 / 2+z)]\}$.

HUYBIN [P2 $12{ }_{12}{ }_{1}, Z$ '=8; 2-(methylamino)-1-(2-thienyl)ethanol, $\left.\mathrm{C}_{7} \mathrm{H}_{11} \mathrm{NOS}\right] \mathrm{A}$ kryptoracemate. The [001]/4 pseudotranslation is obvious. The program lists [401]/8 as a pseudotranslation ( $a v \_r m s d=1.46 \AA$ ) but adjacent molecules are separable enantiomers so that the relationship is better described as an approximate glide. The enant value (1.10 $\AA)$ is a clear warning sign. The structure appears to be modulated form of a Pnca structure (alternate setting of $P b c n, \# 60$ ) having axes $\mathbf{a}, \mathbf{b}$, and $\mathbf{c} / 4$. With increased tolerances PLATON finds approximate inversion centers.

IGARIT [P1, Z=Z'=2 at $93 \mathrm{~K}$; 5-(naphthalen-1-yl)isophthalic acid DMSO solvate dihydrate] The unit cell contains four $\mathrm{C}_{18} \mathrm{H}_{12} \mathrm{O}_{4}$ molecules, two waters, and two DMSOs. The large molecule has a 1-naphthyl group connected to a $\mathrm{Ph}$ ring with $\mathrm{COOH}$ groups at the 3 and 5 positions. Molecules related by the [110]/2 pseudotranslation are conformational enantiomers; the identified pseudotranslation has a conformational fraction 0.84 . The value of enant is $1.35 \AA$; the rmsds for molecular overlay with inversion are 0.07 and $0.06 \AA$ for the two pairs and $1.42 \AA$ without. It seems better to describe the pseudotranslation as an $a$ pseudoglide perpendicular to $\mathbf{b}$ even though the glide is local to layer (001), which has approximate symmetry $p 2 a n$ (standard setting $p b 2 n, \# 24$ ). Pseudoglides in adjacent layers (001) are offset along $\mathbf{b}$ by 0.27 , i.e., not by a simple fraction of $\mathbf{b}$.

\section{Structure in which a pseudotranslation might be better described as a glide mimic}

KISCUM ( $P 1, Z=Z^{\prime}=2$ at $296 \mathrm{~K}$; enantiopure benzyl 2-naphthyl sulfoxide) A switch of the $=\mathrm{O}$ and lone-pair attached to the $\mathrm{S}$ atom in one molecule would make the two molecules enantiomers. While the rmsd for molecular overlay of $1.27 \AA$ is reduced to $0.45 \AA$ if inversion is allowed, it is reduced to $0.10 \AA$ if only torsional rotations are allowed. The structure is an excellent mimic of $P a$ symmetry [transformation $(010|100| 00 \overline{1})]$, with the $[1 \overline{1} 0] / 2$ pseudotranslation becoming an approximate glide with the mirror perpendicular to $\mathbf{a}$ of KISCUM. The value of enant is $0.82 \AA$.

\section{Structures in which a distinction between a possible pseudotranslation and pseudoglide is impossible}

HMHOCN05 $\left[P 2_{1} / c, Z^{\prime}=4\right.$; polymorph $\mathrm{D}$ of triacetone triperoxide (TATP; $\mathrm{C}_{9} \mathrm{H}_{18} \mathrm{O}_{6}$ ) $]$ There is an $n=4$ pseudotranslation along [211] (av_rmsd $=0.59 \AA$ ); the molecule sequences are $\# 1,2,1^{\prime}, 4, \ldots$ and $\# 2,3,4,3^{\prime}, \ldots$, where $\# 1 \& 1^{\prime}$ are related by the $c$ glide as are $\# 3 \& 3^{\prime}$ while molecules $\# 2 \& 4$ are related by a very good pseudotranslation. The sequence along [211] can then be described as an 
ordered fault, e.g., RRRSRRRS,... involving conformational enantiomers The pseudotranslation [010]/2 (av_rmsd=0.52 A) relates \#1\&3, \#2\&2' and \#4\&4'; \#1\&3 are related by a good pseudotranslation but the members of the other two pairs are related by a crystallographic glide. The enant values for [211]/4 and [010]/2 are 0.43 and $0.42 \AA$. The pseudotranslation [001]/2 ( $a v \_r m s d=0.89 \AA$ ) is also listed; members of two of the pairs (\#2\&3', \#4\&4') are related by the $c$ glide while the related $\# 1 \& 3$ are conformational enantiomers (enant $=0.87 \AA$ ) related by an approximate glide.

The publication refers to the doubling of $b$ relative to other phases; the doubling includes a conformational change for some of the molecules.

KAVHOF $\left[P 2{ }_{1} / c, Z^{\prime}=5 ; 2,6\right.$-di-t-butyl-4-(1-pyrazolyl)phenol, $\left.\mathrm{C}_{17} \mathrm{H}_{24} \mathrm{~N}_{2} \mathrm{O}\right]$ has a pseudotranslation $[010] / 5$ (av_rmsd=1.02 $\AA$ ) that would look like a pseudoglide but for the odd number of molecules related (one alternation fault for every five molecules). The mirror of the glide would be in the plane (100). The value of enant is $0.24 \AA$.

SABPOB $\left(P 2{ }_{1}{ }_{1} 2_{1}, Z^{\prime}=7\right.$; [001]/7; trans-anti-2-cyano-2-isonitroso-N-morpholinylacetamide, $\left.\mathrm{C}_{7} \mathrm{H}_{9} \mathrm{~N}_{3} \mathrm{O}_{3}\right)$ A view along c suggests that the structure is modulated but no pseudotranslation is listed, presumably because the $a v \_r m s d s$ exceed the tolerances. The structure is composed of layers (100) having four different H-bonded chains along b (\#3\&2, \#1\&5, \#6\&7, \#4\&4'). The molecules related by the pseudotranslation differ in conformation (inversion of the morpholine ring, rotation of the $-\mathrm{C}(\mathrm{CN})=\mathrm{N}-\mathrm{OH}$ group) as well as orientation [direction of tip relative to

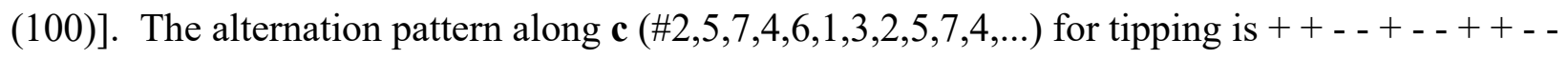
..., so there is one alternation fault (from alternation by pairs) in seven molecules. The H-bonded chain of \#4 has 21 symmetry; the other chains (two independent molecules each) have local glide symmetry. Overall the crystal is a 4:3 conformational kryptoracemate.

\subsection{Layered structures}

\section{Structures having different pseudotranslations in different layers}

In almost all structures the pseudotranslations found apply to the unit cell as a whole. In a small number of structures, however, the pseudotranslations have different directions in adjacent structural layers or relate molecules in different ways. There are three types of such structures:

1/ Structures composed of two or more layers that have different packing arrangements.

2/ Structures in which a pseudotranslation $[u v w] / n$ is a good description in some layers but not in others even though the two sets of layers are related by symmetry.

3/ Structures in which the pseudotranslation $[u v w] / n$ applies to all layers but the orientations of the molecules relative to $[u v w]$ differs between layers.

The pseudotranslations in structures of type 2 are related by symmetry if an average is taken over the entire unit cell but they differ locally. For example, pseudotranslations in monoclinic 
structures can differ with the layer position if the pseudotranslation is neither parallel nor perpendicular to the unique axis (i.e., if $[u v w]$ is neither $[0 v 0]$ nor $[u 0 w]$ for $\mathbf{b}$ unique).

An $n$-fold screw axis perpendicular to a pseudotranslation in a layer has no effect if $n=2$. If $n$ is 3 or higher the screw axis can cause the pseudotranslation directions to vary between layers.

Whether or not it does depends on the order of the pseudotranslation, the order of the screw axis, and on the structure of the layer.

A $4_{1}$ axis may result in layers (001) at different values of $z$ having pseudotranslations [uv0] that point in different directions (e.g., LADQAL). Pseudotranslations in all layers (001) will be the same, however, if the layers include exact 4-fold rotational symmetry or if the axes a and $\mathbf{b}$ in the layer are related by other crystallographic or approximate symmetry (e.g., the twofold axes in the layers of the $P 4{ }_{12} 2$ structure ZZZVCO05).

In a trigonal (or hexagonal) structure in which there are layers related by a 31 axis any $[u v 0] / 3$ or [uv0]/6 pseudotranslation will be a pseudotranslation in all layers (type 3) even if the layer has no rotational symmetry. Within the layers linear combinations with lattice vectors generate two other pseudotranslations that make angles of $120^{\circ}$ with [uv0] (but which may have different ratios of their transverse and longitudinal components). Examples are SEUREA03/04 (P3 1 and $\left.P 32, Z^{\prime}=9 ; \quad[210] / 3\right)$ and YODRAL/YIZTOR $\left(P 3{ }_{1}\right.$ and $\left.P 3_{2}, Z^{\prime}=6 ;[210] / 3\right)$. In the latter structures the basic cell of the layer has quite good approximate symmetry $c 211$. If the order of a [uv0] pseudotranslation in a layered structure is not a multiple of 3 the pseudotranslation could be of type 2 , but no such example was found.

For type 3 structures the quality measures for $[u v w] / n$ are the same for all layers but the ratios of the transverse and longitudinal components often differ.

\section{Type 1a: Structures in which different sets of identical molecules are described by different pseudotranslations}

The example given in the paper is

PIPQUA $\left(P \overline{1}, Z^{\prime}=6 ; 1,8\right.$-diiodonaphthalene) The molecules form two different layers (100), which alternate; the packing in the two layers is not the same. Two molecules are in a layer at $x=0$; this layer has a pseudotranslation $[01 \overline{1}] / 2$. The other four molecules are in a layer at $x=1 / 2$, which has a nearly exact pseudotranslation $[010] / 2$. The $[010] / 2$ pseudotranslation only works for the layer at $x=0$ if a $c a .180^{\circ}$ rotation of one of the two molecules is allowed; for this reason, $[010] / 2$ is not listed in the program output. The $[01 \overline{1}] / 2$ pseudotranslation is not very good for the layer at $x=1 / 2$ because the tilts of the planar molecules vary quite a lot; for $[01 \overline{1}] / 2$ $a v \_r m s d=1.15 \AA$, qual_range $=0.67 \AA$, and enant $=0.09 \AA$.

Other examples:

GENLAN ( $P \overline{1}, Z^{\prime}=12$; benzene with para substituents $\mathrm{NMe}_{2}$ and $\mathrm{CCH}$ ) For the bilayer (100) at $x=0$ that contains molecules $\# 1-8$ there is an excellent [010]/2 pseudotranslation. For the 
bilayer at $x=1 / 2$ that contains molecules $\# 9$ - 12 there is an excellent [001]/2 pseudotranslation. The [001]/2 pseudotranslation works reasonably well for the bilayer at $x=0$ but the rotations of the related $\mathrm{Ph}$ rings and $\mathrm{NMe}_{2}$ groups are quite different (qual_range $=0.76 \AA$ ). The [010]/2 pseudotranslation does not work well for the bilayer at $x=1 / 2$ because it would superimpose the $\mathrm{NMe}_{2}$ and $\mathrm{CCH}$ substituents. The pseudotranslation [001]/2 (av_rmsd=0.75 $\AA$ qual_range $=0.76 \AA$ ) is listed in the program output but $[010] / 2$ is not.

QUJSAP $\left[P \overline{1}, Z^{\prime}=6 ;\left(\mathrm{Me}_{3} \mathrm{Si}\right)_{2} \mathrm{CSi}\left(\mathrm{NH}_{2}\right)_{2} \mathrm{Si}\left(\mathrm{NH}_{2}\right)_{2} \mathrm{C}\left(\mathrm{SiMe}_{3}\right)_{2}\right]$ The [010]/2 pseudotranslation ( $a v \_r m s d=0.92 \AA$ ) is much better for the thicker layer of four molecules around $z=1 / 2$ than for the thinner layer of two molecules at $z=0$ (qual_range $=2.16 \AA$ ). The two molecules near $z=0$ that would be related by the $[010] / 2$ pseudotranslation are approximate conformational enantiomers; the rmsd for their overlap is $1.55 \AA$ but is only $0.11 \AA$ with inversion.

UYOPAA ( $P 2{ }_{1} 2{ }_{1}{ }_{1}, Z^{\prime}=6$; tricyclic molecule $\left.\mathrm{C}_{17} \mathrm{H}_{22} \mathrm{O}_{3} \mathrm{~S}\right)$ The [110]/2 pseudotranslation is very good for the thicker layer (001) at $z=1 / 4$ (four molecules) but much less good for the thinner layer (\#4 and \#6) at $z=0$. For [110]/2 av_rmsd $=0.83 \AA$ and qual_range $=1.95 \AA$.

\section{Type 1b: Structures in which chemically different ions or molecules are described by different pseudotranslations}

HUZDOV $\left[P 1, Z=Z^{\prime}=4 ; \mathrm{N}(n-\mathrm{Bu}) 4^{+} \text {(2,6-dihydroxybenzoate) }\right)^{-}$plus an included 2,6dihydroxybenzoic acid molecule] The cations are in layers near $z=1 / 4$ and $3 / 4$; the cations are related by a $[1 \overline{1} 0] / 2$ pseudotranslation $\left(a v \_r m s d=0.37 \AA\right.$ ).. The other residues make layers of $\mathrm{H}$ bonded tetramers near $z=0$ and $1 / 2$; there is no pseudotranslation in those layers.

OFAXUP ( $P 1, Z=Z^{\prime}=2 ; 2: 1: 3$ hydrated compound) The unit cell contains two independent bis(ethylenedithio)TTFs, one of which has been oxidized to a monocation, a guest anion $\mathrm{C}_{12} \mathrm{H}_{22} \mathrm{~N}_{2} \mathrm{O}_{5} \mathrm{~S}^{-}$, and three water molecules. The two larger residues are separated into layers (001). For the host molecules/ions the [100]/2 pseudotranslation seems almost too good $\left(a v \_r m s d=0.10 \AA\right)$ but the $[1 \overline{2} 0] / 4$ pseudotranslation is better described as an approximate screw axis along a because of the tilts of the molecules. Layers (001) of the host molecule have very good approximate symmetry $p 2111$ (\#9) with $\mathbf{a}^{\prime}=\mathbf{a} / 2$ and $\gamma=89.4^{\circ}$. The two guest molecules are related by approximate $2{ }_{1}$ axes along [110] but there is no overall layer symmetry because of the offsets between adjacent rows along [110]; the angle of [110] with [110] is $108.4^{\circ}$.

\section{Type 2: Structures in which the direction of the pseudotranslation is different in different layers that are related by symmetry}

The example given in the paper is WOPVOO $\left[P 2_{1} / c, Z Z^{\prime}=5 ; \mathrm{C}_{20} \mathrm{H}_{20} \mathrm{~N}_{2} \mathrm{O}_{4} \cdot 0.4\left(\mathrm{H}_{2} \mathrm{O}\right) \cdot 0.8 \mathrm{DMSO}\right]$ There are two centrosymmetric layers (001), at $\mathrm{z}=0$ and $1 / 2$, that are related by the glide plane and screw axis and are separated by the included solvent. In the layer at $z=0$ the shortest pseudotranslation of the largest (i.e. nonsolvent) residue is [120]/5; in the layer at $z=1 / 2$ the shortest pseudotranslation is $[1 \overline{2} 0] / 5$. The 
angle of [120] with [010] is $50.6^{\circ}$. The two directions are interchanged by the $2{ }_{1}$ axes and the $c$ glides. The program finds the $[120] / 5$ and $[1 \overline{2} 0] / 5$ pseudotranslations but marks each as incomplete because they do not apply across the whole unit cell. [Specifically, for this residue: (a) there is a set of acceptable pseudotranslational columns that between them contain at least one instance of each of the symmetry-independent molecules of the residue; but (b) there is not a complete set of acceptable columns that between them contain all molecules of the residue in the unit cell.]

Other examples:

FEHFEF ( $C c, Z^{\prime}=8 ; 2$-methyl-7H-benzo[c]xanthen-7-one, $\left.\mathrm{C}_{18} \mathrm{H}_{12} \mathrm{O}_{2}\right)$ There are good pseudotranslations $[1 \overline{1} 0] / 4, n \_i n d=2$ in the layer $(001)$ at $z=0.01$ and $[110] / 4, n \_i n d=2$ in the layer at $\mathrm{z}=0.51$; the two directions are related by the $c$ glide. Each layer contains all eight independent molecules. For the layer near $z=0,[110] / 4$ is a (quite) approximate pseudotranslation; [11 0$] / 4$ is clearly very much better. For the layer near $z=0.5$ the roles of the two directions are reversed. The two pseudotranslations are marked in the program output as incomplete.

\{Note that since the cell is $C$-centered there are exact [110]/2 and [1T0]/2 translations in both layers. Also, note that the two sets of four molecules in the primary pseudotranslation of each layer (e.g., $[1 \overline{1} 0] / 4, n \_$ind $=2$ at $\left.z=0.01\right)$ are related by a pseudoglide with its mirror in the layer.\}

MAJSOG $\left[C c, Z^{\prime}=8\right.$; quinoline-2 $(1 \mathrm{H})$-thione $]$ The pseudotranslations are very similar to those in FEHFEF: [110]/4 in the layer (001) at $z=-0.01$ and [110]/4 in the layer (001) at $z=0.49$. MAJSOG and FEHFEF differ, however, because the pseudoglides in the layers of MAJSOG have mirrors that are perpendicular to the layer (i.e., have the mirror normal within, rather than perpendicular to, the layer). The difference in the glide-mirror orientation results in the secondary pseudotranslations (which relate the two molecules of an H-bonded pair) in MAJSOG being less good relative to the primary pseudotranslation than is the case in FEHFEF. In MAJSOG the two pseudotranslations are marked as incomplete.

NAXDIZ04 (Cc, Z'=6; 2,5-diphenyl-1,3,4-oxadiazole) There are two layers (001) that are related by the $c$ glide. The layer (001) at $z=0.39$ has a pseudotranslation $[1 \overline{1} 0] / 6, n \_i n d=3$ while the layer at $z=0.89$ has a pseudotranslation $[110] / 6, n \_i n d=3$. The program marks the pseudotranslations as incomplete.

(Note that within each pseudotranslation one of the three unique molecules has an orientation that is related to the other two by an approximate twofold rotation around its longest molecular axis.)

LADQAL ( $P 4_{1}, Z^{\prime}=6$; 4-fluoro-3,5-diphenyl-1,2-oxazole) The $4_{1}$ axis causes layers (001) having $[100] / 3$ and $[010] / 3$ pseudotranslations to alternate. The program marks those pseudotranslation as incomplete.

(Note that the molecule of LADQAL is quite similar to the molecule of NAXDIZ04 and packs in 
similar layers that include similar columns. As in NAXDIZ04 one of the three unique molecules in each column has an orientation that is related to the other two by an approximate twofold rotation around the longest molecular axis.)

NAVHEY $\left[P 2{ }_{1}, Z^{\prime}=6\right.$; hemihydrate of (4-nitroanilinium)((S)-10-camphorsulfonate) $]$ The pseudotranslation describes both ions and the water molecules. The pseudotranslation directions are $[01 \overline{1}] / 3$ in the layer $(100)$ at $x=0.25$ and $[011] / 3$ in the layer at $x=0.75$. The program marks the pseudotranslations as incomplete for all three residues.

VALPOP $\left\{P 2{ }_{1}{ }_{1} 2{ }_{1}, Z^{\prime}=6\right.$; $(2 \mathrm{R}, 5 \mathrm{~S})-\left[1,1^{\prime}\right.$-bi(cyclohexan)]-6-ene-2,5-diol, $\left.\mathrm{C}_{12} \mathrm{H}_{20} \mathrm{O}_{2}\right\}$ The pseudotranslation directions are $[110] / 3$ in the layers $(001)$ at $\mathrm{z}=0.14$ and 0.64 and $[1 \overline{1} 0] / 3$ in the layers at $z=0.36$ and 0.86 . The screw axes along $\mathbf{a}$ and $\mathbf{b}$ are responsible for the difference in the directions. The program marks both pseudotranslations as incomplete.

\section{Type 3: Structures in which the orientation of molecules in a pseudotranslation is different in different layers}

MOCPUQ [P1, Z=Z’=8; (R)-2-((S)-(t-butoxycarbonylamino)(2-chlorophenyl)methyl)-2cyanocyclopentanone, $\mathrm{C}_{18} \mathrm{H}_{21} \mathrm{ClN}_{2} \mathrm{O}_{3}$ ] Two independent layers (001), each composed of two independent $\mathrm{H}$-bonded dimers, are related by an approximate $90^{\circ}$ rotation around $\mathbf{c}$. Layers have good approximate symmetry p $2111(\# 9)$ and reasonably good symmetry $c 2_{1} 11(\# 10)$. The cell dimensions $\left(13.51,13.55,20.35 \AA ; 89.8,89.9,87.8^{\circ}\right)$ suggest a distorted tetragonal cell but the layers are related by alternating, approximate, local $4_{1}$ and $4_{3}$ operations that interchange the $[110] / 2$ and $[1 \overline{1} 0] / 2$ pseudotranslations. The two pseudotranslations are related by the lattice vector [010] and so describe the structure equally well but the approximate $2{ }_{1}$ axis is parallel to a in the layer at $z=0.165$ and parallel to $\mathbf{b}$ in the layer at $z=0.664$. (av_rmsd $=1.07 \AA$;

qual_range $=0.26 \AA$ ).

TAMZIS [C2, Z’=6; $\left(\mathrm{NH}_{2} \mathrm{Me}_{2}{ }^{+}\right)($bis((4-fluorophenyl)sulfonyl)azanide] Layers (201) are not well separated but can be identified because they contain H-bonded chains of the six cations and six anions. Adjacent layers have H-bonded chains with pseudotranslations [132]/6 or [1 $\overline{3} 2] / 6$ but only three ion pairs are independent because [132]/6 includes a centering vector (e.g., $3 *[110] / 2$ $+[\overline{101}]=[132] / 2)$. The [132]/6 and [132]/6 pseudotranslations (av_rmsd $=0.46$ and $0.91 \AA$ for the two different ions) are related by combination with [010] so either applies to all layers but only one of the two in each layer relates ions connected by $\mathrm{H}$ bonds ([132]/6 in one layer and [1532]/6 in the next). Within a chain adjacent ion pairs are related by a pseudoglide with the mirror in the layer (approximate layer group p11a, \#5).

WANJAZ ( $P 2{ }_{1}{ }_{1}{ }_{2}, Z^{\prime}=8 ; \mathrm{C}_{23} \mathrm{H}_{24} \mathrm{BrNO}_{4} ;$ Fig. S13) In the layers (010) at $y=0.125$ and 0.625 there is a pseudotranslation $[201] / 4\left(a v \_r m s d=0.98 \AA\right)$ and an approximate, local $2{ }_{1}$ axis in the same direction; that axis relates the two sets of four molecules related by the pseudotranslation. For the layers at $y=0.375$ and 0.875 the corresponding pseudotranslation is $[20 \overline{1}] / 4$ because adjacent layers are related by a 21 axis along a (at $y=0.25$ or 0.75 ) or $\mathbf{c}$ (at $y=0.0$ or 0.5 ) and 
because $[\overline{2} 01] / 4$ is the same as $[20 \overline{1}] / 4$. For the layers at $\mathrm{y}=0.125$ and $0.625[20 \overline{1}] / 4$ is also a pseudotranslation because $[20 \overline{1}] / 4=[100]-[201] / 4$ and, likewise [201]/4 is a pseudotranslation for the layers at $y=0.375$ and 0.875 , Within a layer, however, [201]/4 and [201] $/ 4$ are clearly different because there is an approximate, local twofold screw along one of the two directions but not along the other.

$\left\{[201] / 4\right.$ and $[20 \overline{1}] / 4(=[100]-[201] / 4)$ make an angle of $44.8^{\circ}$ with $[100]$ and of $89.6^{\circ}$ with each other; the [201] direction in one layer is very nearly the $[\overline{2} 01](=[20 \overline{1}])$ direction in an adjacent layer so that the pseudotranslations work well for the structure as a whole.\}

\subsection{Extra pseudotranslations}

\section{Examples of structures in which there are more pseudotranslations than there can be modulations}

HEYJOK and HEYJOK0 $n, n=2-8\left(P 2{ }_{1} 2_{1} 2_{1}, Z^{\prime}=5\right.$; quinoxaline, $\left.\mathrm{C}_{8} \mathrm{H}_{6} \mathrm{~N}_{2}\right)$ The pseudotranslations listed are [001]/5 (av_rmsd $=0.6)$ and [101]/5 (av_rmsd $=1.2-1.3)$ but five independent molecules located on general positions cannot be related by two independent $n=5$ modulations. The two sets of five related $\mathrm{C}_{8} \mathrm{H}_{6} \mathrm{~N}_{2}$ molecules are the same except for translations along axis $\mathbf{a}$, which is much shorter than $\mathbf{c}(a / c=0.11)$. The conformational components would be the same for [001] $/ 5$ and [101] $/ 5$ even if the molecule were not rigid; the orientational and longitudinal components of the two pseudotranslations differ only a little. The transverse component, however, is considerably larger for [101]/5 than for [001]/5.

HIFWOK (Pn, Z'=4; $\left.\mathrm{C}_{20} \mathrm{H}_{21} \mathrm{NO}_{4}\right)$ Both [011]/2 (av_rmsd=1.62 $\AA$ ) and [001]/2 (av_rmsd=1.72 $\AA$ ) are listed but both pseudotranslations relate the same molecule pairs (\#1\&2; \#3\&4). The axis b is short $(b / c=0.21)$.

AKEVAP $\left(P 21 / c, Z^{\prime}=2\right)$ The pseudotranslations listed are [100]/2 and [101]/2 with av_rmsds of 0.70 and $1.27 \AA$. If the molecules related by [100]/2 are $\# 1$ and $\# 2$, then the molecules related by [101] $/ 2$ are $\# 1$ and $\# 2^{g}$, where $g$ is the $c$ glide. A layer (010) of molecules (at $y=1 / 4$ or $3 / 4$ ) includes the mirror of the $c$ glide. The molecules are planar enough, and the molecular plane is close enough to (010), that both pseudotranslations have av_rmsds that fit within the default tolerances.

DOBTUJ07 [P $\overline{1}, Z^{\prime}=1$; bis(BEDT-TTF)(BrClI), i.e., $\left(\mathrm{C}_{10} \mathrm{H}_{8} \mathrm{~S}_{8}{ }^{+}\right)\left(\mathrm{C}_{10} \mathrm{H}_{8} \mathrm{~S}_{8}\right) \mathrm{BrClI}^{-}$; the $\mathrm{BrClI}^{-}$ anion is end-for-end and compositionally disordered] The pseudotranslations listed are [110]/2 $\left(a v \_r m s d=0.92\right)$ and $[100] / 2\left(a v \_r m s d=1.78\right)$ for the two BEDT-TTFs only. Neither pseudotranslation is especially good because of the difference in the tilts of the two molecules (the dihedral angle between the two molecular planes is $44^{\circ}$ ). One pseudotranslation is, however, much better than the other because its transverse displacement is much smaller The DOBTUJ04/08 $\left(P \overline{1}, Z^{\prime}=1.5\right)$ structure is very similar to DOBUJ07 but $\mathbf{a}$ is lengthened by a factor of $c a$. 1.5. The pseudotranslations in DOBTUJ04/08 are [110]/3 (av_rmsd=0.9) and 
$[010] / 2\left(a v \_r m s d=1.5\right)$ for the BEDT-TTFs. In DOBTUJ04/08 two of the three independent BEDT-TTFs have the same orientation but the third has a quite different orientation.

\subsection{High-symmetry space groups}

In a space group having a rotation or screw axis of order three or higher, two directions (conventionally a and b) are equivalent by symmetry. If a pseudotranslation has a component along one of those axes (i.e., $u$ and/or $v \neq 0$ ) there are so many possible linear combinations, especially when there is rhombohedral centering, that there are sometimes problems with the designations incomplete and none found.

Combinations of pseudotranslations related by a three-, four-, or sixfold axis can have av_rmsd values that differ from the values for the individual components.

(Note that in a trigonal structure equivalent directions are $[u, v, w],[\bar{v}, u-v, w]$. and $[-(u-v), \bar{u}, w]$; in the case of a pseudotranslation $[\overline{u v w}],[v,-(u-v), \bar{w}]$, and $[u-v, u, \bar{w}]$ are also equivalent. The centering vectors in a standard (i.e., obverse) rhombohedral cell described by hexagonal axes are $[0,0,0],[2 / 3,1 / 3,1 / 3]$, and $[1 / 3,2 / 3,2 / 3]$.)

TAJVIK $\left(R \overline{3}, Z^{\prime}=1.167=3(1 / 3)+1 / 6, Z=21 ; \mathrm{Ph} 3 \operatorname{SiCCCCSiPh} 3\right)$ The pseudotranslation is $[001] / 7$, $n \_i n d=4$. There is no problem with the results for this structure because $u=v=0$.

YIZTOR/YODRAL $\left(P 3_{2} / P 3_{1}, Z^{\prime}=6\right)$ The pseudotranslations in these enantiomeric structures are $[1 \overline{1} 0] / 3$ and the symmetry related $[120] / 3$ and $[\overline{210}] / 3$ (or, $[210] / 3$ ). The structure has three identifiable layers (001) that are related by the screw axis and are connected by a 3-D pattern of $\mathrm{H}$ bonds. Approximate axes 2 and $2{ }_{1}$ are obvious in the layers, which have approximate layer symmetry $c 211$ (\#10); the angle of the $c 211$ cell is $90^{\circ}$ by symmetry. The three pseudotranslations in a layer are, in terms of the $c 211$ cell with $\mathbf{b}$ shorter than $\mathbf{a},[01],[\overline{1} / 2 \overline{1} / 2]$, and $[1 / 2 \overline{1} / 2]$; i.e., they are all lattice vectors of a $c 211$ cell. The angles between the three pseudotranslations are $120^{\circ}$; the 31 axis just interchanges the directions of the three pseudotranslations. This pair of trigonal structures presents no problems.

SEUREA03/04 (P31/P32, $Z^{\prime}=9$; selenourea) The first pseudotranslation $[01 \overline{1}] / 3$, which can be seen in slices (011), is marked as incomplete but looks fine. There are nine different columns along that direction with each of the nine independent molecules appearing in three different columns. The $a v \_r m s d s$ for the columns appear to be vary quite a lot.

The third pseudotranslation listed is $[10 \overline{1}] / 3$, which is related to $[01 \overline{1}] / 3$ by $[-(u-v), \bar{u}, w]$ and has the same numerical descriptors.

The second pseudotranslation listed is $[2 \overline{2} 3] / 3$, which is $[001]+2 *([10 \overline{1}] / 3-[01 \overline{1}] / 3)$, It has numerical descriptors that are very similar to, but not exactly the same as, those for $[01 \overline{1}] / 3$ and $[10 \overline{1}] / 3$. While[22̄3]/3 has a large qual_range $(0.75 \AA)$ it is not marked as incomplete. 
VANFOI01/02 $\left(R \overline{3}, Z^{\prime}=4, Z=72 ; \mathrm{C}_{18} \mathrm{H}_{20} \mathrm{OS}, 1 / 3 i-\mathrm{PrOH}\right)$ The pseudotranslations listed are $[1 \overline{1} 2] / 6,[010] / 2$, and [122]/6; all are marked as incomplete. The $n=6$ pseudotranslations include the centering operation and so have $n \_i n d=2$; they are related by $[\bar{v}, u-v, w]$. Then $[010] / 2$ $(=-[0 \overline{3} 0] / 6)$ is just the difference of the other two listed pseudotranslations. A slice $(001)$ of the unit cell with $z$ values of the molecular centroids in the range $0.0-0.3$ shows all possible

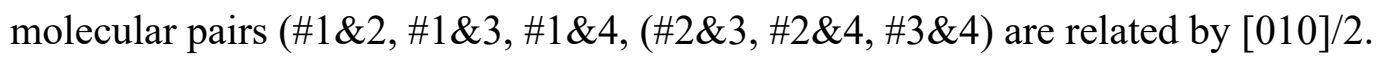
VANFOI01/02 are related to VANFOI $\left(R \overline{3}, Z^{\prime}=1\right)$ by doubling of the axes $\mathbf{a}$ and $\mathbf{b}$,

VANFUO $\left[R \overline{3}, Z^{\prime}=16, Z=288 ; \mathrm{C}_{18} \mathrm{H}_{20} \mathrm{OS}, 1 / 3 i-\mathrm{PrOH}\right]$ The difference between VANFOI01/02 and VANFUO (to be known in the future as VANFOI03) is a twofold lengthening of $\mathbf{a}$ and $\mathbf{b}$. The [010]/2 pseudotranslation of VANFOI01/02 then becomes [010]/4; [112]/6 should then become $[1 / 2 \overline{1} / 22] / 6=[1 \overline{1} 4] / 12$ but is found as $[1 \overline{14}] / 12$ (and $[12 \overline{4}] / 12$ ) because of an inconsistency in the way the axes for the related structures were chosen. The other pseudotranslations listed for VANFUO all follow. All but one are listed as incomplete, almost certainly for the same reason that the VANFOI01/02 pseudotranslations are listed as incomplete.

ZZZVCO05 [P4 $2{ }_{1} 2, Z^{\prime}=4$ at $10 \mathrm{~K}$; perdeutero-4-methylpyridine-N-oxide; note that ZZZVCO05 is a revision of ZZZVCO03 $\left.\left(P 4_{1}, Z^{\prime}=8\right)\right]$. The pseudotranslations listed are $[112] / 4,[110] / 2$, and [010]/2 (marked, probably incorrectly, as incomplete).

The pseudotranslation [112]/4 $\left(n \_i n d=2\right)$ can be understood as a remnant of the $I$ centering of the high-temperature cell (I4 $/$ amd, $\left.Z^{\prime}=1 / 4 ; Z Z Z V C O 01 / 04 / 06\right)$ that has $a$ and $b$ about half as long. When $\mathbf{a}$ and $\mathbf{b}$ are doubled $[1 / 2 / 2 / 21 / 2]$ becomes [ $\left.1 / 4^{1 / 4} / 2\right]$, which is [112]/4. [112]/4 relates four different columns of molecules: \#1,1',4,4',1,..; \#1,3,4,2,1,..; \#3,3", 2,2 ', $, 3, \ldots ; \# 1,2,4,3,1, \ldots$, where the primes refer to molecules related by a 21 operation and the double prime to molecules related by two 41 operations. Along [112] two columns in have $n \_i n d=4$ and two others have $n \_$ind=2.)

OBILOA ( $P 321, Z^{\prime}=8$; MeOMe·7.25 $\left.\mathrm{H}_{2} \mathrm{O}\right)$ The pseudotranslations for the ether are listed as the symmetry-related [100]/2 and [010]/2 (both marked as incomplete), but the structure is so disordered (only five of the eight ether molecules are shown) that no good analysis is really possible.

\section{$7.8 \quad$ Other}

\section{Counting structures}

Structures of enantiomers have different refcodes and so sometimes essentially the same structure appears in the program output twice.

For the $Z>>4$ structures examined there are five such pairs:|

IGUYOA/NAJTIE

KAWDAQ01/KAWDUK

QIYREX/QIYRIB

VIGCIZ/VIGCOF 


\section{YIZTOR/YODRAL}

For the $P 1$ structures there are two such pairs:

GETZUD/GEVBAN

MECRAP/VOZMAY

Structures in the same refcode family may be (1) the same structure, (2) structures related by a modulation (and therefore probably by a phase transition), or (3) quite different polymorphs. It is therefore possible that two or more entries in a refcode family have different sets of pseudotranslations. Only a few such pairs were encountered:

$\operatorname{VIVSAV02}\left(P \overline{1}, Z^{\prime}=12\right.$ at $\left.100 \mathrm{~K}\right)$ and $\operatorname{VIVSAV04}\left(P \overline{1}, Z^{\prime}=6\right.$ at RT).

$\operatorname{TAJVIK}\left(R \overline{3}, Z^{\prime}=3(1 / 3)+1(1 / 6)=1.17\right.$ at $\left.\mathrm{RT}\right)$ and TAJVIK01 $\left(P \overline{1}, Z^{\prime}=2.5\right.$ at $\left.180 \mathrm{~K}\right)$

\section{Inconsistencies in $Z^{\prime}$}

There is considerable inconsistency in the CSD regarding the choice of the asymmetric unit, because authors are inconsistent. A structure of a hemisolvate having four independent main molecules is sometimes $Z^{\prime}=4$ [for $A^{\cdot 1 / 2} S$ ] and sometimes $Z^{\prime}=2$ (for $2 A \cdot S$ ). Inclusion compounds of $n$ host molecules and $m$ guests are sometimes written as $H_{n} \cdot G_{m}$ with $Z^{\prime}=1$ and sometimes as $H \cdot G_{m / n}$ with $Z^{\prime}=n$ (see OKELEW as an example of the latter). Racemic compounds $R_{\mathrm{n}} S_{n}$ normally have $Z^{\prime}=n$ if the two molecules are related by crystallographic symmetry and $Z^{\prime}=2 n$ if they are not.

\section{Material related to paper section}

\section{Discussion}

\subsection{The program identifies pseudotranslations that might otherwise be missed}

\section{Some pseudotranslations that were missed by CPB in her 2016 paper}

AGIXIZ (P21/c, Z'=6; [111]/2) Two of the molecules (\#2\&5) are well related by the pseudotranslation but the other pairs have large perpendicular displacements (av_rmsd $1.43 \AA$; qual_range $1.73 \AA ; 75 \%$ transverse). The modulation can be seen, with some difficulty, in a

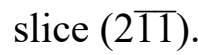

AGIXIZ was included in the 2016 high-Z' study but the pseudotranslation was missed.

DEYXOW (P2 $\left.1, Z^{\prime}=8 ;[010] / 2\right) \quad$ Very large transverse displacements (av_rmsd $1.45 \AA ; 91 \%$ transverse); long distance (length $/ n=16.0 \AA$ ); large molecules that overlap. The pseudotranslation does not apply to the included solvent molecules. DEYXOW was included in the 2016 high-Z' study but the pseudotranslation was not noticed. 
LABQOX $\left(P \overline{1}, Z^{\prime}=8 ;[1 \overline{2} 1] / 4\right.$; a 1:1 salt of a closely related cation and anion; Fig. S7) The very good $[1 \overline{2} 1] / 4$ pseudotranslation (av_rmsds 0.36 and $0.23 \AA$ for the larger anion and smaller cation) is hard to find by eye even when its existence is known, but it can be seen in a slice (111) or maybe (210). The related pseudotranslation [101] $/ 2$ is easier to see.

LABQOX was included in the 2016 high-Z' study but the pseudotranslation was not found.

LUXYOU (P21/c, Z'=12; [234] $/ 12$; Fig. S6) Displacements are not so large (av_rmsd $0.90 \AA$ ) but it is necessary to look across many cells to see the modulation. Slices (201) and (323) give good views. The pseudotranslation is the remnant of the centering vector of the disordered $C 2 / c$, $Z^{\prime}=1$ cell found at RT (LUXYOU01/02).

The 2016 high-Z' study found the [232]/6 but not the [234] $/ 12$ pseudotranslation even though the relationship between the two cells was described in the original paper..

\section{A pseudotranslation that would probably have been missed by CPB}

VANFUO $\left(R \overline{3}, Z^{\prime}=16 ;[1 \overline{14}] / 12\right)$ is a very complicated structure that was published in 2017. The authors recognized that VANFUO (to become VANFOI03), VANFOI $\left(R \overline{3}, Z^{\prime}=1\right)$, and VANFOI01/02 $\left(R \overline{3}, Z^{\prime}=4\right)$ form a series in which the hexagonal axes $\mathbf{a}$ and $\mathbf{b}$ are doubled twice, but the authors did not describe the modulations in any detail. The [1]4]/12 modulation of VANFUO includes three sets of four molecules, with the sets related by the $R$ centering. For $[1 \overline{14}] / 12$ length $/ n=16.54 \AA$; the lengths for lower- $n$ pseudotranslations are much longer. VANFUO is an excellent example of the usefulness of an automatic approach. It is also one of the structures that takes longest for the program to analyze (210 s, see Section 3.12).

\section{Some pseudotranslations are obscured by the interleaving of molecules from two different columns}

In these structures the median vectors for two columns of related molecule are close together.

WANJAZ ( $P 212121, Z^{\prime}=8$; Fig. S13; discussed at the end of Section 7.4) The pseudotranslation [201]/4 is part of a quite strong modulation. Its direction is not simple. Its quality is clearly different for the two sets of layers (010). It would not be easy to find by inspection.

XOJYEC01 $\left[P \overline{1}\right.$, co-crystal with $Z^{\prime}=6$ (for a $1.5: 1$ formulation as in the CSD) or $Z^{\prime}=3$ (for a $3: 2$ formulation); Fig. S14] The [111]/3 pseudotranslation relates three independent sets of the larger molecule and two of the smaller. Interpenetration of the sets obscures the relationship, especially since the orientation of the larger molecule varies between sets. The pseudotranslation is most easily seen in a slice (011). 


\subsection{Criteria for identifying pseudotranslations are not easy to set; judgement is required}

Considerable effort was invested in trying to find a set of criteria that gave no false negatives and no false positives when compared with the manual analysis of Z'>4 structures by CPB. Exact reproduction of human judgements was obviously impossible; tolerances were chosen so that the numbers of false negatives and false positives were approximately equal (see Section 3.11 of the supplementary material). In any event, users of the program can adjust the tolerances.

\subsection{A few pseudotranslations are not modulations}

See the discussion in the latter part of Section 2. See also the discussion in Section 7.4 of type 1 and type 2 layered structures.

\subsection{Identifying the basic cell}

[See Fig. S8 (TAJVIK/01)]

\section{Structures for which a basic cell is in the CSD}

ADUNOF01 $\left(P c, Z^{\prime}=12, Z=24\right.$ at $\left.100 \mathrm{~K}\right) \quad \operatorname{ADUNOF}\left(P 21 / c, Z^{\prime}=1, Z=4\right.$ at $\left.200 \mathrm{~K}\right)$

Basic cell is smaller and has higher symmetry but is disordered.

BOCKEK06 $\left(P 1, Z^{\prime}=Z=4\right.$ at $\left.140 \mathrm{~K}\right) \quad$ BOCKEK05 $\left(C m c{ }_{1}, Z^{\prime}=1 / 2, Z=4\right.$ at $\left.155 \mathrm{~K}\right)$

Basic cell is the same size and has higher symmetry.

CIGHEG02 $\left(P 2{ }_{1}, Z^{\prime}=8, Z=16\right.$ at $\left.112 \mathrm{~K}\right) \quad$ CIGHEG01 $\left(P 2{ }_{1} / n, Z^{\prime}=4, Z=16\right.$ at $\left.179 \mathrm{~K}\right)$

Basic cell is the same size and has higher symmetry.

CILHIO38 $\left(P 1, Z^{\prime}=Z=2\right.$ at $\left.20 \mathrm{~K}\right) \quad$ CILHIO21 $\left(P \overline{1}, Z^{\prime}=1, Z=2\right.$ at RT $)$

Basic cell is the same size and has higher symmetry.

The CILHIO38 paper reports a very careful, multi-technique study of $P \overline{1} \rightarrow P 1$ the phase transition at $c a .150 \mathrm{~K}$ in $\mathrm{TTF}_{2}$ triiodide, $\mathrm{C}_{10} \mathrm{H}_{8} \mathrm{~S} \mathrm{~S}_{8}{ }^{+}, \mathrm{C}_{10} \mathrm{H}_{8} \mathrm{~S}_{8}, \mathrm{I}_{3}$. The paper mentions structures done above the transition (at 210 and $175 \mathrm{~K}$ ) but they are not found in the CSD. Structures in the CSD with $R \leq 0.075$ of that $P \overline{1}$ phase (there is also a different $P \overline{1}$ phase) are CILHIO12 (at $100 \mathrm{~K}$ ), CILHIO20 (at $120 \mathrm{~K}$ ), and CILHIO14/19/21 (at RT) It cannot be determined whether the structures reported at 100 and $120 \mathrm{~K}$ should have been refined in $P 1$ rather than in $P \overline{1}$.

COCMIR02 $\left(P \overline{1}, Z^{\prime}=8, Z=16\right.$ at $\left.120 \mathrm{~K}\right) \quad$ COCMIR01 $\left(P \overline{1}, Z^{\prime}=2, Z=4\right.$ at $\left.145 \mathrm{~K}\right)$

Basic cell is smaller and has the same symmetry.

EJUQIK $\left(P 1, Z^{\prime}=Z=4\right.$ at $\left.123 \mathrm{~K}\right) \quad$ EJUQIK01 $\left(P 1, Z^{\prime}=Z=2\right.$ at RT $)$

Basic cell is smaller and has the same symmetry.

FUGMIF $\left(P 1, Z^{\prime}=Z=4\right.$ at $\left.200 \mathrm{~K}\right) \quad$ FUGMIF01 $\left(P \overline{1}, Z^{\prime}=2, Z=4\right.$ at $\left.413 \mathrm{~K}\right)$

Basic cell is the same size and has higher symmetry. 
GIDHEG01 $\left(P 2{ }_{1} / c, Z^{\prime}=5, Z=20\right.$ at $\left.150 \mathrm{~K}\right) \quad$ GIDHEG $\left(P 2{ }_{1} / n, Z^{\prime}=1, Z=4\right.$ at RT $)$ Basic cell is smaller and has the same symmetry (although the axes were chosen differently).

JAKKUB01 $\left(P 1, Z^{\prime}=Z=2\right.$ at $\left.85 \mathrm{~K}\right) \quad \operatorname{JAKKUB}\left(P 1, Z^{\prime}=Z=1\right.$ at $\left.150 \mathrm{~K}\right)$

Basic cell is smaller and has the same symmetry.

JAWQIH03 (B2 $1, Z^{\prime}=8, Z=32$ at $\left.311 \mathrm{~K}\right) \quad$ JAWQIH01 $\left(P 21 / c, Z^{\prime}=3, Z=12\right.$ at RT)

Basic cell is smaller and has higher symmetry but is found at a lower temperature.

(The transition is SCSC.)

JOWGAF $\left(P 22_{1} / c, Z^{\prime}=5, Z=20\right.$ at $\left.120 \mathrm{~K}\right) \quad J O W G A F 01\left(P 2_{1} / c, Z^{\prime}=1, Z=4\right.$ at $\left.240 \mathrm{~K}\right)$

Basic cell is smaller and has the same symmetry but is somewhat disordered.

KUTMAP02 $\left(P \overline{1}, Z^{\prime}=6, Z=12\right.$ at $\left.187 \mathrm{~K}\right) \quad \mathrm{KUTMAP01}\left(P \overline{1}, Z^{\prime}=1, Z=2\right.$ at $\left.85(?) \mathrm{K}\right)$

(There is some unresolved confusion about the temperatures. It seems

possible that KUTMAP01 is the structure at RT but was flash-cooled to $85 \mathrm{~K}$ without transforming to the larger cell.)

Basic cell is smaller and has the same symmetry but appears to have been found at a lower temperature.

LANXOO02 $\left(P 2{ }_{1}, Z^{\prime}=12, Z=24\right.$ at $\left.120 \mathrm{~K}\right) \quad$ LANXOO $\left(P 2_{1} / n, Z^{\prime}=1, Z=4\right.$ at $\left.200 \mathrm{~K}\right)$

Basic cell is smaller and has higher symmetry but is somewhat disordered.

LUXYOU $\left(P 2{ }_{1} / c, Z^{\prime}=12, Z=48\right.$ at $\left.100 \mathrm{~K}\right) \quad$ LUXYOU01/02 $\left(C 2 / c, Z^{\prime}=1, Z=8\right.$ at RT $)$

Basic cell is smaller and has higher symmetry but is somewhat disordered.

NAKNEV04 ( $P 1, Z^{\prime}=Z=4$ at $\left.200 \mathrm{~K}\right) \quad$ NAKNEV01 $\left(P c a 2_{1}, Z^{\prime}=1, Z=4\right.$ at $\left.233 \mathrm{~K}\right)$

Basic cell is the same size and has higher symmetry.

NAKNOF04 ( $P 1, Z^{\prime}=Z=4$ at $\left.220 \mathrm{~K}\right) \quad$ NAKNOF02 (Pca $2_{1}, Z^{\prime}=1, Z=4$ at $\left.250 \mathrm{~K}\right)$

Basic cell is the same size and has higher symmetry.

QOPVAU $\left(F 1, Z^{\prime}=2, Z^{\prime}=8\right.$ at $\left.100 \mathrm{~K}\right) \quad$ MAMPUM06 $\left(P 2_{1}, Z^{\prime}=1, Z=2\right.$ at $\left.100 \mathrm{~K}\right)$

(for comparisons with MAMPUM06, $Z$ ', $Z$ for QOPVAU should be 4, 16 rather than

2,8 because there is proton transfer in half the formula units of QOPVAU but not in of those in MAMPUM0n family)

Basic cell is smaller and has higher symmetry.

RIDFOA01 $\left(P 1, Z^{\prime}=Z=2\right.$ at $\left.50 \mathrm{~K}\right) \quad \operatorname{RIDFOA}\left(P \overline{1}, Z^{\prime}=1, Z=2\right.$ at $\left.\mathrm{RT}\right)$

The temperature for RIDFOA01 is given in the CSD as RT but in the paper as $50 \mathrm{~K}$. Basic cell is the same size and has higher symmetry.

TAPLII01 $\left(P 2{ }_{1} / n, Z^{\prime}=5, Z=20\right.$ at $\left.100 \mathrm{~K}\right) \quad$ TAPLII $\left(P 21 / n, Z{ }^{\prime}=1, Z=4\right.$ at RT $)$

(There is some disorder in both structures)

Basic cell is smaller and has the same symmetry. 
VIVSAV02 $\left(P \overline{1}, Z^{\prime}=12, Z=24\right.$ at $\left.100 \mathrm{~K}\right) \quad \operatorname{VIVSAV01}\left(P 2_{1} / a, Z^{\prime}=1, Z=4\right.$ at $\left.205 \mathrm{~K}\right)$

(There is some disorder in both structures)

Basic cell is smaller and has higher symmetry.

VIVSAV04 $\left(P \overline{1}, Z^{\prime}=6, Z=12\right.$ at RT) VIVSAV01 $\left(P 2_{1} / a, Z^{\prime}=1, Z=4\right.$ at $\left.205 \mathrm{~K}\right)$

(There is some disorder in both structures)

Basic cell is smaller and has higher symmetry but is found at a lower temperature.

There is also a disordered $P 2{ }_{1} / a, Z^{\prime}=6, Z=24$ phase at $350 \mathrm{~K}$ (VIVSAV03). The $P 2{ }_{1} / a$, $Z^{\prime}=1$ and the $P \overline{1}, Z^{\prime}=6, Z=12$ structures are intermediate phases.

TETBUS02 $\left(C 2, Z^{\prime}=8, Z=32\right.$ at $\left.145 \mathrm{~K}\right) \quad$ TETBUS $\left(C 2 / c, Z^{\prime}=1, Z=8\right.$ at $\left.150 \mathrm{~K}\right)$

Basic cell is smaller and has higher symmetry.

THIOUR05 (Pbnm, Z'=4.5, Z=36 at $170 \mathrm{~K}$ ) THIOUR13 (Pbnm, $Z^{\prime}=1 / 2, Z=4$ at RT)

(Pbnm is an alternative setting of Pnma)

Basic cell is smaller and has the same symmetry.

$\operatorname{UCAYIH}\left(P \overline{1}, Z^{\prime}=8, Z=16\right.$ at $\left.120 \mathrm{~K}\right) \quad \operatorname{UCAYIH01}\left(P \overline{1}, Z^{\prime}=2, Z=4\right.$ at $\left.120 \mathrm{~K}\right)$

$\left[Z^{\prime}=8=6+4 *(1 / 2)\right.$ in UCAYIH; $Z^{\prime}=2=1+2 *(1 / 2)$ in UCAYIH01; there is some disorder in both structures.]

UCAYIH02 at $20 \mathrm{~K}$ has $Z^{\prime}=8$ and seems to be ordered but $R=0.139$.]

Basic cell is smaller and has the same symmetry.

XOJYEC01 $\left(P \overline{1}, Z^{\prime}=6, Z=12\right.$ at $\left.218 \mathrm{~K}\right) \quad$ XOJYEC $\left(P \overline{1}, Z^{\prime}=2, Z=4\right.$ at $\left.273 \mathrm{~K}\right)$

The phase transition is SCSC.

Basic cell is smaller and has the same symmetry.

XOJYEC01 $\left(P \overline{1}, Z^{\prime}=6, Z=12\right.$ at $\left.218 \mathrm{~K}\right) \quad$ XOJYEC02 $\left(P 21 / c, Z^{\prime}=2, Z=8\right.$ at $\left.123 \mathrm{~K}\right)$

The phase transition is scsc.

Basic cell is smaller and has higher symmetry but is found at a lower temperature.

ZATLAJ03 $\left(P 21, Z^{\prime}=8, Z=16\right.$ at $\left.120 \mathrm{~K}\right) \quad$ ZATLAJ01 $\left(P 2{ }_{1}, Z^{\prime}=4, Z=8\right.$ at $\left.130 \mathrm{~K}\right)$

Basic cell is smaller and has the same symmetry.

Some structures for which the presumed basic cell has not been observed

See the examples given in Section 5.4.

\subsection{The interactions responsible for modulations are not easy to determine}

[See Figs. S9 (QAJDAG) and S10 (HONBIW)] 


\subsection{There is no simple way to identify the most important modulation(s)}

\section{Is the shortest pseudotranslation necessarily the structure-determining pseudotranslation?}

It is not clear that there is a link between the length of a pseudotranslation and its role in determining the structure. While it might seem logical that the shortest pseudotranslation relating the largest number of molecules should be the most important, quite often there are several pseudotranslations that are similar in length. On the other hand, very long pseudotranslations (length $/ n>25 \AA$ ?) are likely to be consequences, rather than drivers, of the overall structural modulation.

The following describe situations in which the shortest pseudotranslation may not to be the most important:

\section{1/ The shortest pseudotranslation cannot generate longer, and obvious, pseudotranslations.}

In UZILIA ( $C c, Z^{\prime}=8$; Fig. S11) the shortest pseudotranslation is [010]/2 (9.60 $\AA$ ) but the next shortest, [102]/4 (13.79 $\AA$, chosen by the program as the base pseudotranslation) is more fundamental because [102]/4 can generate [010]/2 when combined with a centering vector but $[010] / 2$ cannot generate [102]/4.

(Actually, as is explained in the paper, it is the $[10 \overline{2}] / 4$ pseudotranslation, length $n=20.61 \AA$, that is the most important. The basic cell seems to have axes $\mathbf{a}^{\prime}=[10 \overline{2}] / 4, \mathbf{b}^{\prime}=[010] / 2, \mathbf{c}^{\prime}=[102] / 4$ and space group $P 21 / n$.)

Note, however, that an $n=2$ pseudotranslation can generate an $n=4$ pseudotranslation if both the basic and modulated cells are centered. Consider EXEMOJ $\left(C 2 / c, Z^{\prime}=4\right)$. The pseudotranslations listed are [110]/4, which includes the centering vector, and [010]/2. Combining those two pseudotranslations gives [100]/2. Examination of a layer (001), $0.0 \leq z$ $\leq 0.5$ shows that the basic cell seems to have $\mathbf{a}^{\prime}=\mathbf{a} / 2, \mathbf{b}^{\prime}=\mathbf{b} / 2$, and the same space group. Then $[110] / 2$ in the basic cell becomes [110]/4 in the modulated structure. Other very similar examples are JIBLUE $\left(C 2 / c, Z^{\prime}=4\right.$, FAMMOY $\left(C 2, Z^{\prime}=4\right)$, and GIKVOO $\left(I a, Z^{\prime}=4\right)$. In GIKVOO the axes of the basic Ia cell are $[10 \overline{1}] / 2, \mathbf{b} / 2$, and $[101] / 2$.

\section{2/ A somewhat longer pseudotranslation shows a clear pattern that is not obvious in shorter pseudotranslations.}

KAYGUO $\left(P \overline{1}, Z^{\prime}=6\right)$ The $n=6$ pseudotranslation along [ $\left.3 \overline{2} 1\right]$ of this acid-base co-crystal is convincingly sinusoidal (Fig. S15). The bases are not in contact along [32 1$]$ but are in contact along the marginally longer $[32 \overline{1}] / 6=[100]-[3 \overline{2} 1] / 6$ (9.40 rather than $9.36 \AA)$. The shortest pseudotranslation in this structure, [011]/3 $(9.04 \AA)$, is less regular ( $a v \_r m s d s$ of 1.22 and $1.23 \AA$ for the acid and base rather than 1.07 and $1.09 \AA$ ) and is less easy to understand. 
3/ A somewhat longer pseudotranslation may reveal distortions from a basic cell (usually of higher symmetry) better than does a shorter pseudotranslation.

In XIFMOQ $\left(C c, Z^{\prime}=6 ; \mathrm{C}_{20} \mathrm{H}_{26} \mathrm{~N}_{3} \mathrm{O}_{5} \mathrm{P}\right)$ the shortest pseudotranslation is $[10 \overline{1}] / 3$ (11.61 $\AA$ ) but the related $[102] / 3=[10 \overline{1}] / 3+[001](21.82 \AA)$, is much more informative because there are obvious approximate twofold axes along [102], which makes an angle of $89.8^{\circ}$ with [100]. There also seems to be centering in a layer (010) if the axes are [100] and [102]. With increased tolerances PLATON suggested the space group Fdd2 with twice the cell volume but only three independent (although somewhat disordered) molecules. The axes of the Fdd2 cell would be -aa, b, and -a-2c.

4/ A pseudotranslation is longer because the length of the van der Waals surface of the molecule is longer in that direction.

In UZILIA ( $C c, Z^{\prime}=8$; discussed in the paper; Fig. S11) length $n$ is $13.79 \AA$ for [102]/4 and $20.61 \AA$ for $[10 \overline{2}] / 4$ because the H-bonded dimers are arranged side-by-side along [102] and end-

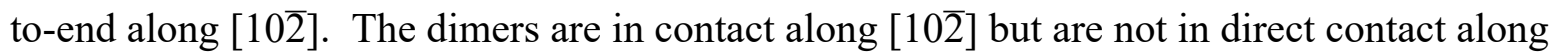
[102].

5/ Molecules in a pseudotranslation are in contact through a third molecule that is not part of the pseudotranslation.

PAMTEF $\left(P 2{ }_{1} / n, Z^{\prime}=5\right)$ The surfaces of the molecules $\left[\mathrm{Cy}_{2} \mathrm{PC}(=\mathrm{O}) \mathrm{N}(\mathrm{H}) \mathrm{Ph}\right]$ are roughly oblate ellipsoids (Fig. S16). The shortest pseudotranslation, [201] $/ 5$ (9.77 $\AA$ ) passes through one of the longer directions of the ellipsoid of molecules that are in van der Waals contact. A just slightly longer pseudotranslation $[301] / 5=[100]-[20 \overline{1}] / 5(9.82 \AA)$ passes through the thinnest direction of the ellipsoid but along [301] the related molecules form half of an H-bonded chain that includes molecules related by the $n$ glide.

\section{6/ A somewhat longer pseudotranslation lies within obvious structural layers.}

QUQQUO $\left(P \overline{1}, Z^{\prime}=8\right)$ has obvious layers $(0 \overline{1} 2)$ with approximate symmetry (pba2) substantially higher than the 3-D symmetry of the crystal (Fig. S17). The shortest pseudotranslation is [101]/2 (length $n=18.75 \AA$ ) but the longer pseudotranslation [121]/2 (=[101]/2+[010]); length_n=26.95 $\AA$ ) lies within the layer.

TADWIH $\left(P \overline{1}, Z^{\prime}=6\right)$ has obvious bilayers $(1 \overline{1} 0)$. The pseudotranslation $[22 \overline{1}] / 6$ lies within the bilayer as does the shortest $n=2$ pseudotranslation ([001]/2). The shortest $n=3$ pseudotranslation in the layer is $[111] / 3$ but it is longer than $[2 \overline{11}] / 3$ (length $/ n=12.51$ vs. $11.13 \AA$ ) so that $[2 \overline{11}] / 3$ is listed instead. 


\section{A longer pseudotranslation is sometimes more informative because it is simple}

In VANFUO $\left(R \overline{3}, Z^{\prime}=16\right)$ length_n is $16.54 \AA$ for $[1 \overline{14}] / 12$ and $27.95 \AA$ for $[010] / 4$. The latter, however, is the key to understanding this structure, which is a modulated form of VANFOI $(R \overline{3}$, $\left.Z^{\prime}=1\right)$. The pseudotranslation $[1 \overline{14}] / 12$ is one of the many possible combinations of $[010] / 4$ with a centering vector of the rhombohedral cell. 


\section{References}

References other than those for individual refcodes:

Betancourt, M. R. \& Skolnick, J. (2001). Biopolymers 59, 305-309.

Brock, C. P. (2016), Acta Cryst. B72, 807-821.

Cole, J. C., Murray, C. W., Nissink, J. W. M., Taylor, R. D. \& Taylor, R. (2005). Proteins:

Struct. Funct. Bioinf. 60, 325-332.

Hempler, D., Schmidt, M. U. \& Streek, J. v. d. (2017). Acta Cryst. B73, 756-766.

Maiorov, V. N. \& Crippen, G. M. (1995). Proteins: Struct. Funct. Bioinf. 22, 273-283.

Marsh, R. E. (1999). Acta Cryst, B55, 931-936. 
Notes re Figures for the Supplementary Material

Crystal axes are color coded: $\mathbf{a}$ is red, $\mathbf{b}$ is green, and $\mathbf{c}$ is blue.

The $\mathrm{C}$ atoms of the independent residues (molecules or ions) are always colored by the number of the residue. In many of the drawings the heteroatoms are colored by type (red for oxygen, green for chlorine, etc). $\mathrm{H}$ atoms are almost never shown. 
Fig. S1 Schematic diagram of an $n=3$ pseudotranslational column. Filled circles: centroids of molecules 1, 2, 3, 1', where $1^{\prime}$ is related to 1 by lattice translation. Solid black arrow: median vector. Red arrows: transverse displacements of centroids from median vector. Tick marks and brace: ideal spacing of intermediate centroids along median vector, separation $=d / 3$ where $d=$ length of lattice translation. Broken arrows: translations applied to molecule 3 prior to calculation of $r m s d s$ with molecule 1 , viz. (a) $r m s d(C)$, measuring conformational deviations (molecule 3 allowed to rotate to optimize fit) and $\mathrm{rmsd}(\mathrm{CO})$, measuring conformational + orientational deviations (molecule 3 not rotated); (b) $r m s d(C O T)$, measuring conformational + rotational + transverse deviations (molecule 3 not rotated); (c) $r m s d(C O T L)=$ rmsd(total), measuring conformational + rotational + transverse + longitudinal deviations (molecule 3 not rotated).

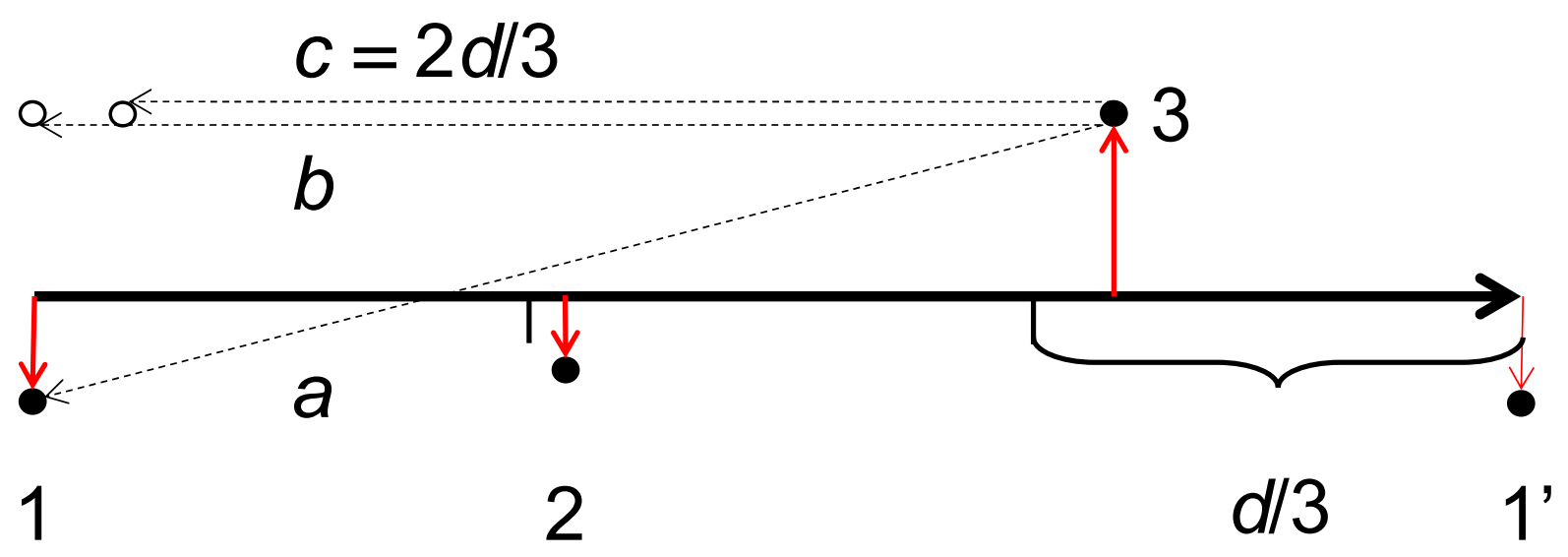


Fig. S2 In SEMPEH $\left(P 2_{1}, Z^{\prime}=10\right)$ the pseudotranslation $[010] / 5$ is found but [015]/10 is not because one of the indices is $>4$

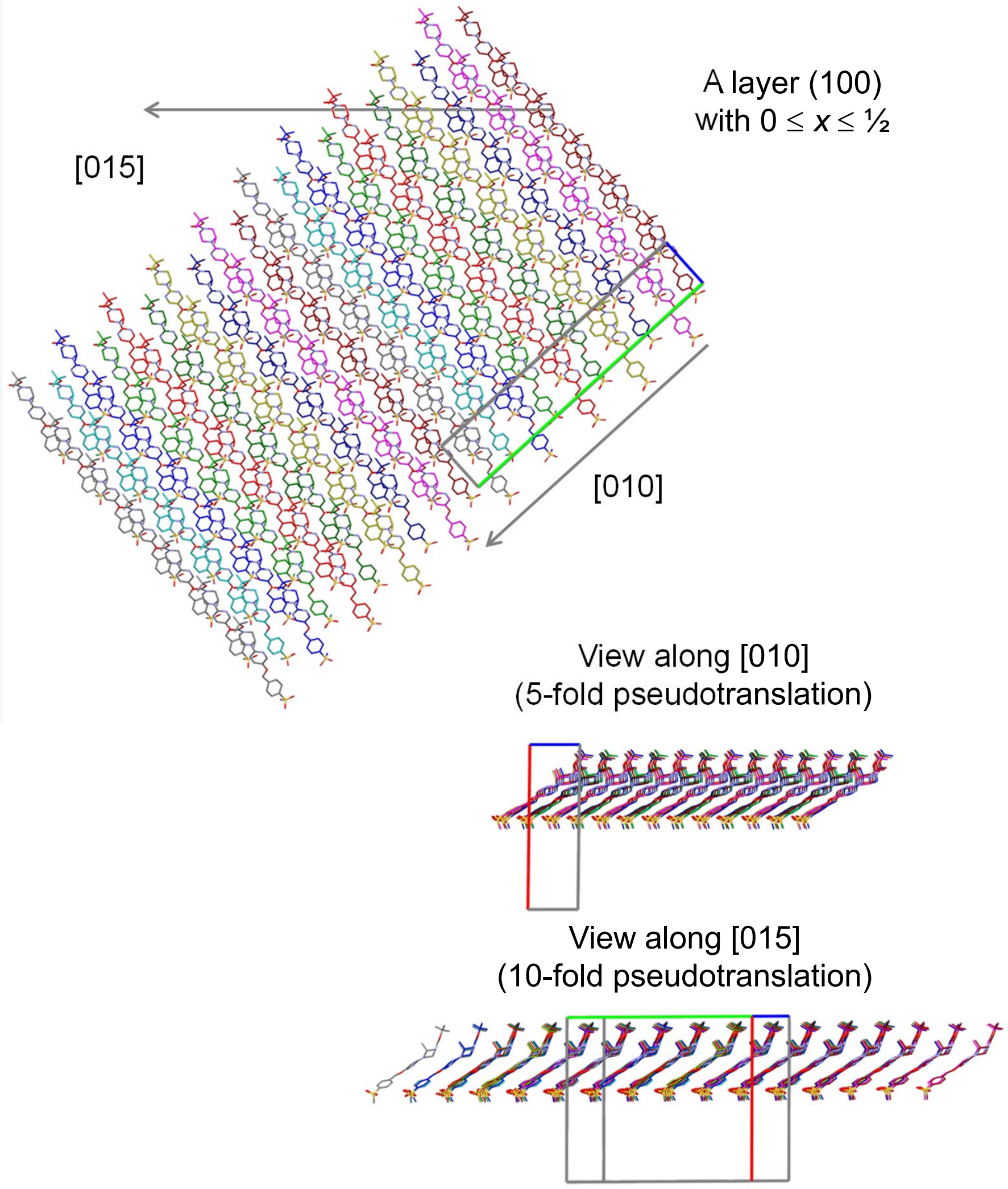


Fig. S3 TARNEG $\left(P \overline{1}, Z^{\prime}=6\right)$ is an example of a pseudotranslation $([001] / 2)$ that relates two independent molecules in two columns and two symmetry-related molecules in two other columns

There are two conformations:

approximate inversion symmetry [molecules 1 (green) and (5) magenta) and approximate twofold symmetry (the other four molecules).

Along [001] the related molecules are $1 \& 1^{i}, 5 \& 5^{i}, 2 \& 4,3 \& 6$.
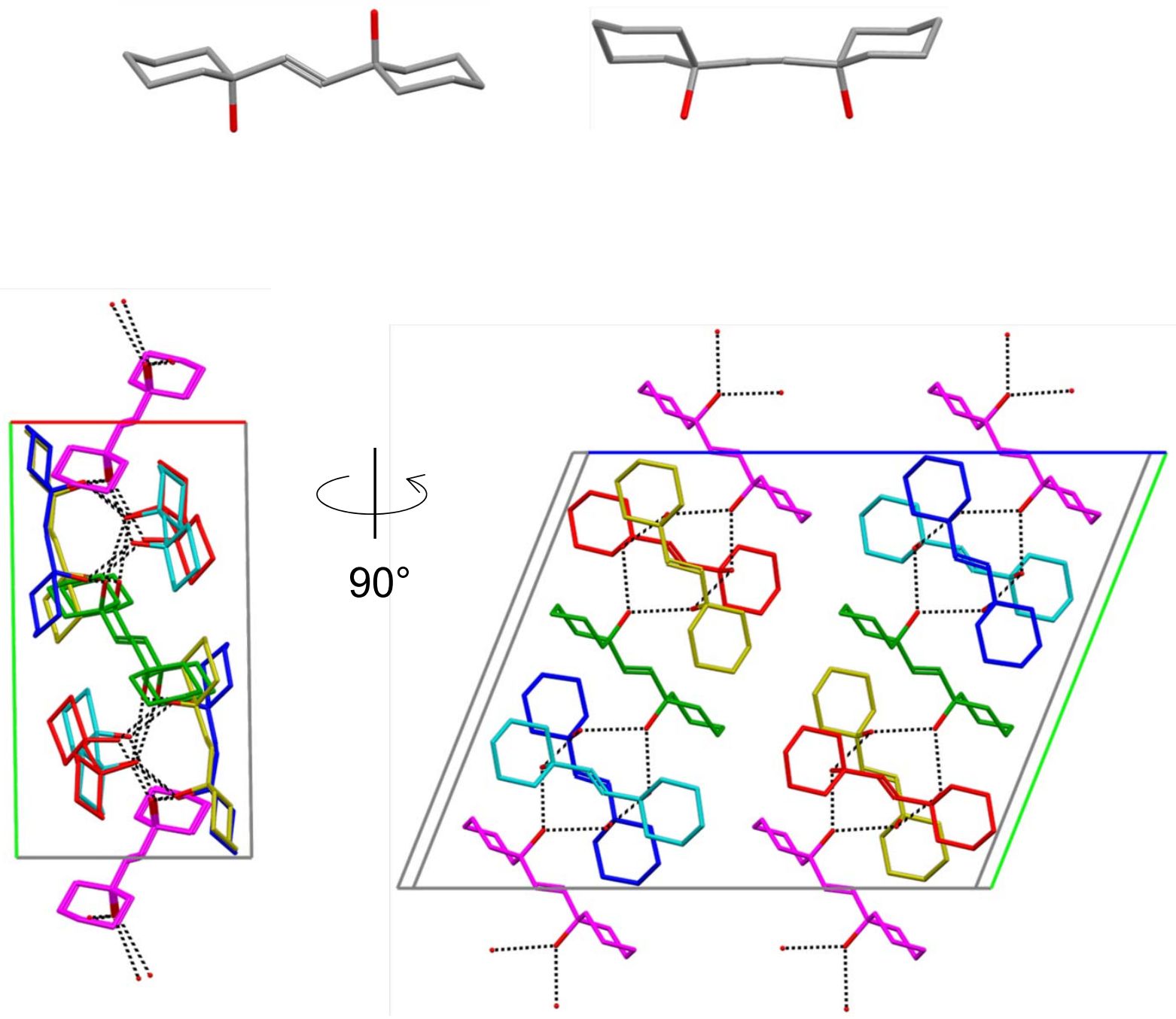

[001] 
Fig. S4 ROPJAJ $\left(P^{\overline{1}}, Z^{\prime}=2\right)$ is an example of a pseudotranslation $([1 \overline{1} 2] / 4)$ that relates four independent molecules in some columns and two independent molecules in other columns

ROPJAJ is a 3:2:3 hydrated co-

crystal that would be formulated as

$1: 2 / 3: 1$ if $Z^{\prime}=6$.

Residue 1 (shown below) is

View along $[1 \overline{1} 2]$

4,4'-ethene-1,2-diyldipyridine.
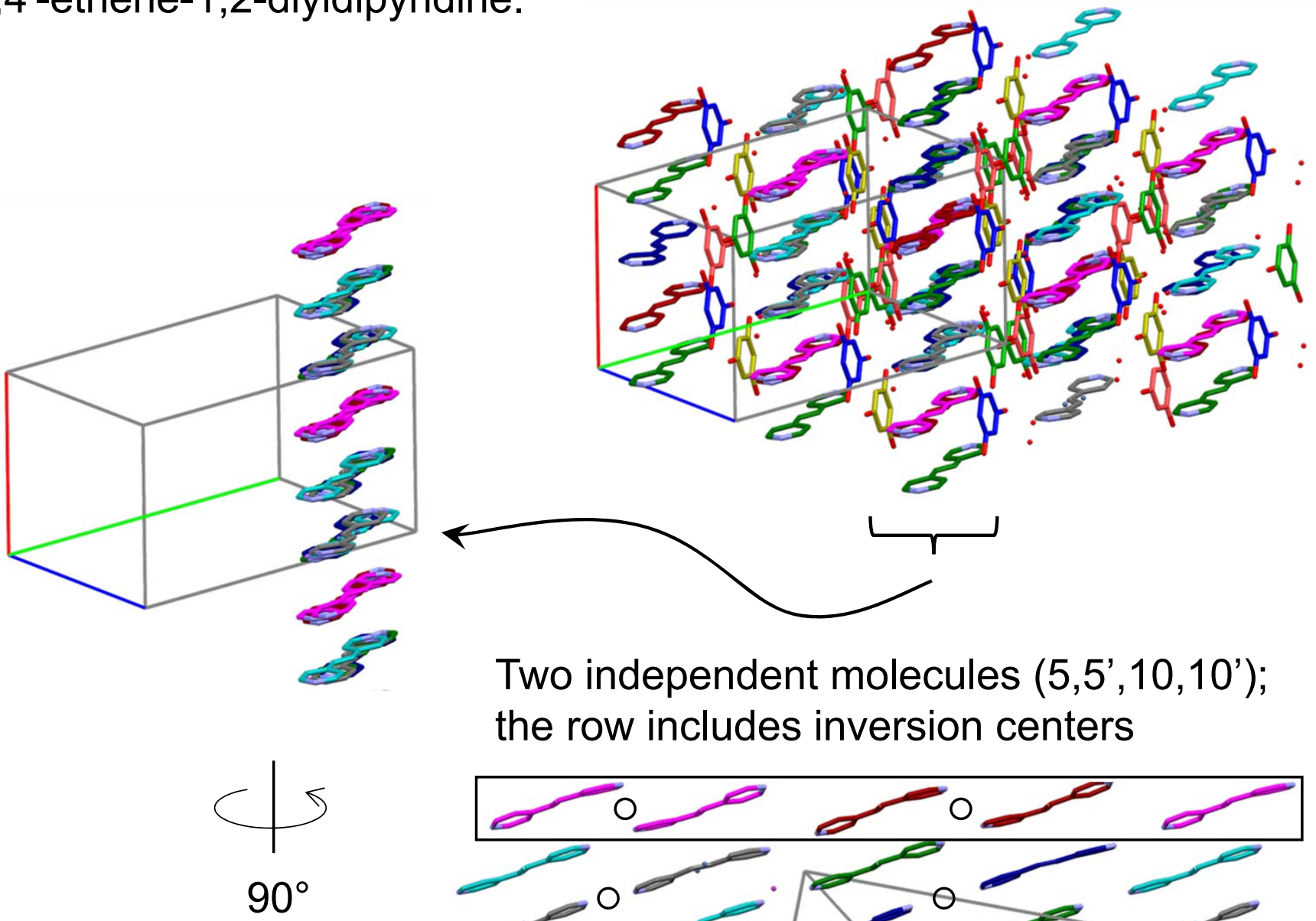

Two independent molecules $\left(5,5^{\prime}, 10,10^{\prime}\right)$; the row includes inversion centers

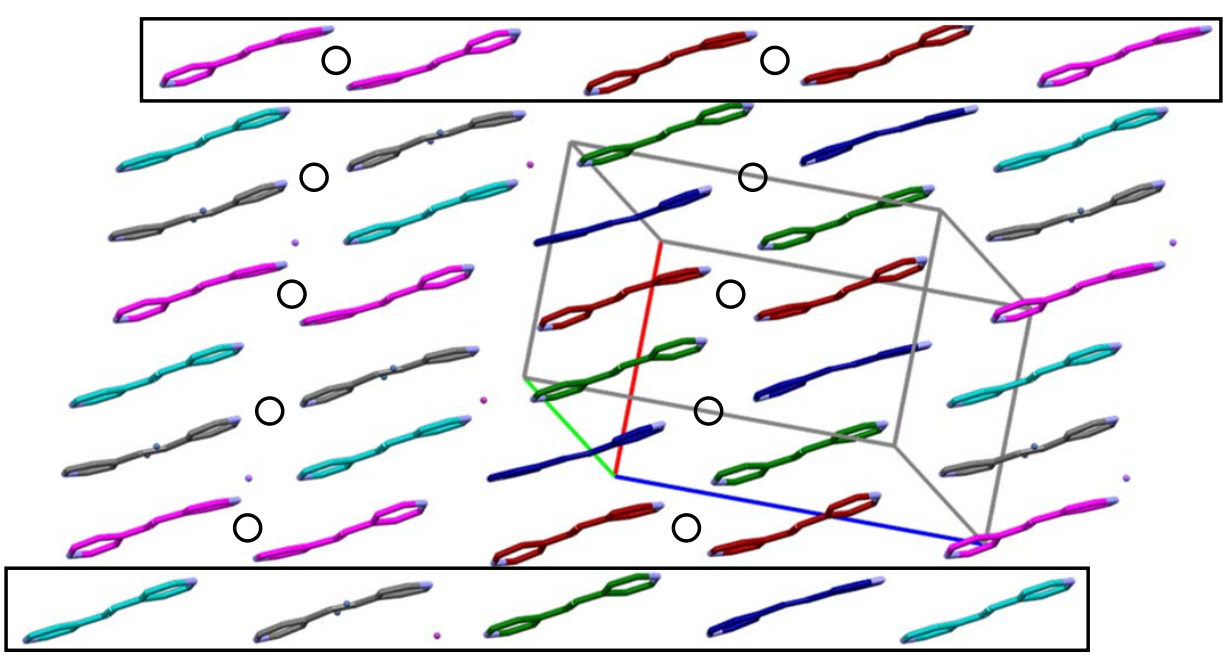

Four independent molecules $(6,7,8,9)$ 
Fig. S5(a) SOYKOH $\left(P \overline{1}, Z^{\prime}=9\right)$ : an example of how a pseudotranslation can combine with lattice vectors

A layer (012), which contains both the pseudotranslation and the axis a

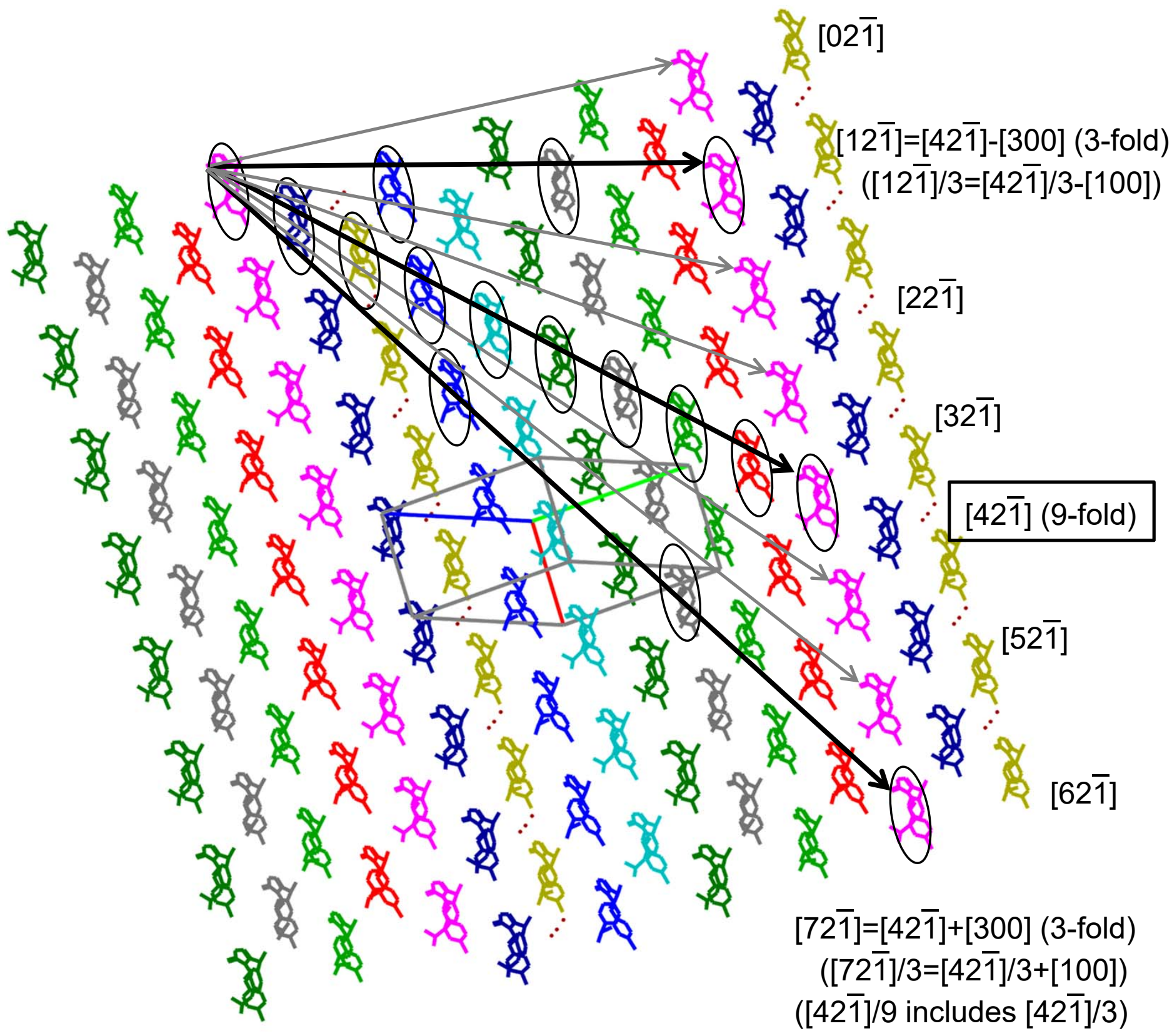


Fig. $S 5(b)$ SOYKOH $\left(P \overline{1}, Z^{\prime}=9\right)$ : a more detailed illustration of how a pseudotranslation can combine with lattice vectors

A layer (012), which contains both the pseudotranslation and the axis a

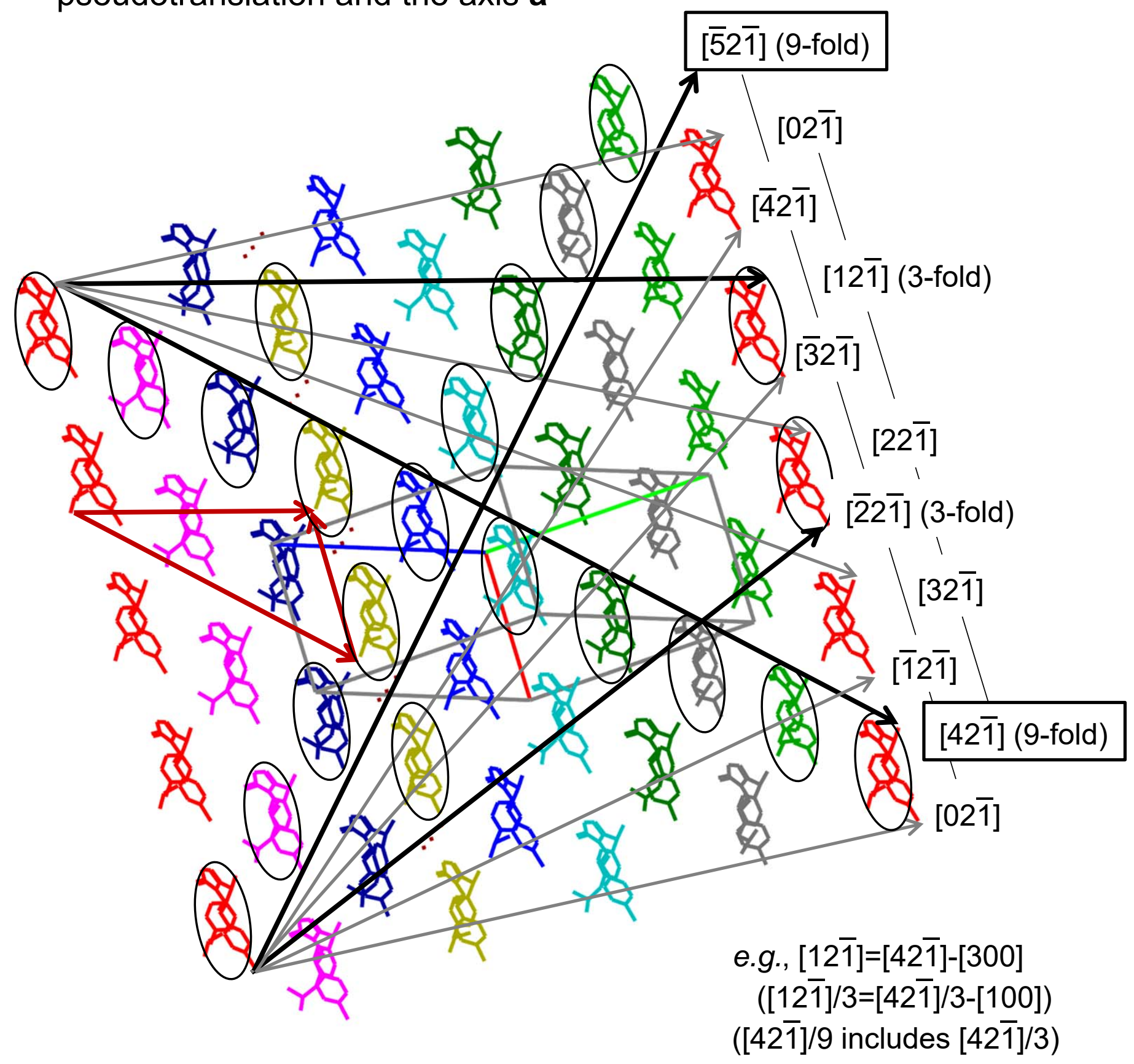


Fig. S6 The pseudotranslation $([23 \overline{4}] / 12)$ in $\operatorname{LUXYOU}\left(P 2_{1} / c, Z^{\prime}=12\right)$ is not so easy to find.

[The basic cell of LUXYOU is seen in LUXYOU01 (C2/c, $Z^{\prime}=1$ ), which is shown in the smaller, B/W drawings]

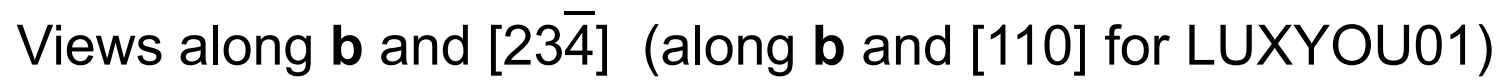
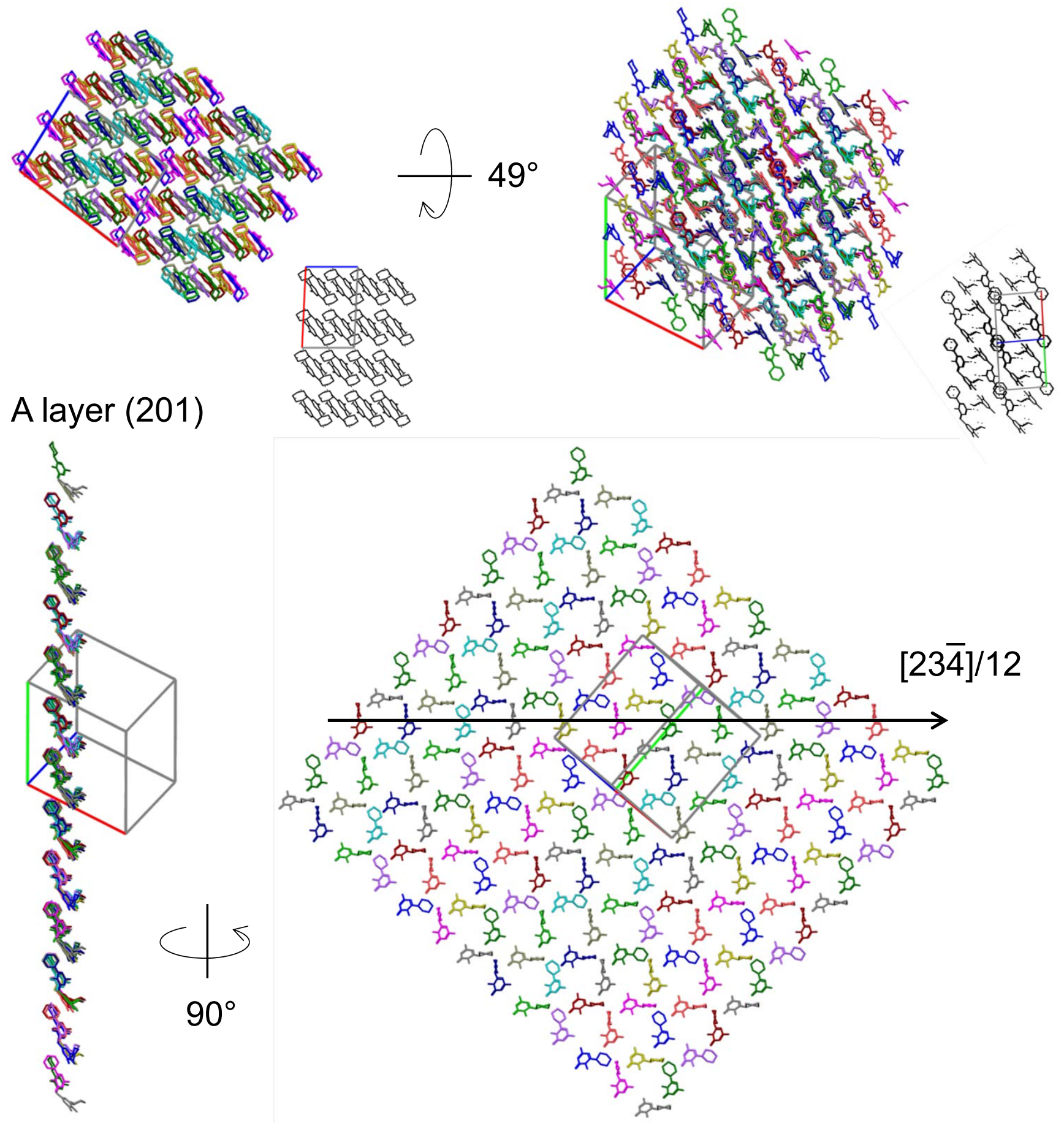
Fig. S7 LABQOX $\left(P^{1}, Z^{\prime}=8\right)$ : $[1 \overline{2} 1] / 4$ and $[10 \overline{1}] / 2$ are examples of pseudotranslations that are difficult to see

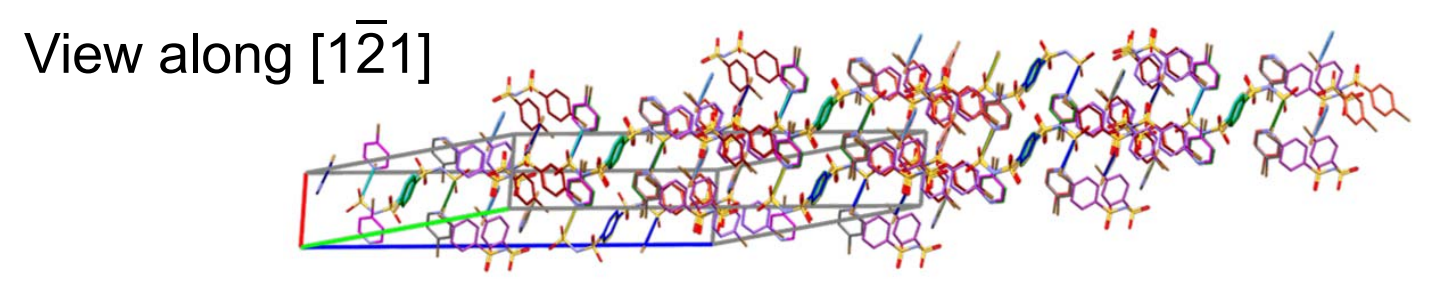

View along [10 $\overline{1}]$

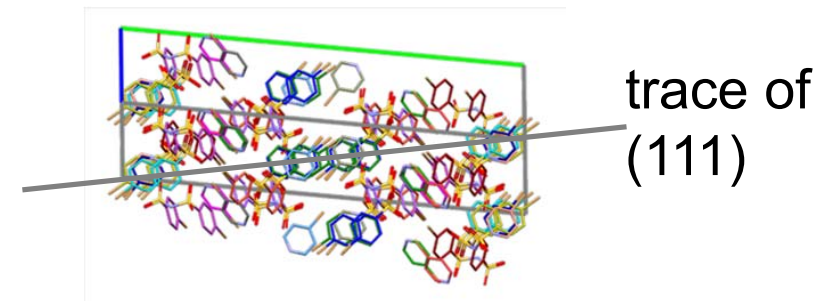

A layer (111)

[101]

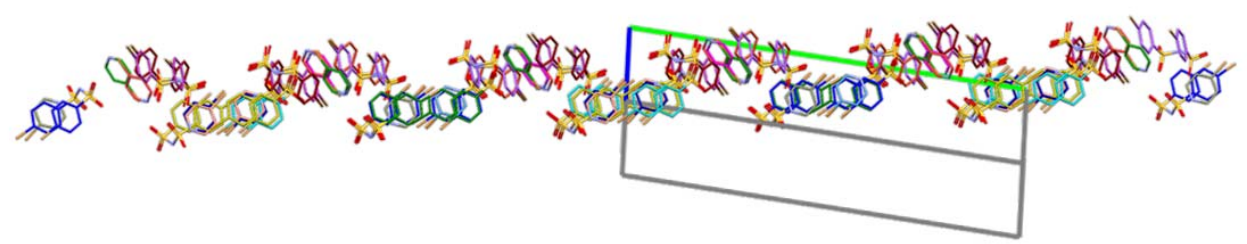

$290^{\circ}$

[1211]

(4 sets of

2 anions)

(pseudotranslations for

4-bromopyridinium cations are not marked)

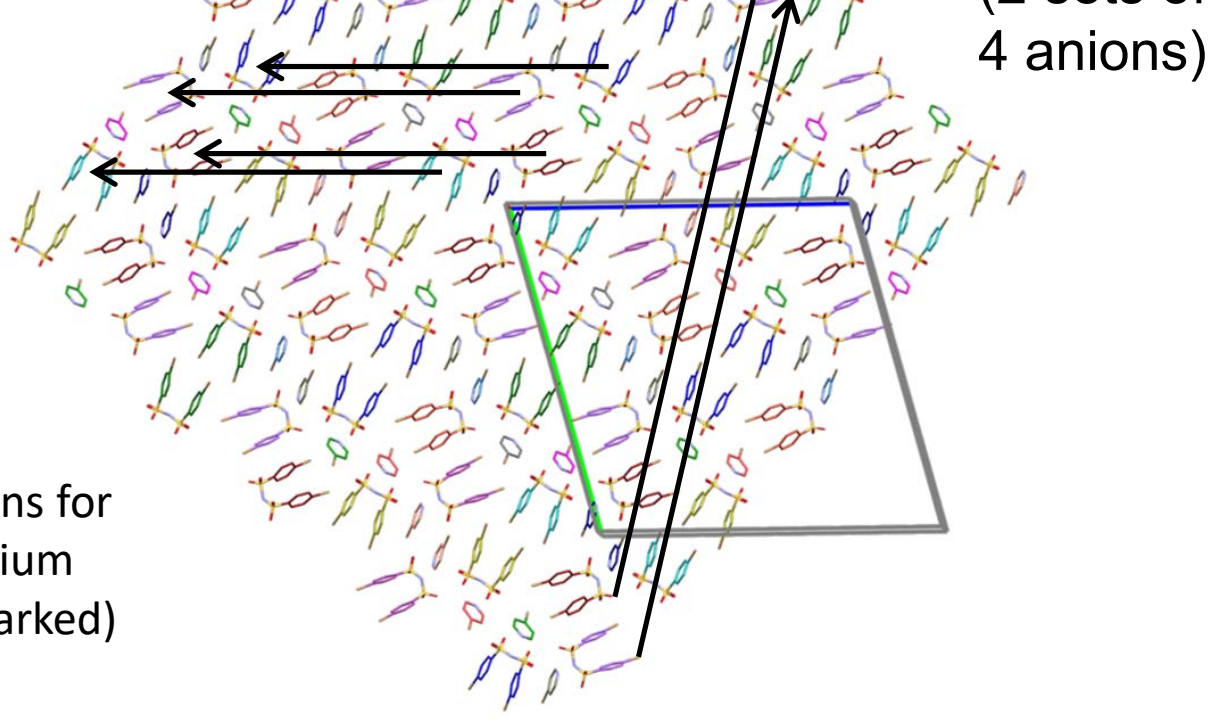


Fig. S8 Relationship of the two structures of $\mathrm{Ph}_{3} \mathrm{Si}-\mathrm{C} \equiv \mathrm{C}-\mathrm{C} \equiv \mathrm{C}-\mathrm{SiPh}_{3}$

TAJVIK01 at $180 \mathrm{~K}, P \overline{1}$,

$$
\begin{gathered}
Z^{\prime}=2.5=2(1)+(1 / 2) \\
Z^{*}=3 ;[234] / 5
\end{gathered}
$$

View along [234]

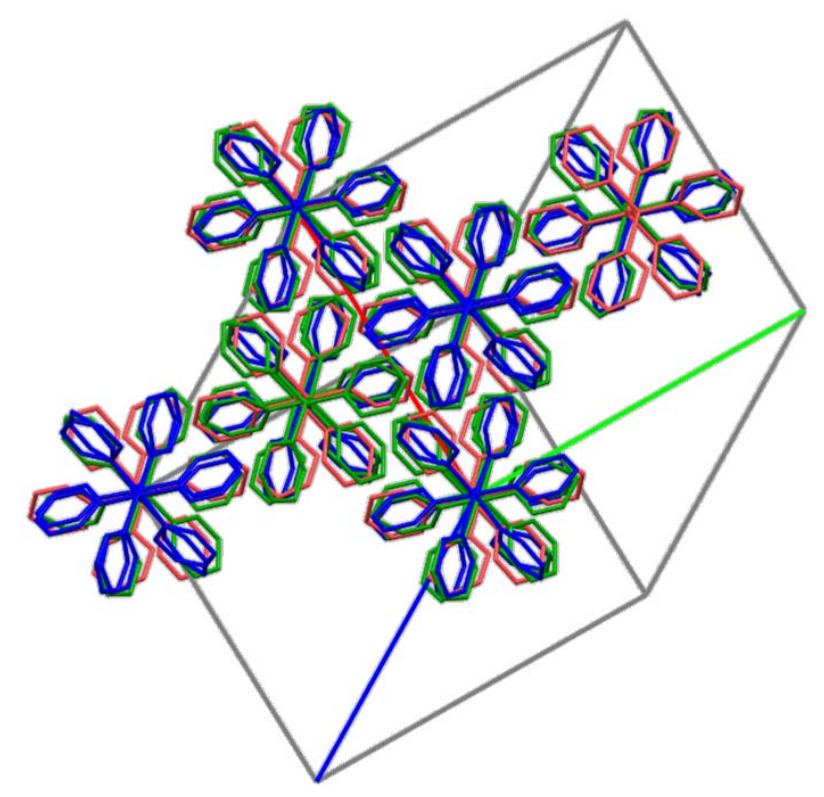

TAJVIK at RT, $R \overline{3}$,

$$
\begin{gathered}
Z^{\prime}=1.17=3(1 / 3)+(1 / 6) \\
Z^{*}=4 ;[001] / 7 \\
\text { View along } \mathrm{c}
\end{gathered}
$$

$$
\left(\frac{1}{5}\right)\left(\begin{array}{ccc}
3 & \overline{3} & 1 \\
2 & 3 & \overline{1} \\
14 & 21 & 28
\end{array}\right) \mathbf{a}_{\text {tricl }} \cong \mathbf{a}_{\text {rhomb }}
$$

Transformed TAJVIK01 at

$180 \mathrm{~K}$ :

$14.3,13.8,96.3 \AA$

$87.9,89.5,118.3^{\circ}$
TAJVIK at RT:

14.2, 14.2, $97.3 \AA$

$90,90,120^{\circ}$ 
Fig. S9 In QAJDAG $\left(P 2_{1}, Z^{\prime}=12\right)$ the molecules related by a pseudotranslation are not in direct contact but are in contact through a molecule in a symmetry-related column. [Structure is shown in Pna2 ${ }_{1}, Z^{\prime}=6$ as recommended by PLATON.

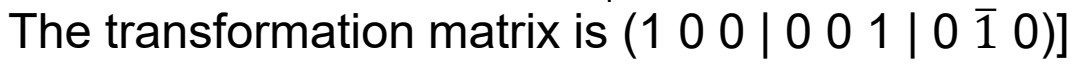

[001]

Projection along a
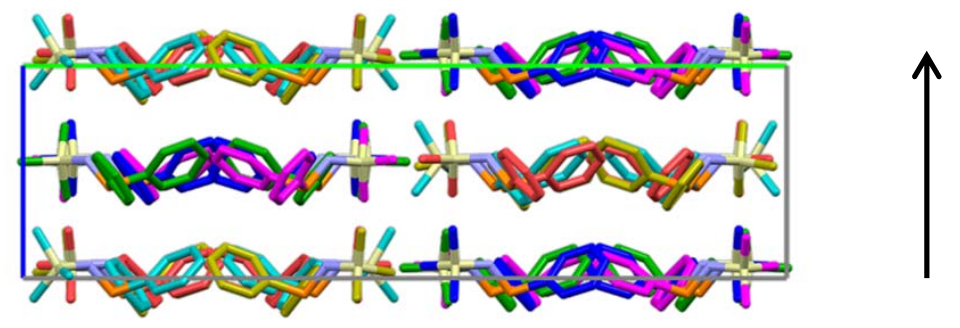

\section{A layer (001)}

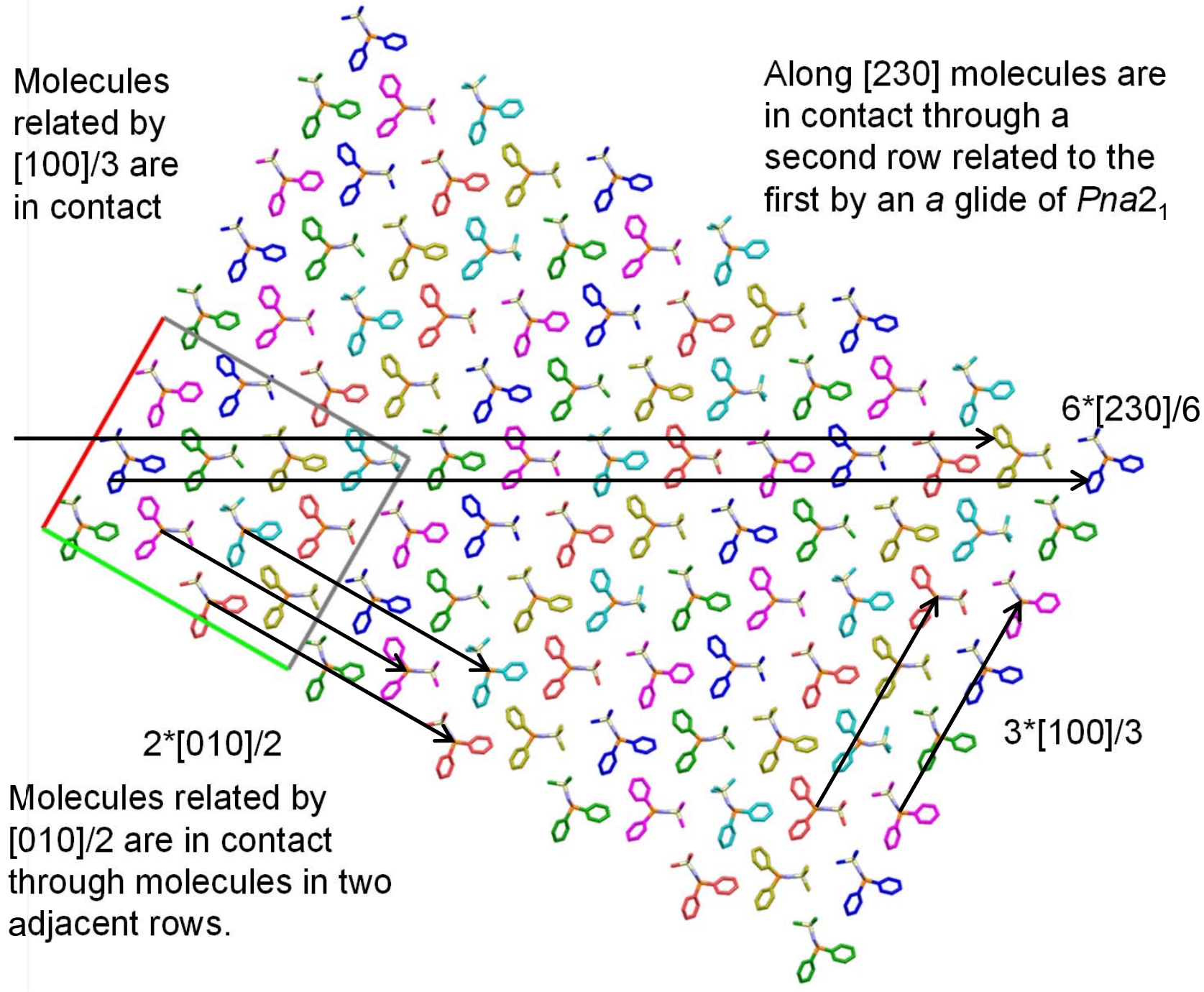


Fig. S10 In HONBIW $\left[P 2_{1}, Z^{\prime}=8\right)$ molecules related by the pseudotranslation ([001]/4) are not in contact but are in contact through molecules related by approximate symmetry

The [001]/4 pseudotranslation relates two groups of four molecules each. The two groups interleave.

Projection along $\mathbf{b}$

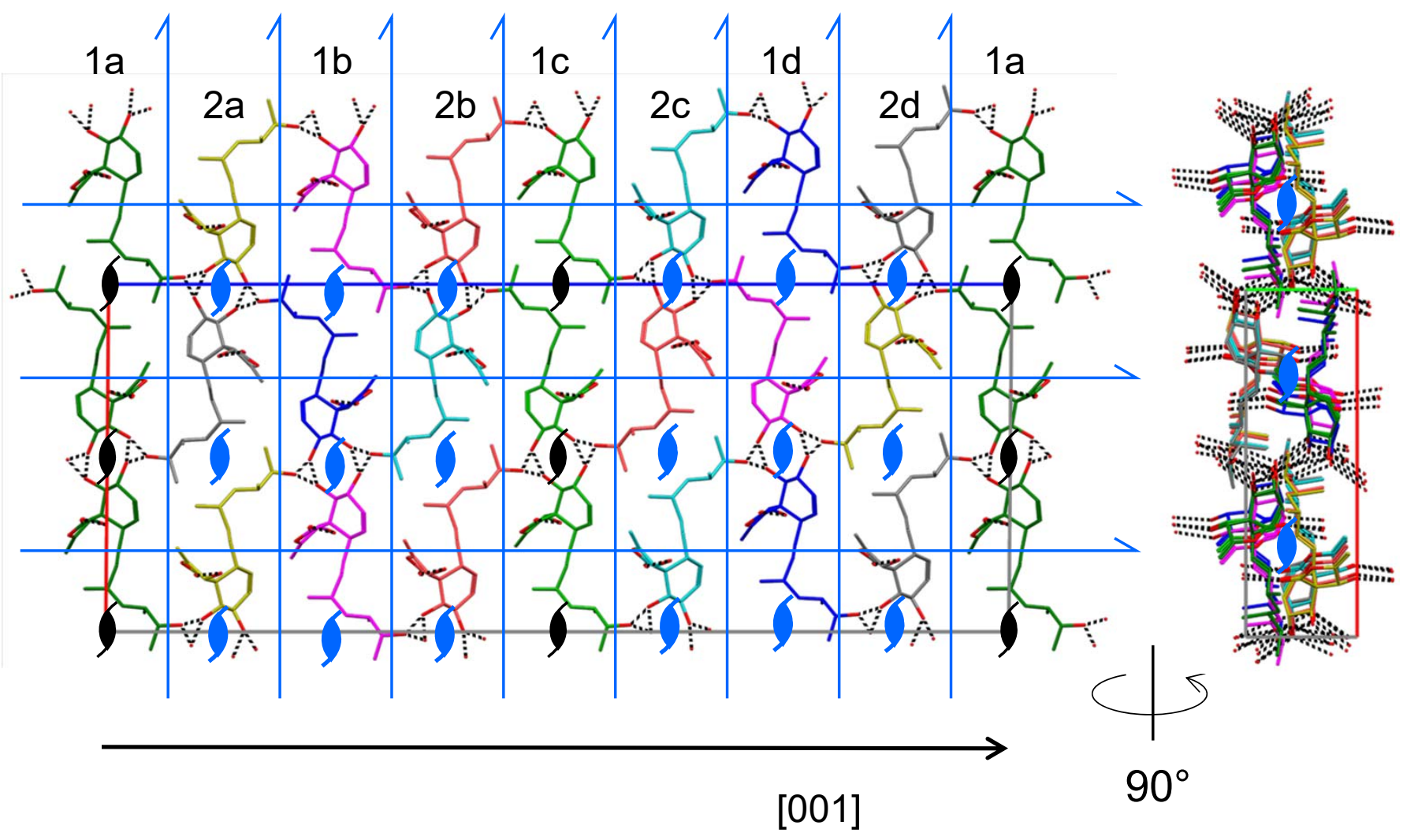

Space-group symmetry elements are shown in black; approximate symmetry elements are shown in blue. The $\mathrm{OH}$... O bonds are shown as dotted lines. The $\mathrm{H}$-bond pattern extends in three dimensions.

The [001]/4 pseudotranslation relates two groups of four molecules each. The two groups interleave. 
Fig. S11 UZILIA $\left(C c, Z^{\prime}=8\right)$ is an example of a structure in which the intermolecular contacts along a shorter pseudotranslation are not as important as those along a longer pseudotranslation

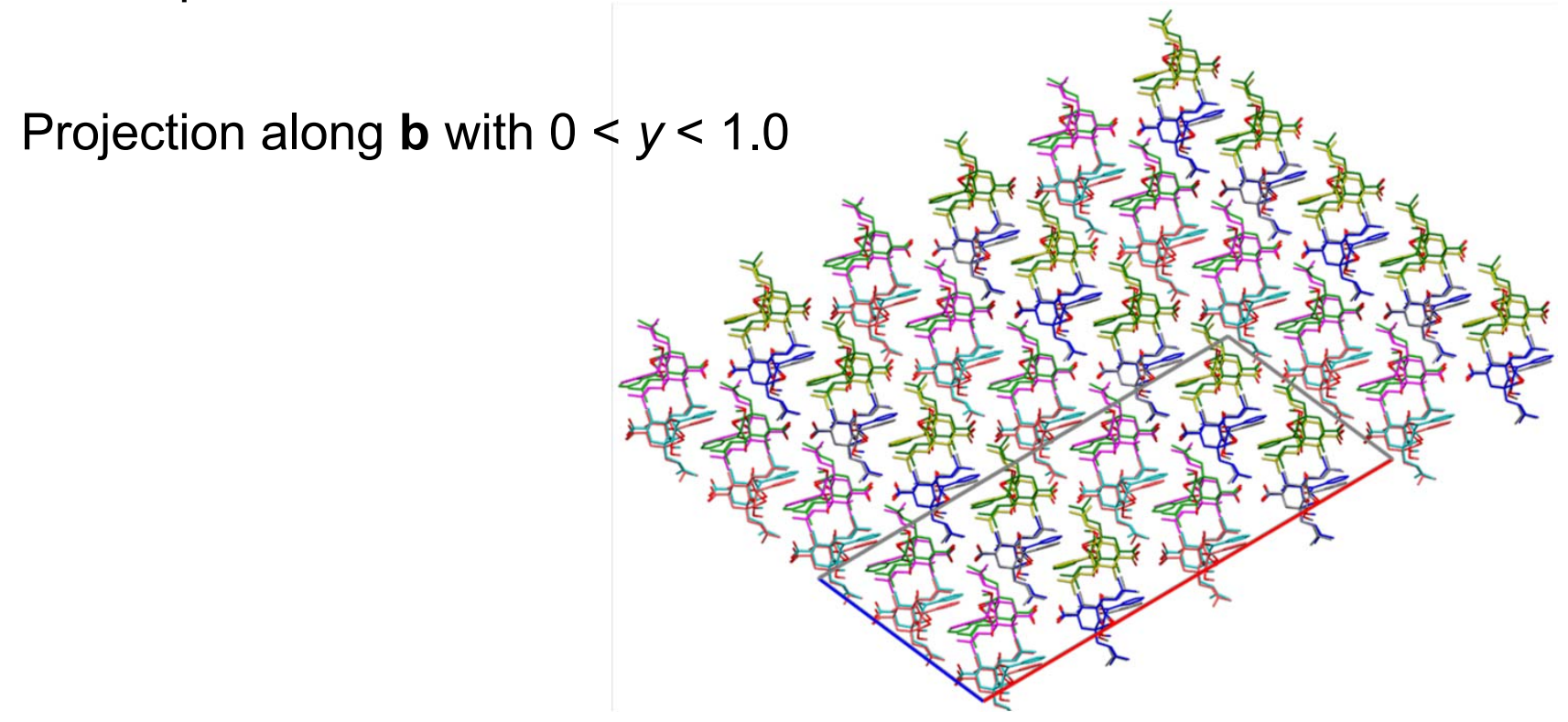

Projections along $\mathbf{b}$ with $0<y<0.3$;

contacts shorter than $\Sigma_{\mathrm{VDW}}$ are marked

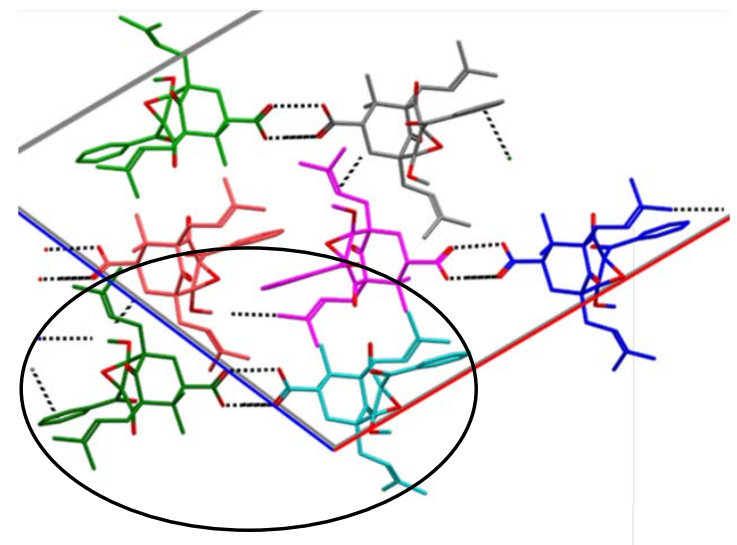

$\mathrm{H}$-bonded dimers are lined up along [10 $\overline{2}]$
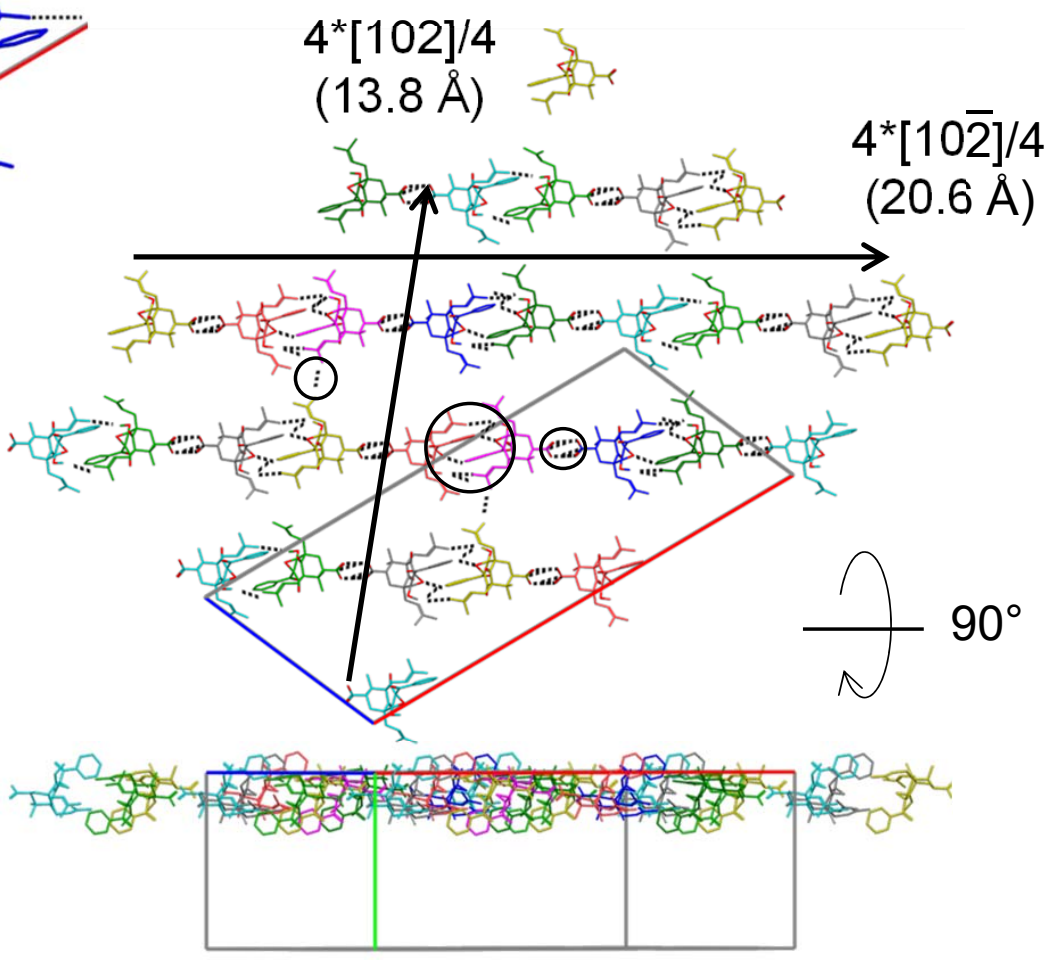
Fig. S12 Space-group percentages for the 10 most common space groups (the color code for the space-group numbers is the same within each set of five bars)

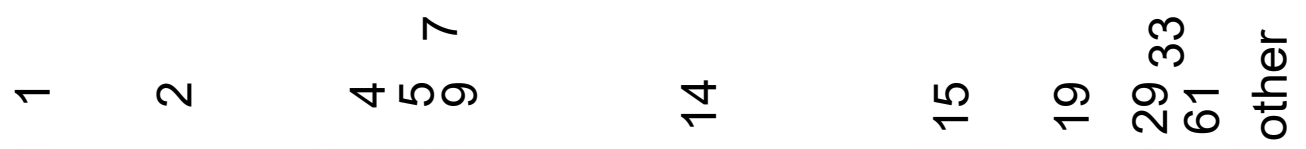

All organic

$Z^{\prime}=1$

(75\% of All)

$Z^{\prime} \geq 2$

(12\% of All)

$Z^{\prime} \geq 2$, no pseudotrans $\left(84 \%\right.$ of $\left.Z^{\prime} \geq 2\right)$

$Z^{\prime} \geq 2$, modulated $\left(16 \%\right.$ of $\left.Z^{\prime} \geq 2\right)$
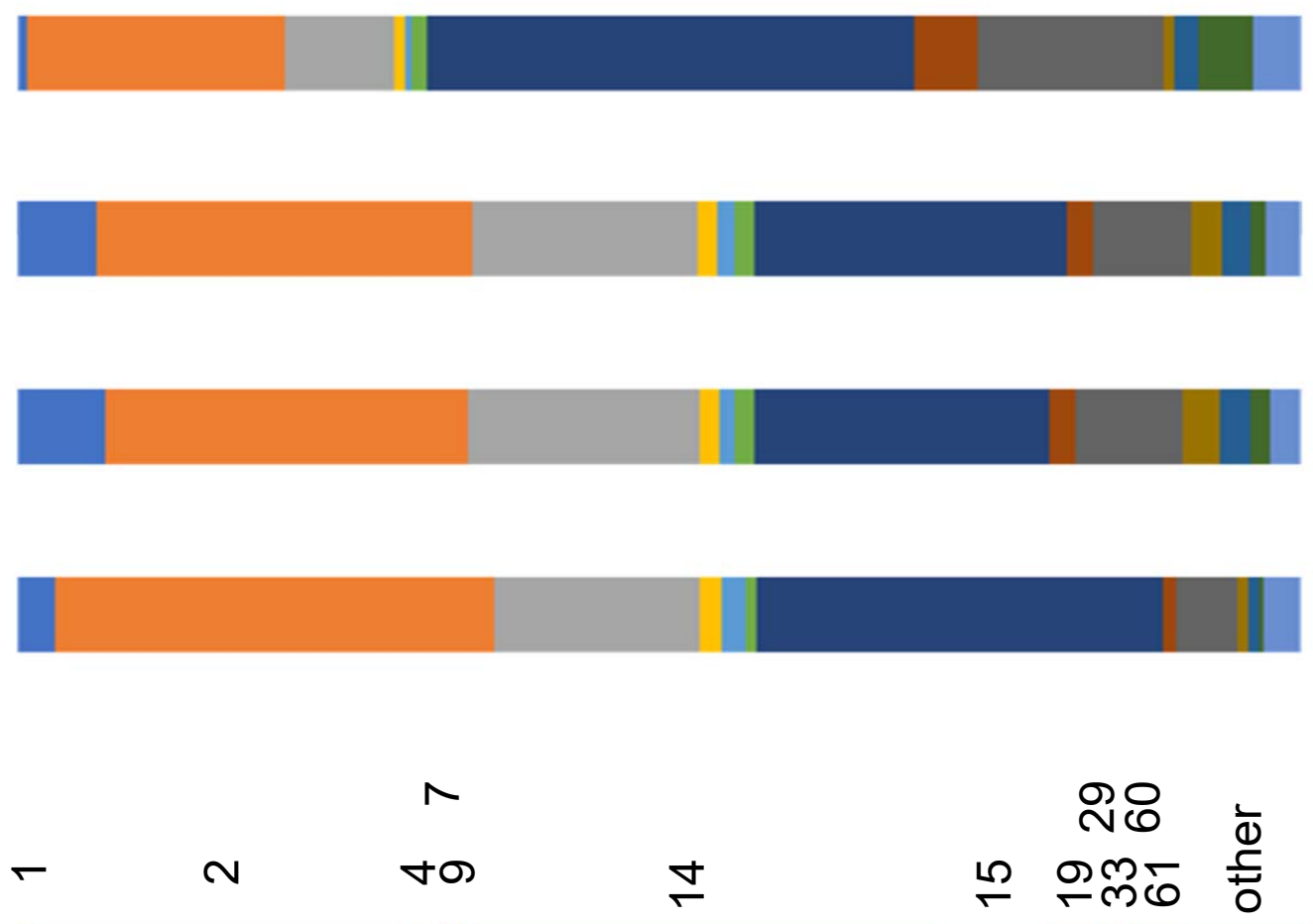

All metalloorganic

$Z^{\prime}=1$

(63\% of All)

$Z^{\prime} \geq 2$

(8\% of All)

$Z^{\prime} \geq 2$, no

pseudotrans

(85\% of $Z^{\prime} \geq 2$ )

$Z^{\prime} \geq 2$,

modulated

( $15 \%$ of $Z^{\prime} \geq 2$ )
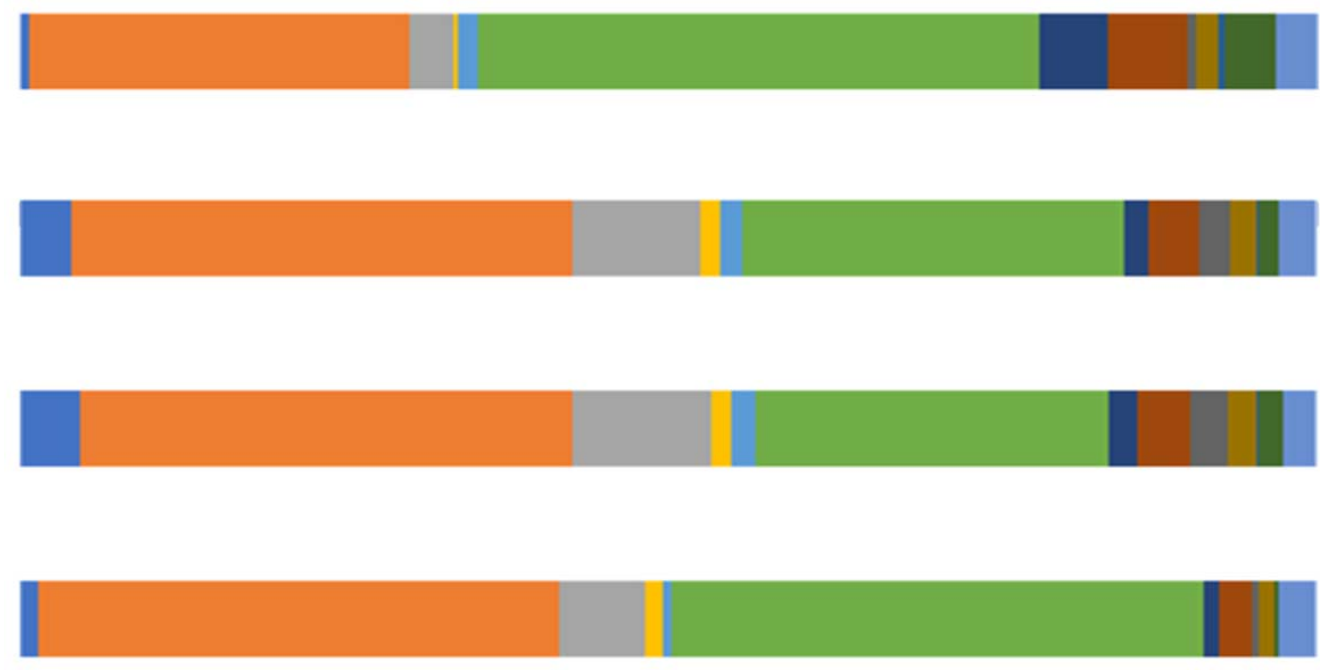
Fig. S13 In WANJAZ $\left(P 22_{1} 2_{1}, Z^{\prime}=8\right)$ the $[201] / 4$ and $[20 \overline{1}] / 4$ pseudotranslations both work well in layers that have different orientations.

The pseudotranslations in WANJAZ are obscured by the interleaving of independent columns.

View along [201] (b is vertical)

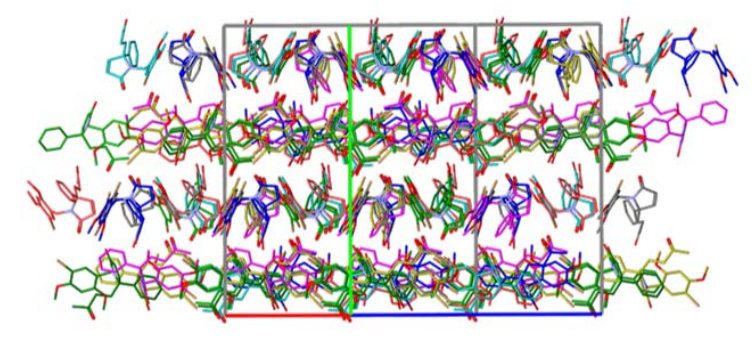

$4^{*}[201] / 4$

( 2 sets of 4$)$ and

$4^{*}[20 \overline{1}] / 4$

(2 sets of 4 )
Layer

(010) at

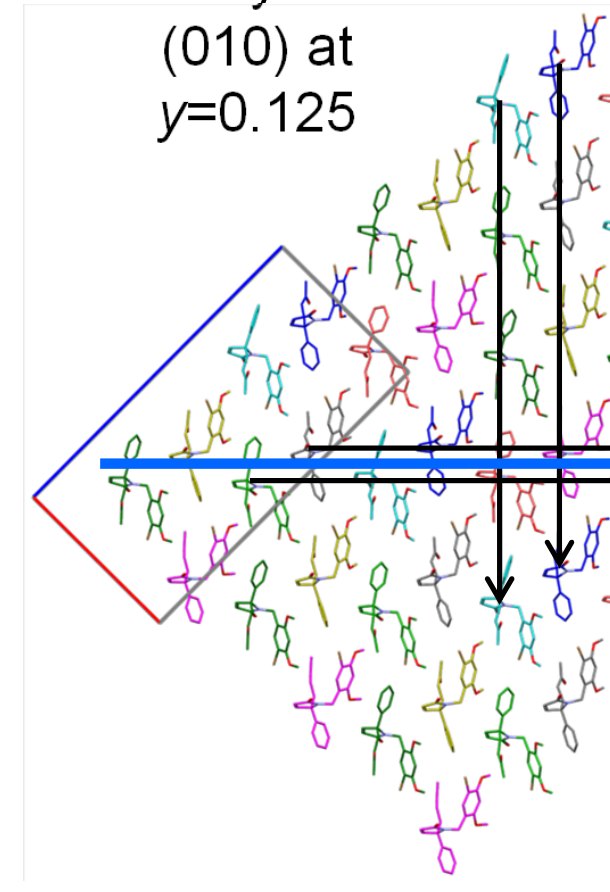

$$
\begin{aligned}
& 4^{*}[201] / 4 \\
& (2 \text { sets of } 4) \text { and } \\
& 4^{*}[20 \overline{1}] / 4 \\
& (2 \text { sets of } 4)
\end{aligned}
$$

Layer

(010) at $y=0.375$

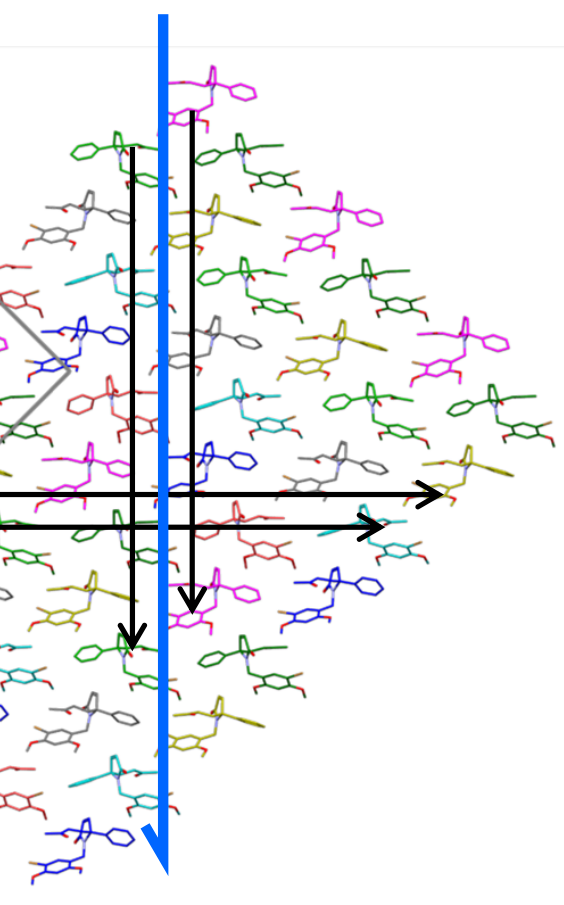

approximate 2 axes have different orientations in adjacent layers 
Fig. S14 In XOJYEC01 $\left(P \overline{1}, Z^{\prime}=3\right.$ for a 3:2 formulation of the cocrystal) the $[1 \overline{11}] / 3$ pseudotranslation is obscured by overlap

\section{A view along $[1 \overline{11}]$}

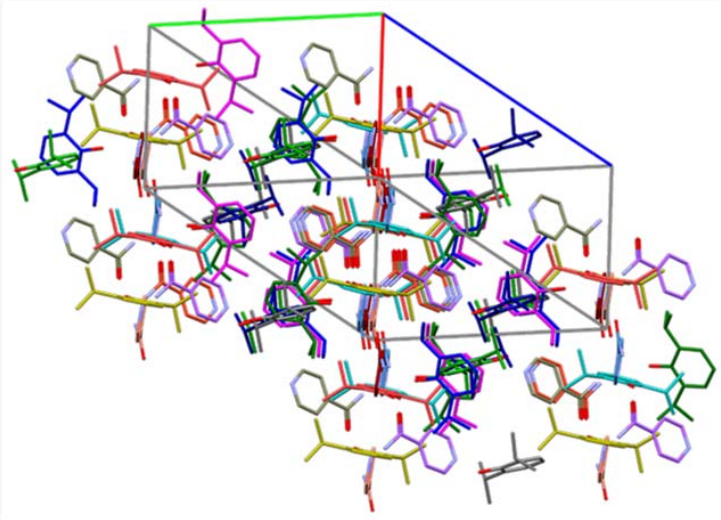

The five median vectors for the $[1 \overline{11}] / 3$ pseudotranslations are not well separated

\section{A layer $(01 \overline{1})$}
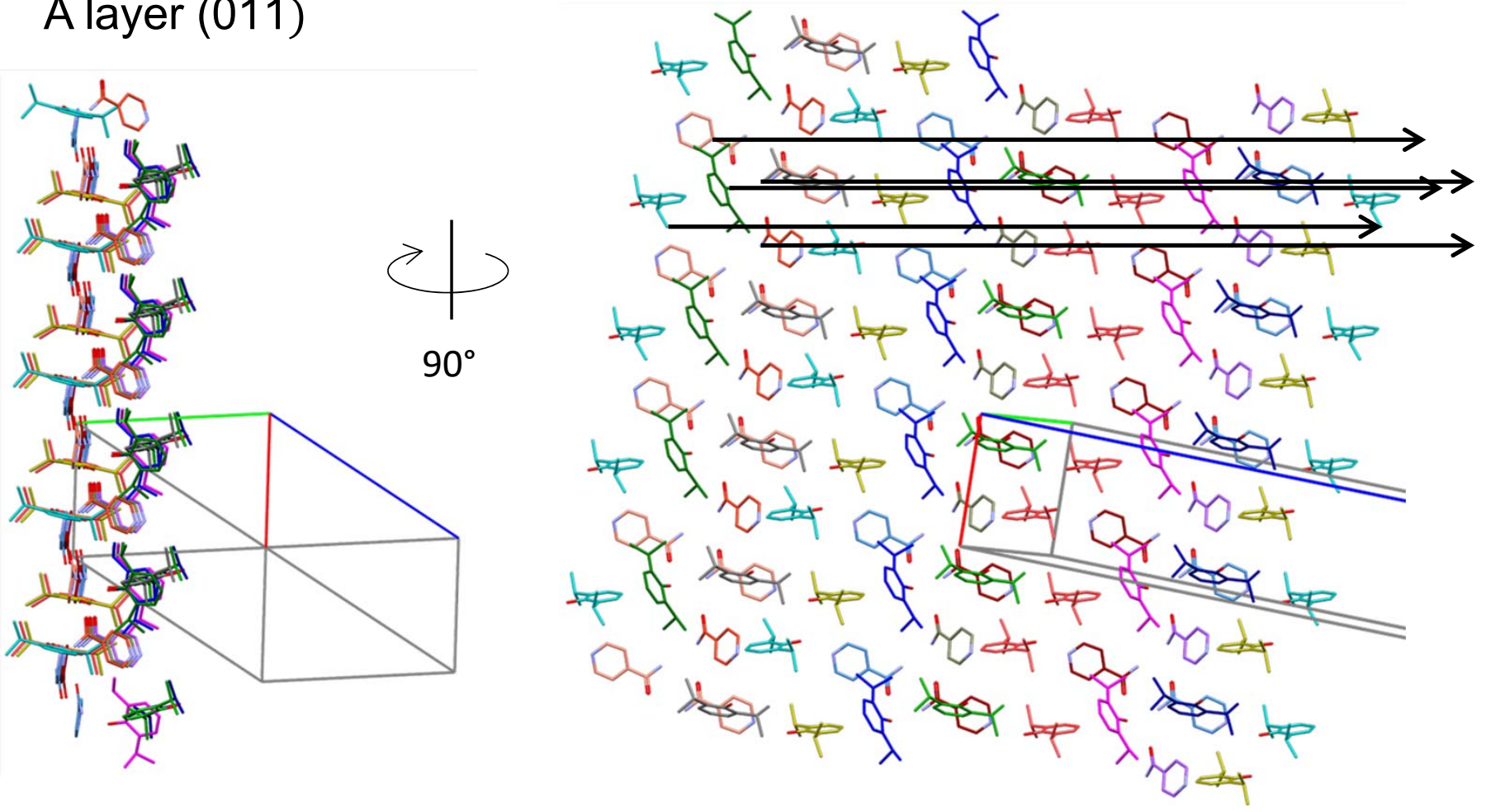
Fig. S15(a) In KAYGUO ( $\left(\overline{1}, Z^{\prime}=6\right)$, a 1:1 acid-base coo-crystal, a longer pseudotranslation is more regular

KAYGUO is a 1:1 acid-base co-crystal; the two sets of three succinic acid molecules in rows that include inversion centers

Views along $\mathbf{b}$ and $\mathbf{a}\left(g=90.3^{\circ}\right)$
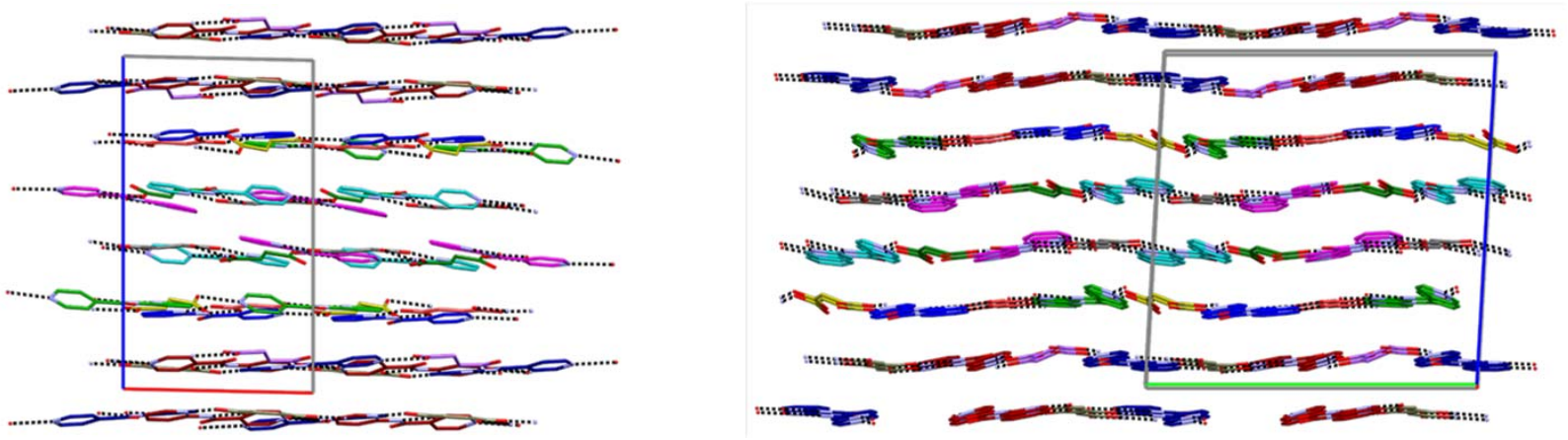

A slice (100) showing [011]/3, the shortest pseudotranslation
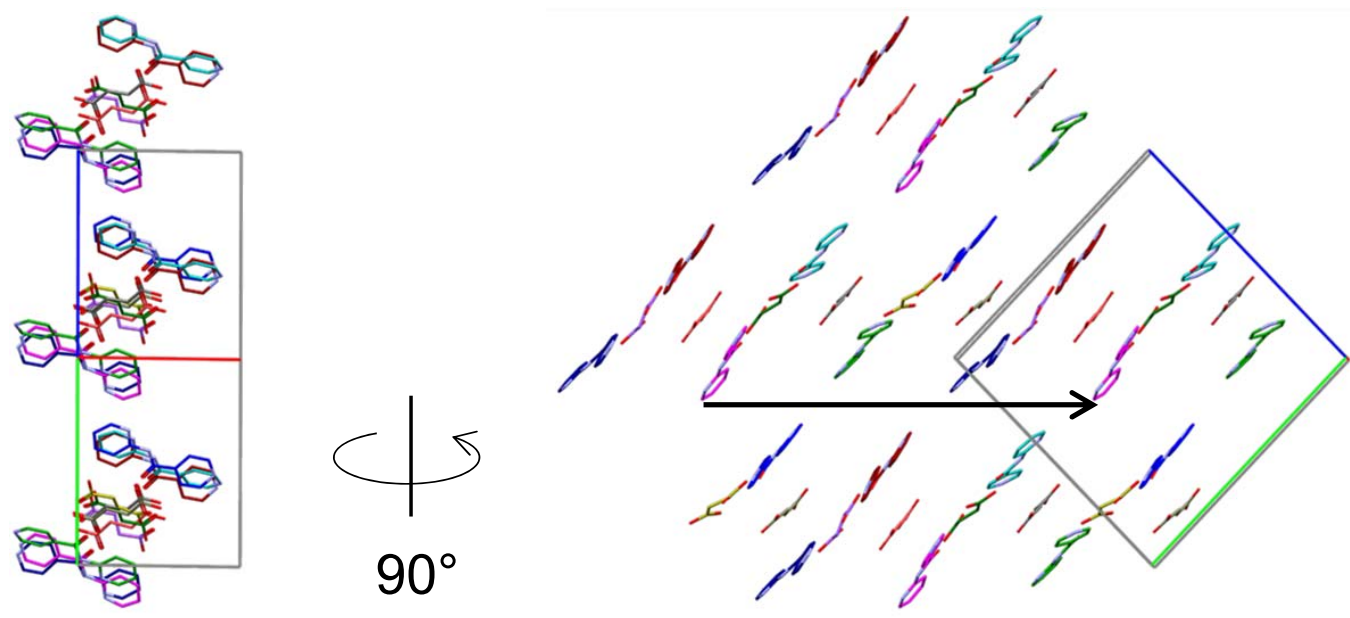
Fig. $S 15(b)$ In KAYGUO $\left(P \overline{1}, Z^{\prime}=6\right)$ a longer pseudotranslation is more regular

A slice (012) showing $[3 \overline{2} 1] / 6$ and $[32 \overline{1}] / 6$
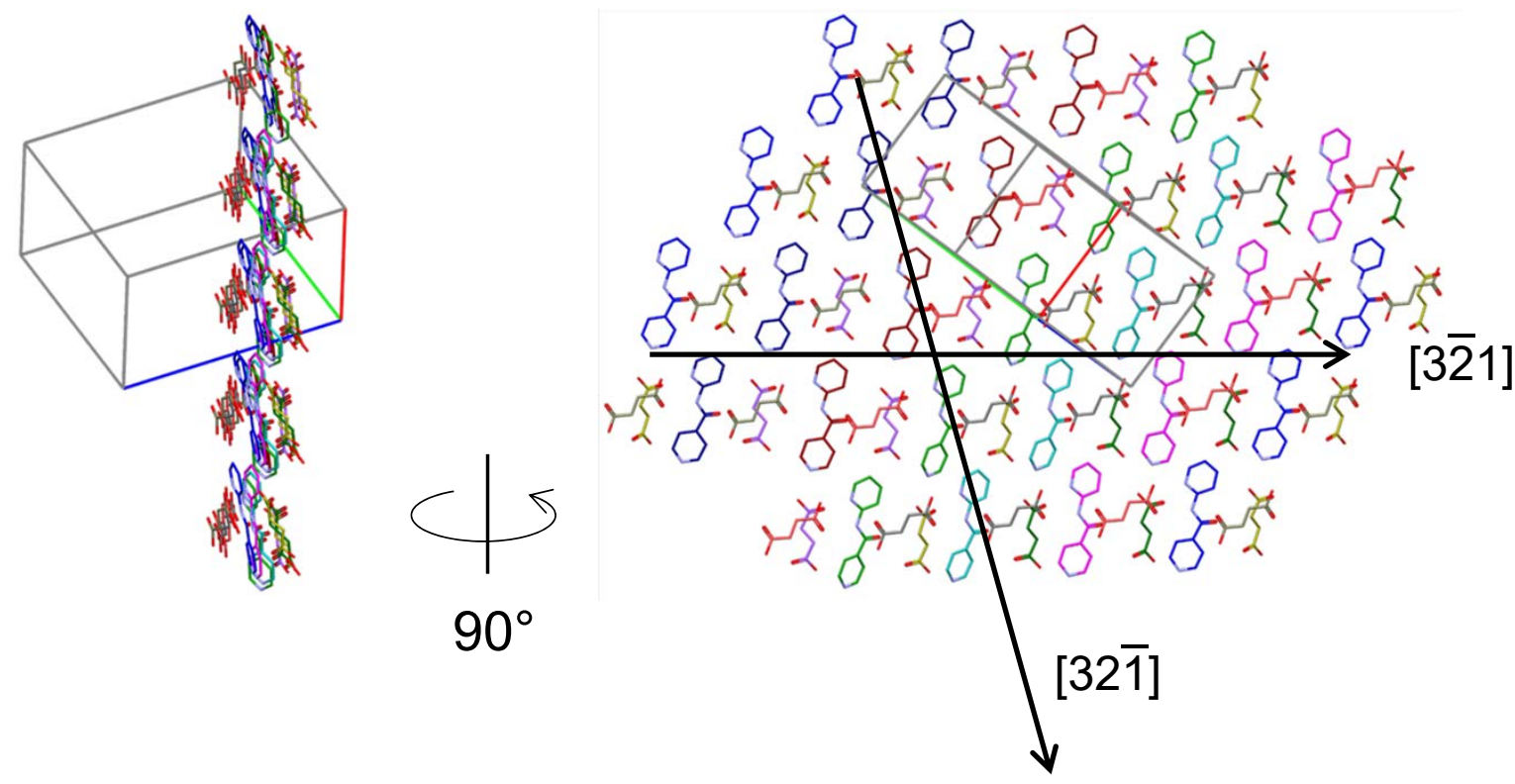

A slice (11 $\overline{1})$ showing $[011] / 3$ and $[3 \overline{2} 1] / 6$
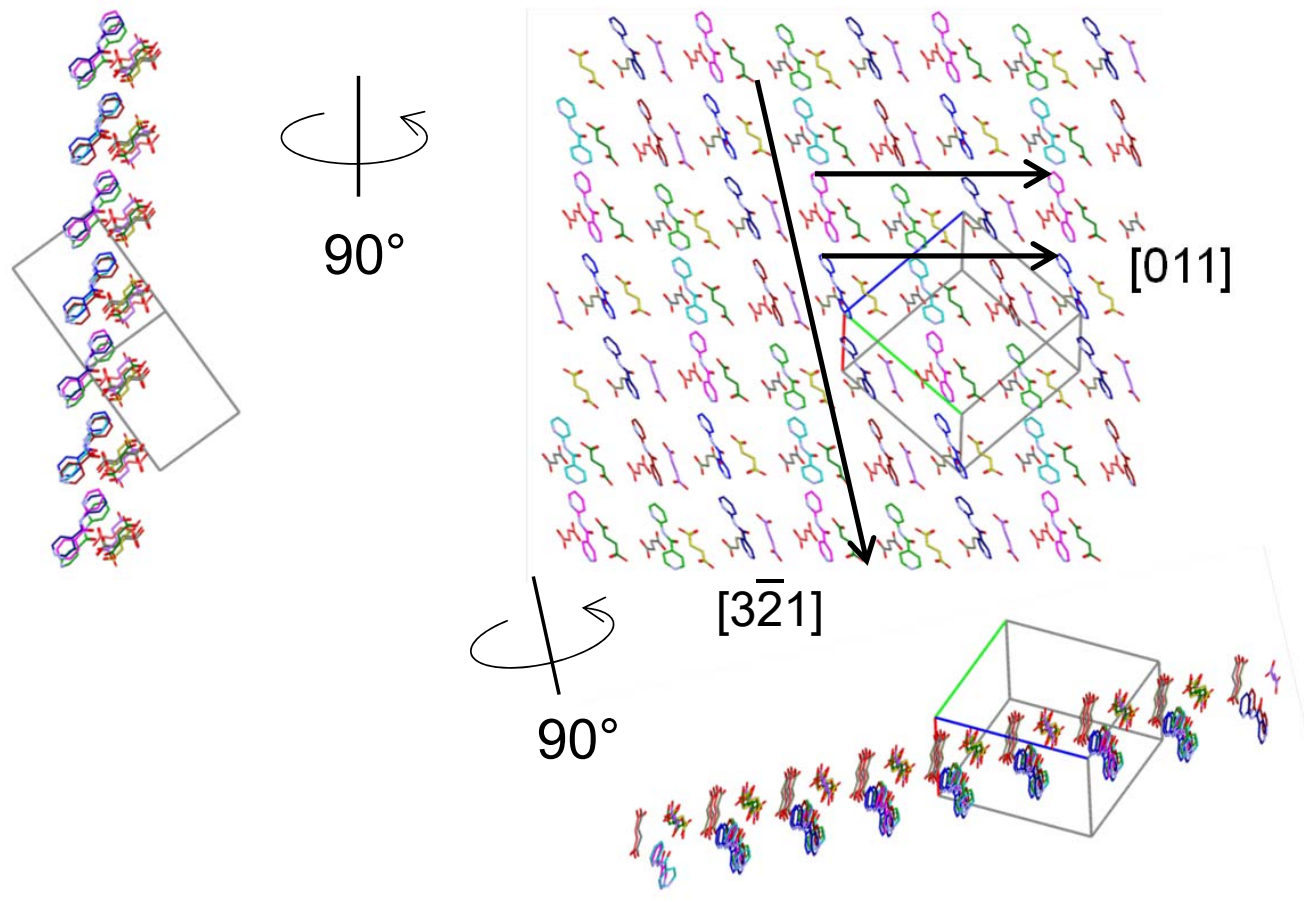
Fig. S16 In PAMTEF $\left(P 2_{1} / n, Z^{\prime}=5\right)[20 \overline{1}] / 5$ is the shortest pseudotranslation but molecules related by the slightly longer [301]/5 pseudotranslation are in close contact through molecules related by the $n$ glide; the two sets of molecules form an $\mathrm{H}$-bonded chain.

Views of a layer (010). H-bonded chains run along [301]

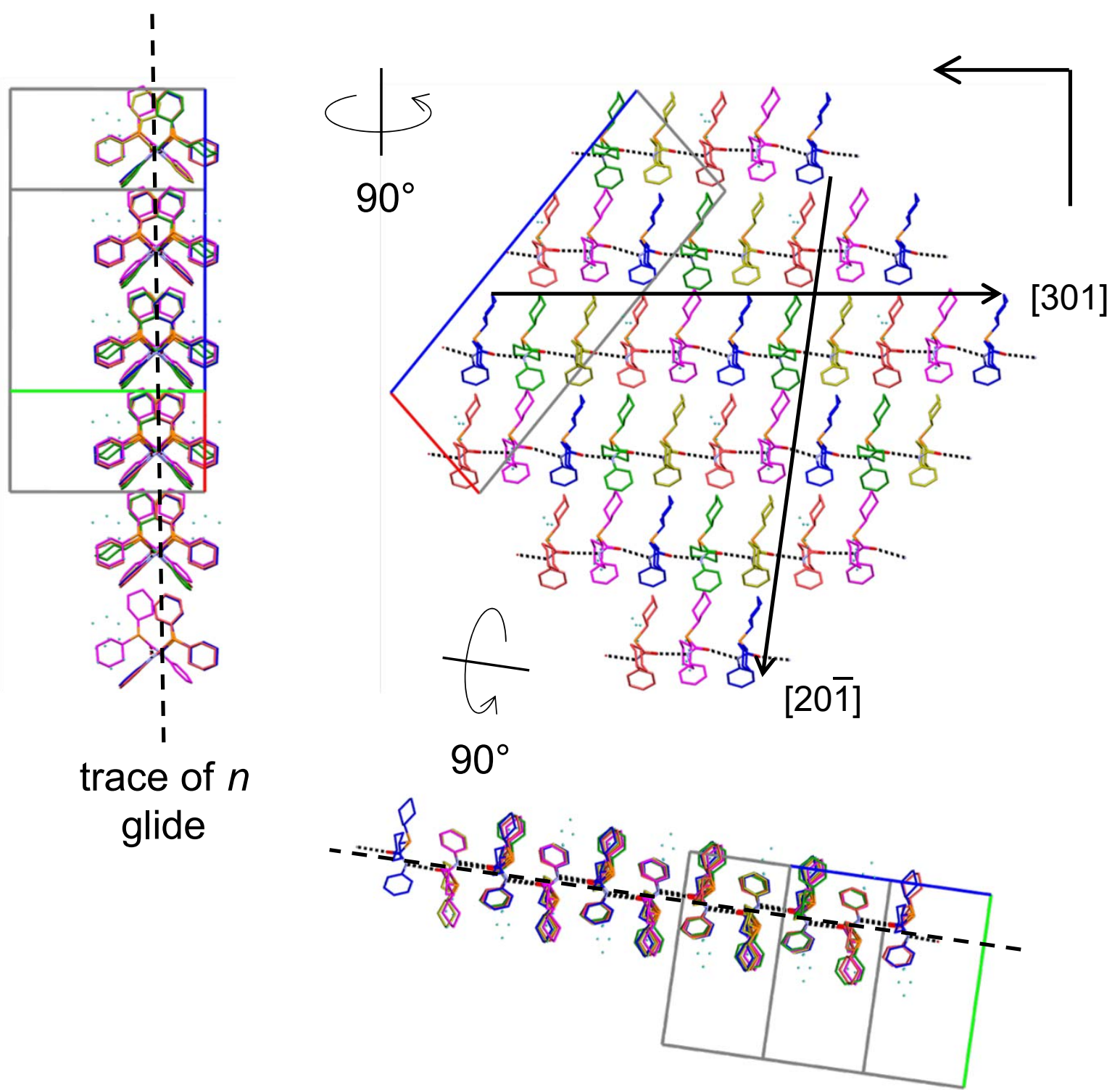


Fig. S17 In QUQQUO $\left(P^{\overline{1}}, Z^{\prime}=8\right)$ the longer pseudotranslation is more informative because it lies within obvious structural layers

The shortest pseudotranslation is [101]/2 (18.75 $\AA$ ) but the longer pseudotranslation [121]/2 (26.84 $\AA$ ) lies within the layer $(0 \overline{1} 2)$

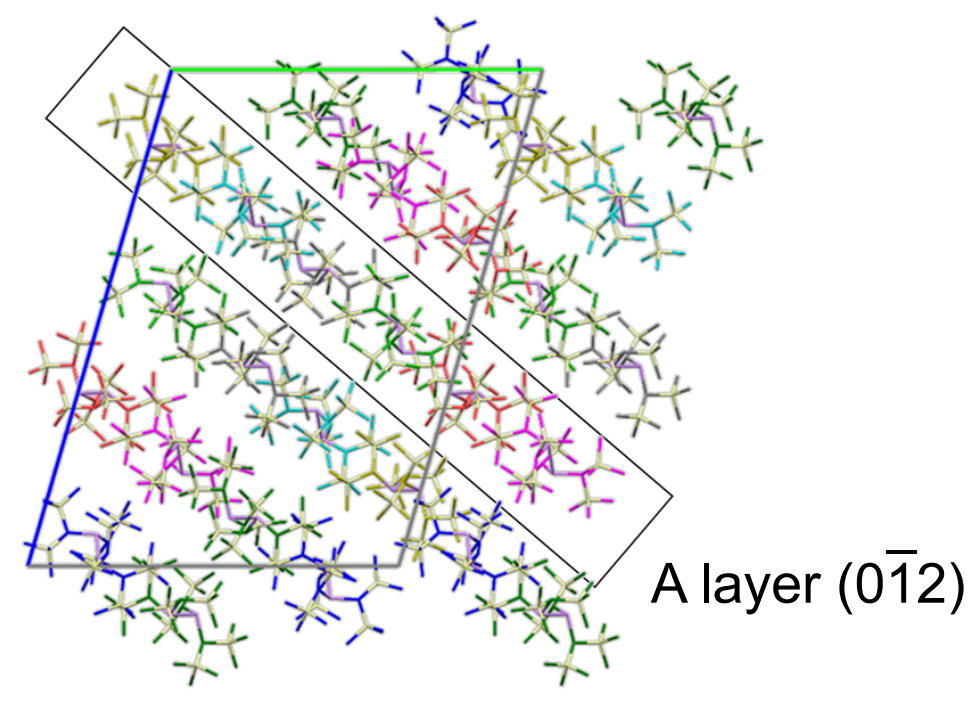

A layer $(0 \overline{1} 2)$

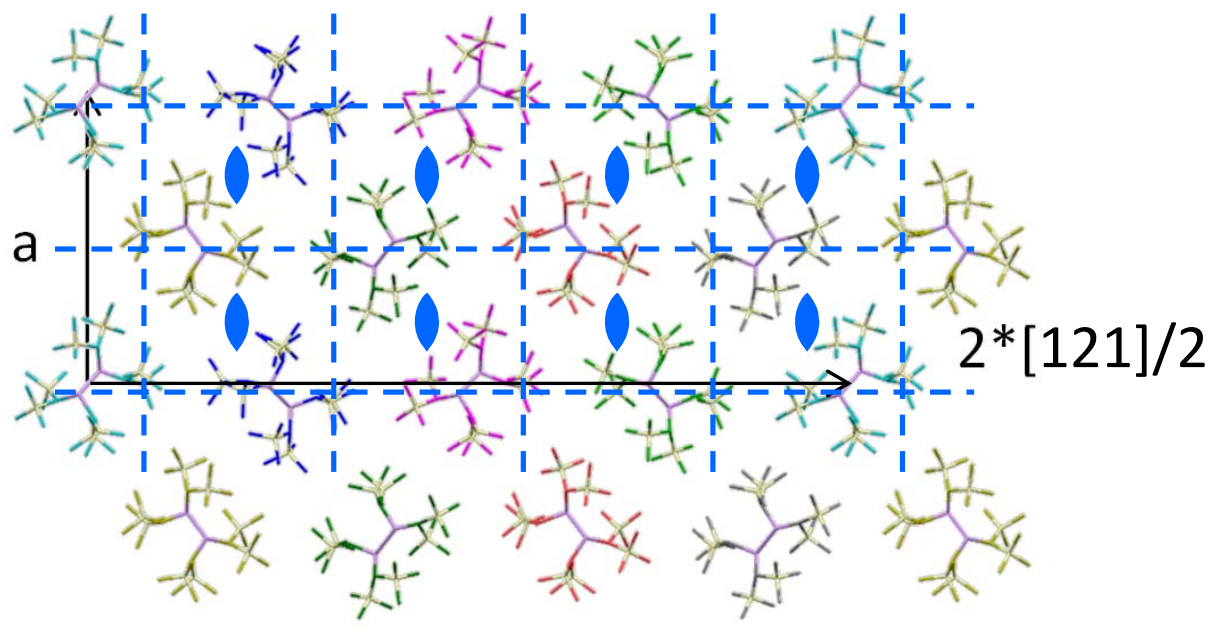


Fig. S18(a) EPUQEM in $P 1$ and in $P \overline{1}$ as recommended by PLATON. The $P \overline{1}$ structure differs from the $P 1$ structure in significant ways.
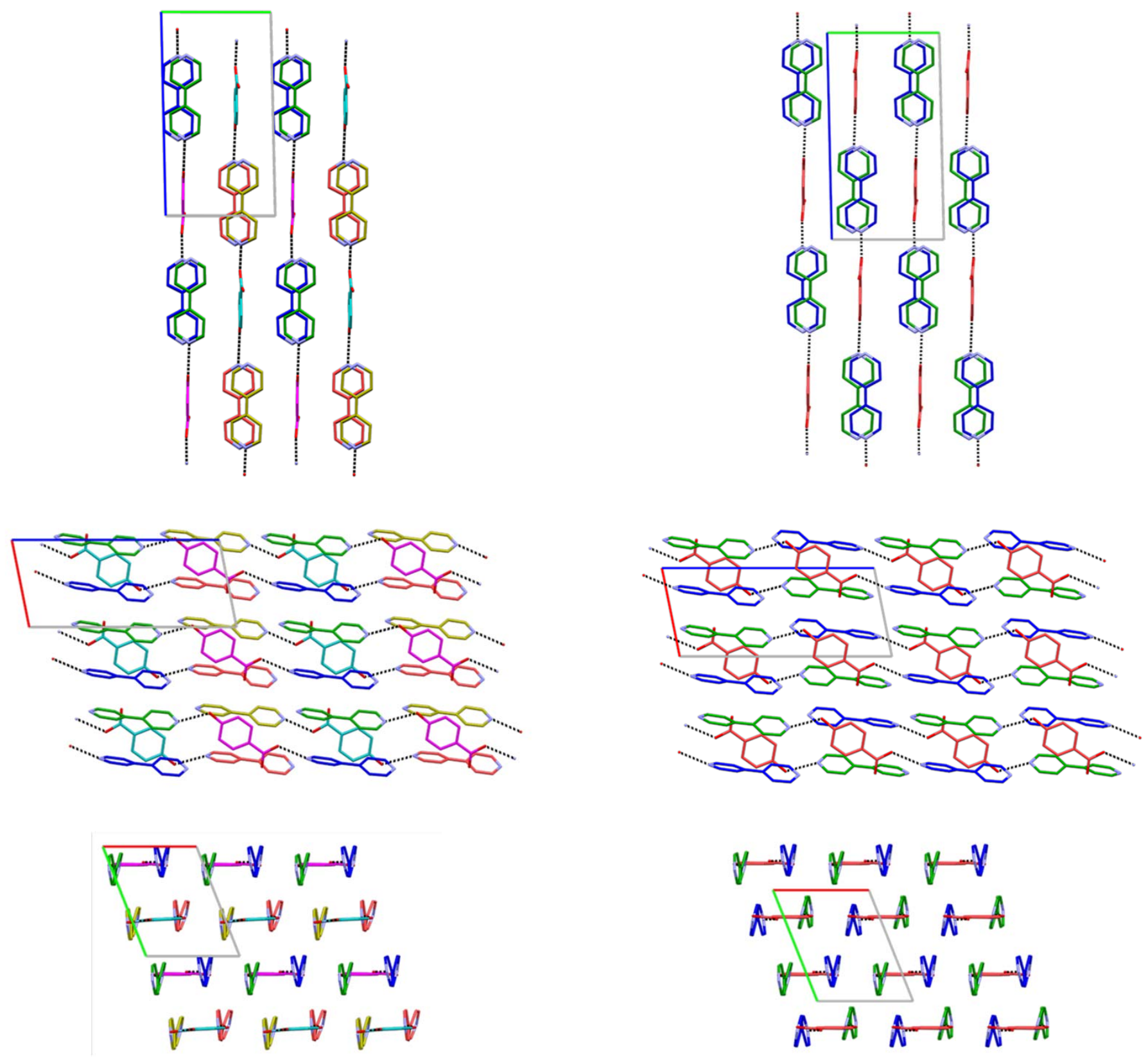

A.Mukherjee \& G.R.Desiraju, Chem.Commun. (2011), 47, 4090-4092. 
Fig. S18(b) Details of the differences between the $P 1$ and $P \overline{1}$ structures of EPUQEM

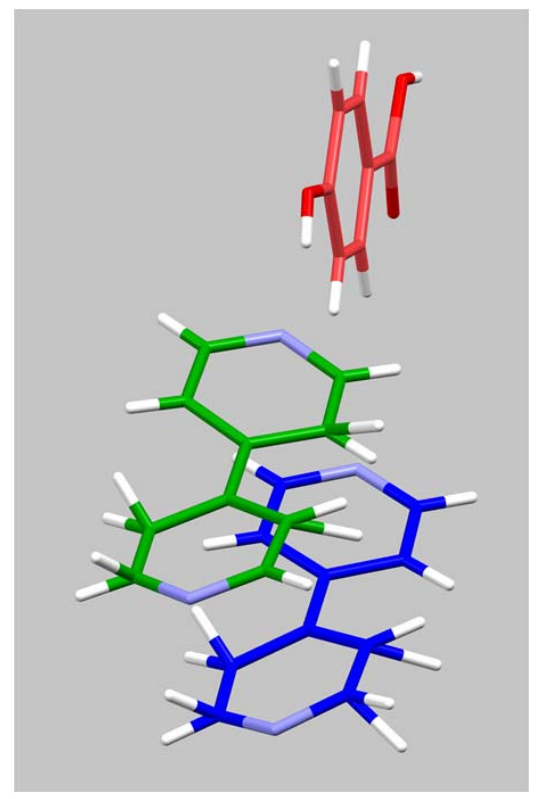

Half of the $\mathrm{H}$ atoms in the averaged bipy molecules are disordered

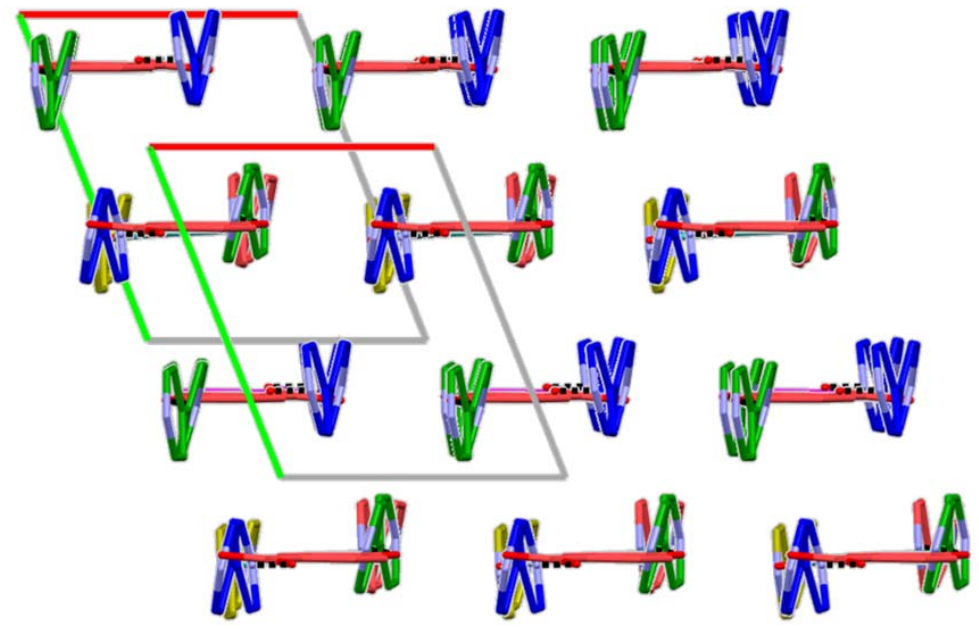

Every other horizontal row has a different orientation in the two structures

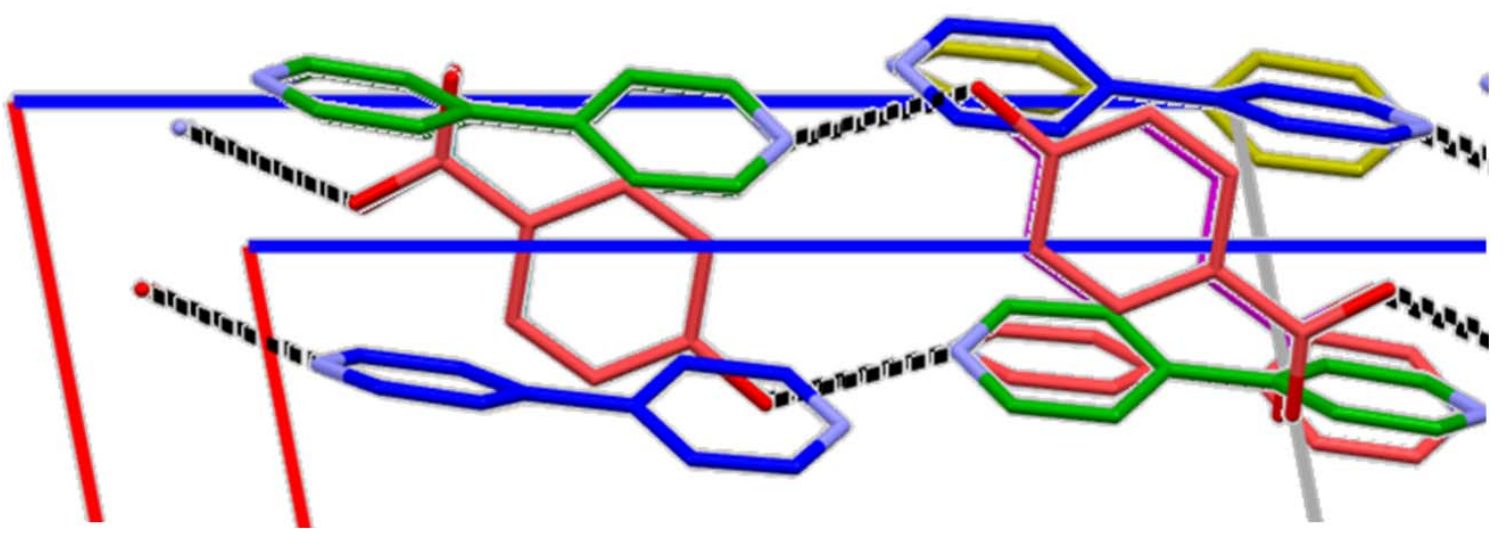

An overlay of the $P 1$ and $P \overline{1}$ structures works well for two of the bipys but much less well for the other two 


\begin{tabular}{|c|c|}
\hline $\begin{array}{l}\text { ADUNOF } \\
\text { ADUNOF01 }\end{array}$ & $\begin{array}{l}\text { Vinokur, A. I., Yakovenko, A., Liu, L., Schomaker, J. M. \& Guzei, I. A. } \\
\text { (2017). Cryst. Growth Des. 17, 5984. }\end{array}$ \\
\hline AFIYUL & $\begin{array}{l}\text { Meister, A. C., Lang, M., Nieger, M. \& Brase, S. (2013). Acta Cryst. E69, } \\
\text { o1303. }\end{array}$ \\
\hline AFOXAW & $\begin{array}{l}\text { Perryman, M. S., Harris, M. E., Foster, J. L., Joshi, A., Clarkson, G. J. \& } \\
\text { Fox, D. J. (2013). Chem. Commun. 49, } 10022 .\end{array}$ \\
\hline AGIXIZ & $\begin{array}{l}\text { Klopfleisch, M., Seidel, R. A., Gorls, H., Richter, H., Beckert, R., Imhof, } \\
\text { W., Reiher, M., Pohnert, G. \& Westerhausen, M. (2013). Org. Lett. 15, } \\
\text { 4608. }\end{array}$ \\
\hline AJEYEU & $\begin{array}{l}\text { Raza, A. R., Tahir, M. N., Sultan, A., Danish, M. \& Sohail, M. (2009). Acta } \\
\text { Cryst. E65, o3172. }\end{array}$ \\
\hline AKEVAP & $\begin{array}{l}\text { Samai, S., Ghosh, D., Das, U. K., Atta, S., Manna, S. K. \& Maiti, D. K. } \\
\text { (2016). Green Chemistry 18, } 2961 .\end{array}$ \\
\hline APUNUV & $\begin{array}{l}\text { Back, O., Donnadieu, B., Hopffgarten, M. v., Klein, S., Tonner, R., } \\
\text { Frenking, G. \& Bertrand, G. (2011). Chemical Science 2, } 858 .\end{array}$ \\
\hline ASATET01 & $\begin{array}{l}\text { Tam, C. N., Cowan, J. A., Schultz, A. J., Junior, V. G. Y., Trouw, F. R. \& } \\
\text { Sykes, A. G. (2003). J. Phys. Chem. B 107, 7601. }\end{array}$ \\
\hline AWAKEO & Lehmler, H. -J., Parkin, S. \& Brock, C. P. (2004). Acta Cryst. B60, 325. \\
\hline AZADUA & $\begin{array}{l}\text { Sousa, C. A. D., Rizzo-Aguiar, F., Vale, M. L. C., Garcia-Mera, X., } \\
\text { Caamano, O. \& Rodriguez-Borges, J. E. (2012). Tetrahedron Lett. 53, } 1029 .\end{array}$ \\
\hline BAZHAM & Mitzel, N. W. (2003). Z. Naturforsch., B: Chem. Sci. 58, 759. \\
\hline BAZHAM01 & Marsh, R. E. (2005). Acta Cryst. B61, 359. \\
\hline $\begin{array}{l}\text { BOCKEK } \\
\text { BOCKEK01 } \\
\text { BOCKEK02 } \\
\text { BOCKEK03 } \\
\text { BOCKEK04 } \\
\text { BOCKEK05 }\end{array}$ & Szafranski, M. (2008). Chem. Phys. Lett. 457, 110. \\
\hline BOGPUK & $\begin{array}{l}\text { Abbasov, M. E., Hudson, B. M., Tantillo, D. J. \& Romo, D. (2014). J. Am. } \\
\text { Chem. Soc. 136, } 4492 .\end{array}$ \\
\hline CEJKEI & $\begin{array}{l}\text { Dediu, O. G. S. n., Oeser, T. \& Muller, T. J. J. (2006). J. Org. Chem. 71, } \\
3494 .\end{array}$ \\
\hline CEQKUH & $\begin{array}{l}\text { DeHaven, B. A., Chen, A. L., Shimizu, E. A., Salpage, S. R., Smith, M. D. } \\
\text { \& Shimizu, L. S. (2018). Supramol. Chem. 30, } 315 .\end{array}$ \\
\hline CHOEST21 & Hsu, L. -Y., Kampf, J. W. \& Nordman, C. E. (2002). Acta Cryst. B58, 260. \\
\hline $\begin{array}{l}\text { CIGHEG01 } \\
\text { CIGHEG02 }\end{array}$ & $\begin{array}{l}\text { Yamamura, S., Sugawara, Y., Terao, H., Matsushita, M. M. \& Sugawara, T. } \\
\text { (2006). Chem. Phys. 322, 392. }\end{array}$ \\
\hline
\end{tabular}




\begin{tabular}{|c|c|}
\hline CILHIO12 & $\begin{array}{l}\text { Endres, H., Keller, H. J., Swietlik, R., Schweitzer, D., Angermund, K. \& } \\
\text { Kruger, C. (1986). Z. Naturforsch. A 41, } 1319 .\end{array}$ \\
\hline CILHIO14 & $\begin{array}{l}\text { Kaminskii, V. F., Laukhin, V. N., Merzhanov, V. A., Neiland, O. Y., } \\
\text { Khodorkovskii, V. Y., Shibaeva, R. P. \& Yagubskii, E. B. (1986). Izv. Akad. } \\
\text { Nauk. SSSR, Ser. Khim., } 342 .\end{array}$ \\
\hline CILHIO19 & $\begin{array}{l}\text { Bender, K., Hennig, I., Schweitzer, D., Dietz, K., Endres, H. \& Keller, H. J. } \\
\text { (1984). Mol. Cryst. Liq. Cryst. 108, } 359 \text {. }\end{array}$ \\
\hline $\begin{array}{l}\text { CILHIO20 } \\
\text { CILHIO21 }\end{array}$ & $\begin{array}{l}\text { Emge, T. J., Leung, P. C. W., Beno, M. A., Wang, H. H., Williams, J. M., } \\
\text { Whangbo, M.-H. \& Evain, M. (1986). Mol. Cryst. Liq. Cryst. 138, } 393 .\end{array}$ \\
\hline CILHIO38 & $\begin{array}{l}\text { Kakiuchi, T., Wakabayashi, Y., Sawa, H., Takahashi, T. \& Nakamura, T. } \\
\text { (2007). J. Phys. Soc. Jpn. 76, } 113702 .\end{array}$ \\
\hline CILHIO40 & $\begin{array}{l}\text { Hiramatsu, T., Yoshida, Y., Saito, G., Otsuka, A., Yamochi, H., Maesato, } \\
\text { M., Shimizu, Y., Ito, H. \& Kishida, H. (2015). J. Mater. Chem. C 3, } 1378 .\end{array}$ \\
\hline $\begin{array}{l}\text { COCMIR01 } \\
\text { COCMIR02 }\end{array}$ & Howard, J. A. K. \& Sparkes, H. A. (2008). CrystEngComm 10, 502. \\
\hline CUHZAH & Li, P. \& Yamamoto, H. (2009). J. Am. Chem. Soc. 131, 16628. \\
\hline$\overline{D A Q Y I G}$ & Mapp, L. K., Coles, S. J. \& Aitipamula, S. (2017). CrystEngComm 19, 2925. \\
\hline DATTAV & $\begin{array}{l}\text { Gerus, I. I., Mironetz, R. X., Kondratov, I. S., Bezdudny, A. V., Dmytriv, Y. } \\
\text { V., Shishkin, O. V., Starova, V. S., Zaporozhets, O. A., Tolmachev, A. A. \& } \\
\text { Mykhailiuk, P. K. (2012). J. Org. Chem. 77, } 47 .\end{array}$ \\
\hline DEYXOW & $\begin{array}{l}\text { Wang, Y., Liu, J., Dransfield, P. J., Zhu, L., Wang, Z., Du, X., Jiao, X., Su, } \\
\text { Y., Li, A. -r., Brown, S. P., Kasparian, A., Vimolratana, M., Yu, M., } \\
\text { Pattaropong, V., Houze, J. B., Swaminath, G., Tran, T., Nguyen, K., Guo, } \\
\text { Q., Zhang, J., Zhuang, R., Li, F., Miao, L., Bartberger, M. D., Correll, T. L., } \\
\text { Chow, D., Wong, S., Luo, J., Lin, D. C. -H. \& Medina, J. C. (2013). ACS. } \\
\text { Med. Chem. Lett. 4, 551. }\end{array}$ \\
\hline DHXANT13 & $\begin{array}{l}\text { Cheuk, D., Svard, M., Seaton, C., McArdle, P. \& Rasmuson, A. C. (2015). } \\
\text { CrystEngComm 17, } 3985 .\end{array}$ \\
\hline DOBTUJ07 & $\begin{array}{l}\text { Laukhina, E., Vidal-Gancedo, J., Laukhin, V., Veciana, J., Chuev, I., } \\
\text { Tkacheva, V., Wurst, K. \& Rovira, C. (2003). J. Am. Chem. Soc. 125, } 3948 .\end{array}$ \\
\hline EBODOR & $\begin{array}{l}\text { Nitti, A., Villafiorita-Monteleone, F., Pacini, A., Botta, C., Virgili, T., Forni, } \\
\text { A., Cariati, E., Boiocchi, M. \& Pasini, D. (2017). Faraday Discuss. 196, } \\
\text { 143. }\end{array}$ \\
\hline EGOZIK & $\begin{array}{l}\text { Forero, J. E., Avila, L., Taborda, N., Tabares, P., Lopez, A., Torres, F., } \\
\text { Quinones, W., Bucio, M. A., Mora-Perez, Y., Rugeles, M. T., Joseph- } \\
\text { Nathan, P. \& Echeverri, F. (2008). Phytochemistry 69, } 2815 .\end{array}$ \\
\hline $\begin{array}{l}\text { EJUQIK } \\
\text { EJUQIK01 }\end{array}$ & $\begin{array}{l}\text { Wu, D. -H., Ge, J. -Z., Cai, H. -L., Zhang, W. \& Xiong, R. -G. (2011). } \\
\text { CrystEngComm 13, } 319 .\end{array}$ \\
\hline
\end{tabular}




\begin{tabular}{|c|c|}
\hline EPUQEM & Mukherjee, A. \& Desiraju, G. R. (2011). Chem. Commun. 47, 4090. \\
\hline EXEMOJ & He, H., Rodgers, K. R. \& Arif, A. M. (2004). J. Inorg. Biochem. 98, 667. \\
\hline EZAWAF & $\begin{array}{l}\text { Hariss, L., Bouhadir, K. H., Roisnel, T., Gree, R. \& Hachem, A. (2017). } \\
\text { Synlett 28, } 195 .\end{array}$ \\
\hline EZUZEG & Clegg, W. \& Horsburgh, L. (2016). CSD Communication. \\
\hline FADVOW & $\begin{array}{l}\text { Miyaji, H., Dudic, M., Tucker, J. H. R., Prokes, I., Light, M. E., Hursthouse, } \\
\text { M. B., Stibor, I. \& Lhotak, P. (2002). Tetrahedron Lett. 43, } 873 \text {. }\end{array}$ \\
\hline FAMMOY & $\begin{array}{l}\text { Panda, M. K., Pal, K. B., Raj, G., Jana, R., Moriwaki, T., Mukherjee, G. D., } \\
\text { Mukhopadhyay, B. \& Naumov, P. (2017). Cryst. Growth Des. 17, } 1759 .\end{array}$ \\
\hline FEHFEF & $\begin{array}{l}\text { Cheng, M., Yan, J., Hu, F., Chen, H. \& Hu, Y. (2013). Chemical Science 4, } \\
526 .\end{array}$ \\
\hline FIDJOS & $\begin{array}{l}\text { Karlen, S. D., Khan, S. I. \& Garcia-Garibay, M. A. (2005). Cryst. Growth } \\
\text { Des. 5, 53. }\end{array}$ \\
\hline FOKROO & $\begin{array}{l}\text { Budanow, A., Sinke, T., Lerner, H.-W. \& Bolte, M. (2014). Acta Cryst. C70 } \\
662 .\end{array}$ \\
\hline FUCTIG01 & $\begin{array}{l}\text { Barker, D. J., Buckleton, J. S., Clark, G. R., Cooney, R. P. \& Rickard, C. E. } \\
\text { F. (1990). J. Mol. Struct. 239, } 249 .\end{array}$ \\
\hline FUCTIG02 & $\begin{array}{l}\text { Iyere, P. A., Boadi, W. Y., Atwood, D. \& Parkin, S. (2003). Acta Cryst. B59 } \\
664 .\end{array}$ \\
\hline FUCTIG03 & Mao, H., Zhang, C. \& Shi, H. (2011). J. Phys. Chem. Solids 72, 1230. \\
\hline FUFJUL & $\begin{array}{l}\text { Freer, A. A., Payling, D. W. \& Suschitzky, J. L. (1987). Acta Cryst. C43, } \\
1900 .\end{array}$ \\
\hline $\begin{array}{l}\text { FUGMIF } \\
\text { FUGMIF01 }\end{array}$ & $\begin{array}{l}\text { Wojtas, M., Gagor, A., Czupinski, O., Piecha-Bisiorek, A., Isakov, D., } \\
\text { Medycki, W. \& Jakubas, R. (2015). CrystEngComm 17, } 3171 .\end{array}$ \\
\hline FULLOP & Vo, T. T. \& Shreeve, J. M. (2015). J. Mater. Chem. A 3, 8756. \\
\hline GASWII & $\begin{array}{l}\text { Bezensek, J., Groselj, U., Stare, K., Svete, J. \& Stanovnik, B. (2012). } \\
\text { Tetrahedron 68, 516. }\end{array}$ \\
\hline GENLAN & $\begin{array}{l}\text { Batsanov, A. S., Collings, J. C., Ward, R. M., Goeta, A. E., Porres, L., } \\
\text { Beeby, A., Howard, J. A. K., Steed, J. W. \& Marder, T. B. (2006). } \\
\text { CrystEngComm 8, 622. }\end{array}$ \\
\hline $\begin{array}{l}\text { GETZUD } \\
\text { GEVBAN }\end{array}$ & $\begin{array}{l}\text { Toularoud, M. E., Pourayoubi, M., Dusek, M., Eigner, V. \& Damodaran, K. } \\
\text { (2018). Acta Cryst. C74, } 608 .\end{array}$ \\
\hline GIDHEG & $\begin{array}{l}\text { Braun, U., Sieler, J., Richter, R., Leban, I. \& Golic, L. (1988). Cryst. Res. } \\
\text { Technol. 23, } 35 .\end{array}$ \\
\hline GIDHEG01 & $\begin{array}{l}\text { Schroder, B., Gomes, L. R., Santos, L. M. N. B. F., Brandao, P. \& Low, J. } \\
\text { N. (2011). Acta Cryst. E67, o962. }\end{array}$ \\
\hline
\end{tabular}




\begin{tabular}{|c|c|}
\hline GIKVOO & $\begin{array}{l}\text { Hu, X., Chen, F., Deng, Y., Jiang, H. \& Zeng, W. (2018). Org. Lett. 20, } \\
6140 .\end{array}$ \\
\hline GIYNAE & Menard, F. \& Lautens, M. (2008). Angew. Chem., Int. Ed. 47, 2085. \\
\hline GOLGIX & $\begin{array}{l}\text { Shan, Y. \& Huang, S. D. (1999). Z. Kristallogr. - New Cryst. Struct. 214, } \\
\text { 391. }\end{array}$ \\
\hline GOMKAU & Lehmann, J., Linden, A. \& Heimgartner, H. (1999). Tetrahedron 55, 5359. \\
\hline HAZDOC & $\begin{array}{l}\text { Diaz-Oltra, S., Murga, J., Falomir, E., Carda, M., Peris, G. \& Marco, J. A. } \\
\text { (2005). J.Org.Chem. 70, } 8130 .\end{array}$ \\
\hline HEKZOO & $\begin{array}{l}\text { Peuronen, A., Valkonen, A., Kortelainen, M., Rissanen, K. \& Lahtinen, M. } \\
\text { (2012). Cryst. Growth Des. 12, } 4157 .\end{array}$ \\
\hline HEYJOK & $\begin{array}{l}\text { Anthony, A., Desiraju, G. R., Jetti, R. K. R., Kuduva, S. S., Madhavi, N. N. } \\
\text { L., Nangia, A., Thaimattam, R. \& Thalladi, V. R. (1998). Crystal } \\
\text { Engineering 1, 1. }\end{array}$ \\
\hline $\begin{array}{l}\text { HEYJOK02 } \\
\text { HEYJOK03 } \\
\text { HEYJOK04 } \\
\text { HEYJOK05 } \\
\text { HEYJOK06 } \\
\text { HEYJOK07 } \\
\text { HEYJOK08 }\end{array}$ & $\begin{array}{l}\text { Sathishkumar, R., Mahapatra, S., Thakur, T. S. \& Desiraju, G. R. (2010). } \\
\text { Curr. Sci. 99, } 1807 .\end{array}$ \\
\hline HIFWOK & $\begin{array}{l}\text { Mondal, M., Ho, H. -J., Peraino, N. J., Gary, M. A., Wheeler, K. A. \& } \\
\text { Kerrigan, N. J. (2013). J. Org. Chem. 78, } 4587 .\end{array}$ \\
\hline HMHOCN05 & $\begin{array}{l}\text { Reany, O., Kapon, M., Botoshansky, M. \& Keinan, E. (2009). Cryst. Growth } \\
\text { Des. 9, } 3661 .\end{array}$ \\
\hline HONBIW & $\begin{array}{l}\text { Murakami, T., Tsushima, T., Takada, N., Tanaka, K., Nihei, K., Miura, T. \& } \\
\text { Hashimoto, M. (2009). Bioorg. Med. Chem. 17, } 492 .\end{array}$ \\
\hline HUHMII & $\begin{array}{l}\text { Singh, B., Chauhan, A. K. S., Srivastava, R. C., Duthie, A. \& Butcher, R. J. } \\
\text { (2015). RSC Advances 5, } 58246 .\end{array}$ \\
\hline HUYBIN & $\begin{array}{l}\text { Ning, F., Anderson, R. J., Hibbs, D. E. \& Groundwater, P. W. (2010). } \\
\text { Tetrahedron Lett. 51, } 843 .\end{array}$ \\
\hline HUZDOV & $\begin{array}{l}\text { Paz, F. A. A., Soares-Santos, P. C. R., Nogueira, H. I. S., Trindade, T. \& } \\
\text { Klinowski, J. (2003). Acta Cryst. E59, o506. }\end{array}$ \\
\hline IFOCIQ & Basak, A., Mitra, D., Kar, M. \& Biradha, K. (2008). Chem. Commun., 3067. \\
\hline IFULUQ02 & $\begin{array}{l}\text { Bond, A. D., Haynes, D. A., Pask, C. M. \& Rawson, J. M. (2002). J. Chem. } \\
\text { Soc. Dalton Trans., } 2522 .\end{array}$ \\
\hline IGARIT & Vetter, A., Seichter, W. \& Weber, E. (2013). Acta Cryst. E69, o912. \\
\hline IGUYOA & Tian, T., Li, L., Xue, J., Zhang, J. \& Li, Y. (2015). J. Org. Chem. 80, 4189. \\
\hline
\end{tabular}




\begin{tabular}{|c|c|}
\hline IHIZIK & Shemet, A., Sarlah, D. \& Carreira, E. M. (2015). Org. Lett. 17, 1878. \\
\hline IHOYOT & $\begin{array}{l}\text { Su, Q., Beeler, A. B., Lobkovsky, E., Junior, J. A. P. \& Panek, J. S. (2003). } \\
\text { Org. Lett. 5, } 2149 .\end{array}$ \\
\hline IVUBUY & $\begin{array}{l}\text { Lozynskyi, A., Golota, S., Zimenkovsky, B., Atamanyuk, D., Gzella, A. \& } \\
\text { Lesyk, R. (2016). Phosphorus, Sulfur, Silicon, Relat. Elem. 191, } 1245 .\end{array}$ \\
\hline IWUGIS & $\begin{array}{l}\text { Lin, T.-Y., Zhu, C.-Z., Zhang, P., Wang, Y., Wu, H.-H., Feng, J.-J. \& } \\
\text { Zhang, J. (2016). Angew. Chem. Int. Ed. Engl. 55, } 10844 .\end{array}$ \\
\hline JACVOZ & $\begin{array}{l}\text { Kulesza, A., Mieczkowski, A., Romanski, J. \& Jurczak, J. (2003). } \\
\text { Tetrahedron: Asymmetry 14, } 1161 .\end{array}$ \\
\hline $\begin{array}{l}\text { JAKKUB } \\
\text { JAKKUB01 }\end{array}$ & $\begin{array}{l}\text { Potrzebowski, M. J., Michalska, M., Koziol, A. E., Kazmierski, S., Lis, T., } \\
\text { Pluskowski, J. \& Ciesielski, W. (1998). J. Org. Chem. 63, } 4209 .\end{array}$ \\
\hline JATNEX & $\begin{array}{l}\text { Banister, A. J., Hansford, M. I., Hauptman, Z. V., Wait, S. T. \& Clegg, W. } \\
\text { (1989). J. Chem. Soc., Dalton Trans., } 1705 .\end{array}$ \\
\hline JAWQIH01 & Hao, X., Parkin, S. \& Brock, C. P. (2005). Acta Cryst. B61, 675. \\
\hline JAWQIH03 & $\begin{array}{l}\text { Siegler, M. A., Hao, X., Parkin, S. \& Brock, C. P. (2008). Acta Cryst. B64, } \\
738 .\end{array}$ \\
\hline JECREO & $\begin{array}{l}\text { Ohno, H., Toda, A., Miwa, Y., Taga, T., Fujii, N. \& Ibuka, T. (1999). } \\
\text { Tetrahedron Lett. 40, } 349 .\end{array}$ \\
\hline JEDTIY & $\begin{array}{l}\text { Sriyatep, T., Tantapakul, C., Andersen, R. J., Patrick, B. O., Pyne, S. G., } \\
\text { Muanprasat, C., Seemakhan, S., Borwornpinyo, S. \& Laphookhieo, S. } \\
\text { (2018). Fitoterapia 124, } 34 .\end{array}$ \\
\hline JETYOZ & Karmel, C., Li, B. \& Hartwig, J. F. (2018). J. Am. Chem. Soc. 140, 1460. \\
\hline JIBLUE & $\begin{array}{l}\text { Kerisit, N., Gawel, P., Levandowski, B., Yang, Y. -F., Garcia-Lopez, V., } \\
\text { Trapp, N., Ruhlmann, L., Boudon, C., Houk, K. N. \& Diederich, F. (2018). } \\
\text { Chem. -Eur. J. 24, 159. }\end{array}$ \\
\hline JOKNED & $\begin{array}{l}\text { Jarowicki, K., Kilner, C., Kocienski, P. J., Komsta, Z., Milne, J. E., } \\
\text { Wojtasiewicz, A. \& Coombs, V. (2008). Synthesis, } 2747 .\end{array}$ \\
\hline $\begin{array}{l}\text { JOWGAF } \\
\text { JOWGAF01 }\end{array}$ & $\begin{array}{l}\text { Zhou, Y., Chen, T., Sun, Z., Zhang, S., Ji, C., Song, C. \& Luo, J. (2015). } \\
\text { Chem. Asian J. 10, } 247 .\end{array}$ \\
\hline JOZPIX & $\begin{array}{l}\text { Greaves, M. R., Hamor, T. A., Howlin, B. J., Lobana, T. S., Mbogo, S. A., } \\
\text { McWhinnie, W. R. \& Povey, D. C. (1991). J. Organomet. Chem. 420, } 327 .\end{array}$ \\
\hline KAFDIH & $\begin{array}{l}\text { Jankowski, P., Dranka, M., Zukowska, G. Z. \& Zachara, J. (2015). J. Phys. } \\
\text { Chem. C 119, } 9108 .\end{array}$ \\
\hline KAGVAS & $\begin{array}{l}\text { Jawad, J. K., Mohamed, T. A., Soliman, U. A., Wilson, L. D. \& Abuelela, A } \\
\text { M. (2015). Res. Chem. Intermed. 41, } 4761 \text {. }\end{array}$ \\
\hline KAVHOF & $\begin{array}{l}\text { Delen, Z., Xie, C., Hill, P. J., Choi, J. \& Lahti, P. M. (2005). Cryst. Growth } \\
\text { Des. 5, } 1867 .\end{array}$ \\
\hline
\end{tabular}




\begin{tabular}{|c|c|}
\hline KAVLUP & $\begin{array}{l}\text { Axtell, A. T., Cobley, C. J., Klosin, J., Whiteker, G. T., Zanotti-Gerosa, A. } \\
\text { \& Abboud, K. A. (2005). Angew. Chem., Int. Ed. 44, } 5834 .\end{array}$ \\
\hline $\begin{array}{l}\text { KAWDAQ01 } \\
\text { KAWDUK }\end{array}$ & $\begin{array}{l}\text { Martin, L., Wallis, J. D., Guziak, M., Maksymiw, P., Konalian-Kempf, F., } \\
\text { Christian, A., Nakatsuji, S., Yamada, J. \& Akutsu, H. (2017). Dalton Trans. } \\
\text { 46, } 4225 \text {. }\end{array}$ \\
\hline KAYGUO & $\begin{array}{l}\text { Aakeroy, C. B., Panikkattu, S. V., DeHaven, B. \& Desper, J. (2012). Cryst. } \\
\text { Growth Des. 12, } 2579 .\end{array}$ \\
\hline KISCUM & $\begin{array}{l}\text { O'Mahony, G. E., Eccles, K. S., Morrison, R. E., Ford, A., Lawrence, S. E. } \\
\text { \& Maguire, A. R. (2013). Tetrahedron 69, } 10168 .\end{array}$ \\
\hline KOHRAA & Prasad, G. S. \& Vijayan, M. (1991). Acta Cryst. B47, 927. \\
\hline KURHUC & Dennany, L., Kennedy, A. R. \& Walker, B. (2015). Acta Cryst. C71, 844. \\
\hline $\begin{array}{l}\text { KUTMAP } \\
\text { KUTMAP01 } \\
\text { KUTMAP02 }\end{array}$ & Lopez-Mejias, V. \& Matzger, A. J. (2015). Cryst. Growth Des. 15, 3955. \\
\hline LABQOX & $\begin{array}{l}\text { Blaschette, A., Jones, P. G., Lozano, V. \& Freytag, M. (2014). CSD } \\
\text { Communication(Private Communication). }\end{array}$ \\
\hline LADQAL & $\begin{array}{l}\text { Sato, K., Sandford, G., Shimizu, K., Akiyama, S., Lancashire, M. J., Yufit, } \\
\text { D. S., Tarui, A., Omote, M., Kumadaki, I., Harusawa, S. \& Ando, A. (2016). } \\
\text { Tetrahedron 72, 1690. }\end{array}$ \\
\hline LANBOS & $\begin{array}{l}\text { Banerjee, R., Bhatt, P. M., Kirchner, M. T. \& Desiraju, G. R. (2005). Angew. } \\
\text { Chem., Int. Ed. 44, } 2515 .\end{array}$ \\
\hline $\begin{array}{l}\text { LANXOO } \\
\text { LANXOO01 } \\
\text { LANXOO02 }\end{array}$ & Zielinski, T. \& Jurczak, J. (2005). Tetrahedron 61, 4081. \\
\hline LANXOO01 & $\begin{array}{l}\text { Dobrzycki, L., Zielinski, T., Jurczak, J. \& Wozniak, K. (2005). J. Phys. Org. } \\
\text { Chem. 18, } 864 .\end{array}$ \\
\hline LEPMEZ03 & Schmidt, C. L. \& Jansen, M. (2012). Eur. J. Inorg. Chem., 5649. \\
\hline LOHPON & $\begin{array}{l}\text { Kushch, P. P., Konovalikhin, S. V., Shilov, G. V., Atovmyan, L. O., } \\
\text { Khannanova, T. A. \& Lyubovskaya, R. N. (2000). Izv. Akad. Nauk SSSR, } \\
\text { Ser. Khim. (Russ.)(Russ. Chem. Bull.), 370. }\end{array}$ \\
\hline $\begin{array}{l}\text { LUXYOU } \\
\text { LUXYOU01 } \\
\text { LUXYOU02 }\end{array}$ & $\begin{array}{l}\text { Brandel, C., Cartigny, Y., Couvrat, N., Eusebio, M. E. S., Canotilho, J., } \\
\text { Petit, S. \& Coquerel, G. (2015). Chem. Mater. 27, } 6360 .\end{array}$ \\
\hline LUYPIE & $\begin{array}{l}\text { Karle, I. L., Flippen-Anderson, J. L., Uma, K. \& Balaram, P. (1993). } \\
\text { Int.J.Pept.Protein Res. 42, } 401 .\end{array}$ \\
\hline MAJSOG & Kus, P. \& Jones, P. G. (2004). Acta Cryst. C60, o865. \\
\hline $\begin{array}{l}\text { MAMPUM06 } \\
\text { QOPVAU }\end{array}$ & $\begin{array}{l}\text { Noohinejad, L., Mondal, S., Wolfel, A., Ali, S., Schoenleber, A. \& Smaal } \\
\text { S. v. (2014). J. Chem. Cryst. 44, } 387 .\end{array}$ \\
\hline
\end{tabular}




\begin{tabular}{|c|c|}
\hline MECRAP & $\begin{array}{l}\text { Derollez, P., Guinet, Y., Affouard, F., Danede, F., Carpentier, L. \& Hedoux, } \\
\text { A. (2012). Acta Cryst. B68, } 407 .\end{array}$ \\
\hline MERFEU & $\begin{array}{l}\text { Lhotak, P., Himl, M., Stibor, I., Sykora, J. \& Cisarova, I. (2001). } \\
\text { Tetrahedron Lett. 42, } 7107 .\end{array}$ \\
\hline MEZQIU & $\begin{array}{l}\text { Nisar, M., Wong, L. W. -Y., Sung, H. H. -Y., Haynes, R. K. \& Williams, I. } \\
\text { D. (2018). Acta Cryst. C74, } 742 .\end{array}$ \\
\hline MOBXUW01 & Duncan, L. L., Patrick, B. O. \& Brock, C. P. (2002). Acta Cryst. B58, 502. \\
\hline MOCPUQ & $\begin{array}{l}\text { Nojiri, A., Kumagai, N. \& Shibasaki, M. (2008). J. Am. Chem. Soc. 130, } \\
5630 .\end{array}$ \\
\hline MOGJAV & $\begin{array}{l}\text { Dorrich, S., Ulmer, A., Mahler, C., Burschka, C., Baus, J. A., Tacke, R., } \\
\text { Chai, A., Ding, C., Zou, Y., Brunner, G., Goeke, A. \& Kraft, P. (2014). } \\
\text { Eur.J.Inorg.Chem., } 4394 .\end{array}$ \\
\hline MOVTIB02 & $\begin{array}{l}\text { Bathori, N. B., Lemmerer, A., Venter, G. A., Bourne, S. A. \& Caira, M. R. } \\
\text { (2011). Cryst. Growth Des. 11, } 75 .\end{array}$ \\
\hline MOVWIE & $\begin{array}{l}\text { Nassimbeni, L. R., Ramon, G. \& Taljaard, J. H. (2009). Cryst. Growth Des. } \\
\text { 9, } 88 .\end{array}$ \\
\hline $\begin{array}{l}\text { MUFQAH } \\
\text { MUFQAH01 } \\
\text { MUFQAH02 }\end{array}$ & Schwarzer, A., Fels, S. \& Bohme, U. (2015). Acta Cryst. C71, 511. \\
\hline NAHCOQ & $\begin{array}{l}\text { Mukhopadhyay, C., Rana, S. \& Butcher, R. J. (2010). ARKIVOC 11, 291- } \\
210 .\end{array}$ \\
\hline NAJTIE & $\begin{array}{l}\text { Xue, J., Zhang, H., Tian, T., Yin, K., Liu, D., Jiang, X., Li, Y., Jin, X. \& } \\
\text { Yao, X. (2016). Adv. Synth. Catal. 358, } 370 .\end{array}$ \\
\hline NAJYAB02 & Bin, Z. (2016). CSD Communication. \\
\hline $\begin{array}{l}\text { NAKNEV02 } \\
\text { NAKNEV03 } \\
\text { NAKNEV04 } \\
\text { NAKNOF02 } \\
\text { NAKNOF03 } \\
\text { NAKNOF04 }\end{array}$ & Szafranski, M. (2017). CrystEngComm 19, 179. \\
\hline $\begin{array}{l}\text { NAKNOF } \\
\text { NAKNOF01 }\end{array}$ & Han, X. -B., Hu, P., Shi, C. \& Zhang, W. (2016). CrystEngComm 18, 1563. \\
\hline NANBEL & $\begin{array}{l}\text { Fresno, N., Perez-Fernandez, R., Goya, P., Jimeno, M. L., Alkorta, I., } \\
\text { Elguero, J., Menendez-Taboada, L. \& Garcia-Granda, S. (2011). } \\
\text { Tetrahedron 67, } 9104 .\end{array}$ \\
\hline NAVHEY & Prakash, M. J. \& Radhakrishnan, T. P. (2005). Cryst. Growth Des. 5, 1831. \\
\hline NAXDIZ04 & $\begin{array}{l}\text { Franco, O., Reck, G., Orgzall, I., Schulz, B. W. \& Schulz, B. (2003). J. Mol. } \\
\text { Struct. 649, } 219 .\end{array}$ \\
\hline
\end{tabular}




\begin{tabular}{|c|c|}
\hline NULBIH & Weingand, D., Kiefer, C. \& Podlech, J. (2015). Tetrahedron 71, 1261. \\
\hline NUVJIZ & $\begin{array}{l}\text { Majumder, J., Das, M. R., Deb, J., Jana, S. S. \& Dastidar, P. (2013). } \\
\text { Langmuir 29, } 10254 .\end{array}$ \\
\hline OBILOA & $\begin{array}{l}\text { Udachin, K. A., Ratcliffe, C. I. \& Ripmeester, J. A. (2001). Angew. Chem., } \\
\text { Int. Ed. 40, } 1303 .\end{array}$ \\
\hline OCAZEX & Jones, P. G. (2001). Acta Cryst. C57, 880. \\
\hline OCAZOI & $\begin{array}{l}\text { Parsons, S., Bland, L., Ramage, R. \& Wood, P. A. (2004). CSD } \\
\text { Communication. }\end{array}$ \\
\hline ODUWEQ & $\begin{array}{l}\text { Beckett, M. A., Bland, C. C., Horton, P. N., Hursthouse, M. B. \& Varma, K. } \\
\text { S. (2007). J. Organomet. Chem. 692, } 2832 .\end{array}$ \\
\hline OFANIV & $\begin{array}{l}\text { Bathori, N. B., Jacobs, A., Mei, M. \& Nassimbeni, L. R. (2015). Can. J. } \\
\text { Chem. 93, 858. }\end{array}$ \\
\hline OFAXUP & $\begin{array}{l}\text { Akutsu, H., Yamada, J., Nakatsuji, S. \& Turner, S. S. (2006). Solid State } \\
\text { Commun. 140, 256. }\end{array}$ \\
\hline OGUROZ & $\begin{array}{l}\text { Zentner, C. A., Lai, H. W. H., Greenfield, J. T., Wiscons, R. A., Zeller, M., } \\
\text { Campana, C. F., Talu, O., FitzGerald, S. A. \& Rowsell, J. L. C. (2015). } \\
\text { Chem. Commun. 51, } 11642 .\end{array}$ \\
\hline OKELEW & Varughese, S. \& Desiraju, G. R. (2010). Cryst. Growth Des. 10, 4184. \\
\hline OMOBUP & $\begin{array}{l}\text { Shang, Y., Jin, B., Peng, R., Guo, Z., Liu, Q., Zhao, J. \& Zhang, Q. (2016). } \\
\text { RSC Advances 6, } 48590 .\end{array}$ \\
\hline OMOSAK & Taraba, J. \& Zak, Z. (2004). Acta Cryst. C60, o79. \\
\hline ONANIC01 & $\begin{array}{l}\text { Widlicka, D. W., Murray, J. C., Coffman, K. J., Xiao, C., Brodney, M. A., } \\
\text { Rainville, J. P. \& Samas, B. (2016). Org. Process Res. Dev. 20, } 233 .\end{array}$ \\
\hline OVAPEI & $\begin{array}{l}\text { Green, N. J., Willis, A. C. \& Sherburn, M. S. (2016). Angew. Chem., Int. Ed. } \\
\mathbf{5 5}, 9244 .\end{array}$ \\
\hline PAMTEF & $\begin{array}{l}\text { Schwamm, R. J., Fulton, J. R., Coles, M. P. \& Fitchett, C. M. (2017). Dalton } \\
\text { Trans. 46, 2068. }\end{array}$ \\
\hline PEXTER & $\begin{array}{l}\text { Geiser, U., Schlueter, J. A., Dudek, J. D. \& Williams, J. M. (1996). Mol. } \\
\text { Cryst. Liq. Cryst. Sci. Technol., Sect. A 284, } 203 .\end{array}$ \\
\hline PINCOO & $\begin{array}{l}\text { Huang, L., Turnipseed, S. B., Haltiwanger, R. C., Barkley, R. M. \& Sievers, } \\
\text { R. E. (1994). Inorg. Chem. 33, } 798 .\end{array}$ \\
\hline PIPQUA & Bock, H., Sievert, M. \& Havlas, Z. (1998). Chem. -Eur. J. 4, 677. \\
\hline POLPOX & $\begin{array}{l}\text { Kawazoe, S., Yoshida, K., Shimazaki, Y. \& Oriyama, T. (2014). Chem. Lett. } \\
\text { 43, } 1659 .\end{array}$ \\
\hline PUWRIK & $\begin{array}{l}\text { Dutronc, T., Terazzi, E., Guenee, L., Buchwalder, K.-L., Floquet, S. \& } \\
\text { Piguet, C. (2016). Chem. Eur. J. 22, } 1385 .\end{array}$ \\
\hline
\end{tabular}




\begin{tabular}{|c|c|}
\hline QADTEW & $\begin{array}{l}\text { Pena-Hueso, A., Tellez, F., Vieto-Pena, R., Esquivel, R. O., Esparza-Ruiz, } \\
\text { A., Ramos-Garcia, I., Contreras, R., Barba-Behrens, N. \& Flores-Parra, A. } \\
\text { (2010). J. Mol. Struct. 984, 409. }\end{array}$ \\
\hline QAJDAG & $\begin{array}{l}\text { Wingerter, S., Pfeiffer, M., Baier, F., Stey, T. \& Stalke, D. (2000). Z. Anorg. } \\
\text { Allg. Chem. 626, } 1121 \text {. }\end{array}$ \\
\hline QANVUW & $\begin{array}{l}\text { Furuta, H., Ishizuka, T., Osuka, A. \& Ogawa, T. (2000). J. Am. Chem. Soc. } \\
\text { 122, } 5748 .\end{array}$ \\
\hline QAVYAO & $\begin{array}{l}\text { Toker, J. D., Tremblay, M. R., Yli-Kauhaluoma, J., Wentworth, A. D., Zhou, } \\
\text { B., Jr., P. W. \& Janda, K. D. (2005). J. Org. Chem. 70, } 7810 .\end{array}$ \\
\hline $\begin{array}{l}\text { QIYREX } \\
\text { QIYRIB }\end{array}$ & $\begin{array}{l}\text { Dassonville-Klimpt, A., Cezard, C., Mullie, C., Agnamey, P., Jonet, A., } \\
\text { Nascimento, S. D., Marchivie, M., Guillon, J. \& Sonnet, P. (2013). } \\
\text { ChemPlusChem 78, } 642 .\end{array}$ \\
\hline QIZWIF & $\begin{array}{l}\text { Petra, D. G. I., Kamer, P. C. J., Spek, A. L., Schoemaker, H. E. \& Leeuwen, } \\
\text { P. W. N. M. v. (2000). J. Org. Chem. 65, } 3010 .\end{array}$ \\
\hline QOPVAU & See MAMPUM06, \\
\hline QOSTEZ & $\begin{array}{l}\text { Hebbachi, R., Djedouani, A., Kadri, S., Mousser, H. \& Mousser, A. (2015). } \\
\text { Acta Cryst. E71, o109. }\end{array}$ \\
\hline QUCXOD & $\begin{array}{l}\text { Zhuo, C. -X., Cheng, Q., Liu, W. -B., Zhao, Q. \& You, S. -L. (2015). } \\
\text { Angew. Chem., Int. Ed. 54, } 8475 .\end{array}$ \\
\hline QUJSAP & $\begin{array}{l}\text { Ackerhans, C., Bottcher, P., Muller, P., Roesky, H. W., Uson, I., Schmidt, H. } \\
\text {-G. \& Noltemeyer, M. (2001). Inorg. Chem. 40, } 3766 .\end{array}$ \\
\hline QUQQUO & $\begin{array}{l}\text { Hinchley, S. L., Morrison, C. A., Rankin, D. W. H., Macdonald, C. L. B., } \\
\text { Wiacek, R. J., Voigt, A., Cowley, A. H., Lappert, M. F., Gundersen, G., } \\
\text { Clyburne, J. A. C. \& Power, P. P. (2001). J. Am. Chem. Soc. 123, } 9045 .\end{array}$ \\
\hline QURQOK & $\begin{array}{l}\text { Gharzaryan, V. V., Fleck, M. \& Petrosya, A. M. (2010). J. Mol. Struct. 977, } \\
117 .\end{array}$ \\
\hline QUYNUU & $\begin{array}{l}\text { Ali, Y., Peng, Y., Hua, E., Afza, N. \& Khan, R. A. (2010). Acta Cryst. E66, } \\
\text { o1579. }\end{array}$ \\
\hline RAKZUA & $\begin{array}{l}\text { Lemouchi, C., Simonov, S., Zorina, L., Gautier, C., Hudhomme, P. \& Batail, } \\
\text { P. (2011). Org.Biomol.Chem. 9, } 8096 .\end{array}$ \\
\hline RESMUX & $\begin{array}{l}\text { Raabe, G., Hall, S. R., Thomas, H. G., Wellen, U. \& Simons, J. (1997). Acta } \\
\text { Cryst. C53, } 1107 .\end{array}$ \\
\hline $\begin{array}{l}\text { RIDFOA } \\
\text { RIDFOA01 }\end{array}$ & $\begin{array}{l}\text { Horiuchi, S., Kumai, R. \& Tokura, Y. (2007). Angew. Chem., Int. Ed. 46, } \\
3497 .\end{array}$ \\
\hline RIGSEF & $\begin{array}{l}\text { Avenoza, A., Cativiela, C., Fernandez-Recio, M. A. \& Peregrina, J. M. } \\
\text { (1997). Synthesis, } 165 .\end{array}$ \\
\hline RIQLUZ & $\begin{array}{l}\text { Bichlmaier, I., Kurkela, M., Joshi, T., Siiskonen, A., Ruffer, T., Lang, H., } \\
\text { Finel, M. \& Yli-Kauhaluoma, J. (2007). ChemMedChem 2, } 881 .\end{array}$ \\
\hline
\end{tabular}




\begin{tabular}{|c|c|}
\hline RIWSUL & Nathan, L. C. \& Silver, M. E. (1997). Acta Cryst. C53, 1351. \\
\hline ROPJAJ & Dubey, R. \& Desiraju, G. R. (2014). Angew. Chem., Int. Ed. 53, 13178. \\
\hline SABPOB & $\begin{array}{l}\text { Eddings, D., Barnes, C., Gerasimchuk, N., Durham, P. \& Domasevich, K. } \\
\text { (2004). Inorg. Chem. 43, } 3894 .\end{array}$ \\
\hline SAXNUD & $\begin{array}{l}\text { Chelini, A., Brogi, S., Paolino, M., Capua, A. D., Cappelli, A., Giorgi, G., } \\
\text { Farzad, M., Mannelli, L. D. C., Micheli, L., Ghelardini, C. \& Anzini, M. } \\
\text { (2017). J. Med. Chem. 60, 5216. }\end{array}$ \\
\hline SECHUG & $\begin{array}{l}\text { Luo, X., Lin, X., Salendra, L., Pang, X., Dai, Y., Yang, B., Liu, J., Wang, J., } \\
\text { Zhou, X. \& Liu, Y. (2017). Marine Drugs 15, } 204 .\end{array}$ \\
\hline SEMPEH & $\begin{array}{l}\text { Scott, J. S., Birch, A. M., Brocklehurst, K. J., Broo, A., Brown, H. S., Butlin } \\
\text { R. J., Clarke, D. S., Davidsson, O., Ertan, A., Goldberg, K., Groombridge, S. } \\
\text { D., Hudson, J. A., Laber, D., Leach, A. G., MacFaul, P. A., McKerrecher, } \\
\text { D., Pickup, A., Schofield, P., Svensson, P. H., Sorme, P. \& Teague, J. } \\
\text { (2012). J. Med. Chem. 55, 5361. }\end{array}$ \\
\hline $\begin{array}{l}\text { SEUREA03 } \\
\text { SEUREA04 }\end{array}$ & Luo, Z. \& Dauter, Z. (2017). Plos One 12, e0171740. \\
\hline SEVHAD & $\begin{array}{l}\text { Zanatta, N., Alves, S. H., Coelho, H. S., Borchhardt, D. M., Machado, P., } \\
\text { Flores, K. M., Silva, F. M. d., Spader, T. B., Santurio, J. M., Bonacorso, H. } \\
\text { G. \& Martins, M. A. P. (2007). Bioorg. Med. Chem. 15, } 1947 .\end{array}$ \\
\hline SILJAB & $\begin{array}{l}\text { Zhao, P., Wu, S., Ke, C., Liu, X. \& Feng, X. (2018). Chem. Commun. 54, } \\
9837 .\end{array}$ \\
\hline SIMHUS & $\begin{array}{l}\text { Ma, R., Ma, R., Hou, Y., Yong, X. \& Bao, F. (2007). Acta Cryst. E63, } \\
\text { o4310. }\end{array}$ \\
\hline SOYKOH & $\begin{array}{l}\text { Fun, H. -K., Jebas, S. R., Sujith, K. V. \& Kalluraya, B. (2009). Acta Cryst. } \\
\text { E65, o1242. }\end{array}$ \\
\hline SUHBIG & Kottke, T. \& Stalke, D. (1993). Angew. Chem., Int. Ed. 32, 580. \\
\hline TADWIH & $\begin{array}{l}\text { Bentley, K. W., Joyce, L. A., Sherer, E. C., Sheng, H., Wolf, C. \& Welch, C. } \\
\text { J. (2016). J. Org. Chem. 81, } 1185 .\end{array}$ \\
\hline TAFLET & Fang, Z., Zhou, C., Fu, C. \& Ma, S. (2010). Org. Biomol. Chem. 8, 4554. \\
\hline $\begin{array}{l}\text { TAJVIK } \\
\text { TAJVIK01 }\end{array}$ & $\begin{array}{l}\text { Carre, F., Devylder, N., Dutremez, S. G., Guerin, C., Henner, B. J. L., } \\
\text { Jolivet, A., Tomberli, V. \& Dahan, F. (2003). Organometallics 22, } 2014 .\end{array}$ \\
\hline TAMZIS & $\begin{array}{l}\text { Wolper, C., Rodriguez-Gimeno, A., Iborra, K. C., Dix, I., Freytag, M., } \\
\text { Jones, P. G. \& Blaschette, A. (2011). Z. Naturforsch., B: Chem. Sci. 66, } \\
1161 .\end{array}$ \\
\hline $\begin{array}{l}\text { TAPLII } \\
\text { TAPLII01 }\end{array}$ & $\begin{array}{l}\text { Saito, K., Ikeda, T., Yamamura, Y., Saitoh, H., Hishida, M., Kobayashi, Y., } \\
\text { Fujita, T. \& Ichikawa, J. (2017). J. Chem. Phys. 146, } 74503 .\end{array}$ \\
\hline TARNEG & Yus, M. (2005). Tetrahedron 61, 9325. \\
\hline
\end{tabular}




\begin{tabular}{|c|c|}
\hline TCLOBQ & Zanotti, G. \& Pra, A. D. (1978). Acta Cryst. B34, 2997. \\
\hline TEMBAQ & $\begin{array}{l}\text { Baltus, C. B., Press, N. J., Antonijevic, M. D., Tizzard, G. J., Coles, S. J. \& } \\
\text { Spencer, J. (2012). Tetrahedron 68, } 9272 .\end{array}$ \\
\hline $\begin{array}{l}\text { TETBUS } \\
\text { TETBUS01 } \\
\text { TETBUS02 } \\
\text { TETBUS03 } \\
\text { TETBUS04 }\end{array}$ & $\begin{array}{l}\text { Smets, M. M. H., Pitak, M. B., Cadden, J., Kip, V. R., Wijs, G. A. d., Eck, E. } \\
\text { R. H. v., Tinnemans, P., Meekes, H., Vlieg, E., Coles, S. J. \& Cuppen, H. M. } \\
\text { (2017). Cryst. Growth Des. 18, } 242 .\end{array}$ \\
\hline THIOUR05 & Tanisaki, S., Mashiyama, H. \& Hasebe, K. (1988). Acta Cryst. B44, 441. \\
\hline THIOUR13 & Takahashi, I., Onodera, A. \& Shiozaki, Y. (1990). Acta Cryst. B46, 661. \\
\hline TIWFAG & $\begin{array}{l}\text { Bakshi, P. K., James, M. A., Cameron, T. S. \& Knop, O. (1996). Can. J. } \\
\text { Chem. 74, 559. }\end{array}$ \\
\hline TOXQOO & $\begin{array}{l}\text { Djurendic, E. A., Klisuric, O. R., Szecsi, M., Sakac, M. N., Jovanovic-Santa, } \\
\text { S. S., Ignath, I., Kojic, V. V., Okljesa, A. M., Savic, M. P. \& Penov-Gasi, K. } \\
\text { M. (2014). Struct.Chem. 25, } 1747 .\end{array}$ \\
\hline TPSICI & Sheldrick, G. M. \& Taylor, R. (1975). J. Organomet. Chem. 101, 19. \\
\hline $\begin{array}{l}\text { UCAYIH } \\
\text { UCAYIH01 }\end{array}$ & $\begin{array}{l}\text { Das, D., Banerjee, R., Mondal, R., Howard, J. A. K., Boese, R. \& Desiraju, } \\
\text { G. R. (2006). Chem. Commun., } 555 .\end{array}$ \\
\hline UGOVER & Kamijo, S. \& Yamamoto, Y. (2002). J. Am. Chem. Soc. 124, 11940. \\
\hline UYOPAA & $\begin{array}{l}\text { Lewis, F. W., McCabe, T. C. \& Grayson, D. H. (2011). Tetrahedron 67, } \\
7517 .\end{array}$ \\
\hline UZILIA & $\begin{array}{l}\text { Lobkovsky, E. \& Porco, J. (2016). CSD Communication(Private } \\
\text { Communication). }\end{array}$ \\
\hline VADVIH & $\begin{array}{l}\text { Seredyuk, M., Fritsky, I. O., Kramer, R., Kozlowski, H., Haukka, M. \& } \\
\text { Gutlich, P. (2010). Tetrahedron 66, } 8772 .\end{array}$ \\
\hline VAFHEQ & $\begin{array}{l}\text { Harmsen, D., Erker, G., Frohlich, R. \& Kehr, G. (2002). Eur. J. Inorg. } \\
\text { Chem., } 3156 .\end{array}$ \\
\hline VAHKIB & $\begin{array}{l}\text { Davies, S. G., Fletcher, A. M., Frost, A. B., Kennedy, M. S., Roberts, P. M. } \\
\text { \& Thomson, J. E. (2016). Tetrahedron 72, } 2139 .\end{array}$ \\
\hline VALPOP & Hong, K. \& Morken, J. P. (2011). J. Org. Chem. 76, 9102. \\
\hline $\begin{array}{l}\text { VANFOI01 } \\
\text { VANFOI02 } \\
\text { VANFOI03 }\end{array}$ & $\begin{array}{l}\text { Frampton, C. S., Ketuly, K. K., Ali, H. B. M., Azizan, A. H. S., Gall, J. H. \& } \\
\text { MacNicol, D. D. (2017). CrystEngComm 19, } 2653 . \\
\text { (NB/ refcode VANFOIO3 was VANFUO until mid-2019) }\end{array}$ \\
\hline VETNIR & $\begin{array}{l}\text { Roussis, V., Wu, Z., Fenical, W., Strobel, S. A., Duyne, G. D. V. \& Clardy, } \\
\text { J. (1990). J.Org.Chem. 55, } 4916 .\end{array}$ \\
\hline $\begin{array}{l}\text { VIGCIZ } \\
\text { VIGCOF }\end{array}$ & $\begin{array}{l}\text { Gao, N., Ma, X., Petit, L., Schwartz, B. D., Banwell, M. G., Willis, A. C., } \\
\text { Cade, I. A. \& Rae, A. D. (2013). Aust. J. Chem. 66, } 30 .\end{array}$ \\
\hline
\end{tabular}




\begin{tabular}{|c|c|}
\hline $\begin{array}{l}\text { VIVSAV01 } \\
\text { VIVSAV02 } \\
\text { VIVSAV03 } \\
\text { VIVSAV04 }\end{array}$ & Slepokura, K. A. (2016). Acta Cryst. B72, 117. \\
\hline VOZMAY & Kopf, J., Morf, M., Zimmer, B. \& Koll, P. (1991). Carbohydr. Res. 218, 9. \\
\hline VUZTIU & $\begin{array}{l}\text { Mahmud, T., Thebo, K. H., Rehman, R., Malik, M. A. \& Helliwell, M. } \\
\text { (2010). Acta Cryst. E66, o2781. }\end{array}$ \\
\hline WADXAA & $\begin{array}{l}\text { Ando, T., Ota, M., Kashiwagi, T., Nagashima, N., Ariyoshi, Y., Chadha, R. } \\
\text { K., Yamazaki, T. \& Goodman, M. (1993). J. Am. Chem. Soc. 115, } 397 .\end{array}$ \\
\hline WAKWEM & $\begin{array}{l}\text { Etzkorn, M., Smeltz-Zapata, S. D., Meyers, T. B., Yu, X. \& Gerken, M. } \\
\text { (2010). Tetrahedron Lett. 51, 6075. }\end{array}$ \\
\hline WANJAZ & $\begin{array}{l}\text { Arlt, A., Toyama, H., Takada, K., Hashimoto, T. \& Maruoka, K. (2017). } \\
\text { Chem. Commun. 53, } 4779 .\end{array}$ \\
\hline WAWPES & Thieme, N. \& Breit, B. (2017). Angew. Chem., Int. Ed. 56, 1520. \\
\hline WEZBAF & $\begin{array}{l}\text { Metta-Magana, A. J., Reyes-Martinez, R. \& Tlahuext, H. (2007). } \\
\text { Carbohydr. Res. 342, } 243 .\end{array}$ \\
\hline WEZBAF01 & Marsh, R. E. (2009). Acta Cryst. B65, 782. \\
\hline WOPVOO & $\begin{array}{l}\text { Prohens, R., Font-Bardia, M. \& Portell, A. (2014). CSD } \\
\text { Communication(Private Communication). }\end{array}$ \\
\hline WUHNOC01 & $\begin{array}{l}\text { Zhang, L.-X., Hu, M.-L., Zhang, A.-J. \& Xiang, G.-Q. (2002) Z. Kristallogr. } \\
\text { - New Cryst. Struct. 217, } 494\end{array}$ \\
\hline XAPKOQ & $\begin{array}{l}\text { Wu, Y. -J., Huang, S., Ng, A., Gao, Q., Kimura, S. R. \& Langley, D. R. } \\
\text { (2010). Tetrahedron Lett. 51, } 2144 .\end{array}$ \\
\hline XATRAL & Meyer, O. G. J., Frohlich, R. \& Haufe, G. (2000). Synthesis 2000, 1479. \\
\hline XECPON & $\begin{array}{l}\text { Gunawardana, C. A., Desper, J., Sinha, A. S., akovic, M. \& Aakeroy, C. B. } \\
\text { (2017). Faraday Discuss. 203, } 371 .\end{array}$ \\
\hline XEFXAJ & $\begin{array}{l}\text { Kennedy, R. D., Halim, M., Khan, S. I., Schwartz, B. J., Tolbert, S. H. \& } \\
\text { Rubin, Y. (2012). Chem. Eur. J. 18, } 7418 .\end{array}$ \\
\hline XEGKIG & Ambika, R. (2017). CSD Communication(Private Communication). \\
\hline XELKAB & $\begin{array}{l}\text { Horikawa, M., Hashimoto, T., Asakawa, Y., Takaoka, S., Tanaka, M., Kaku, } \\
\text { H., Nishii, T., Yamaguchi, K., Masu, H., Kawase, M., Suzuki, S., Sato, M. \& } \\
\text { Tsunoda, T. (2006). Tetrahedron 62, } 9072 .\end{array}$ \\
\hline XEPHUX & Sun, L., Wang, T. \& Ye, S. (2012). Chin. J. Chem. 30, 190. \\
\hline XIFMOQ & $\begin{array}{l}\text { Villemin, E., Robeyns, K., Robiette, R., Herent, M. -F. \& Marchand- } \\
\text { Brynaert, J. (2013). Tetrahedron 69, } 1138 .\end{array}$ \\
\hline XODGAA & Ren, J., Liu, Y., Song, L. \& Tong, R. (2014). Org.Lett. 16, 2986. \\
\hline
\end{tabular}




\begin{tabular}{|l|l|}
\hline $\begin{array}{l}\text { XOJYEC } \\
\text { XOJYEC01 } \\
\text { XOJYEC02 }\end{array}$ & $\begin{array}{l}\text { McKellar, S. C., Kennedy, A. R., McCloy, N. C., McBride, E. \& Florence, } \\
\text { A. J. (2014). Cryst. Growth Des. 14, 2422. }\end{array}$ \\
\hline XUYTIW & $\begin{array}{l}\text { Kulikov, O. V., McCandless, G. T., Siriwardane, D. A., Sevryugina, Y. V. \& } \\
\text { Novak, B. M. (2015). Tetrahedron Lett. 56, 6309. }\end{array}$ \\
\hline YARZAV & $\begin{array}{l}\text { Zhou, W., Wang, H., Tao, M., Zhu, C. -Z., Lin, T. -Y. \& Zhang, J. (2017). } \\
\text { Chemical Science 8, 4660. }\end{array}$ \\
\hline YERFOT & $\begin{array}{l}\text { Stieler, R., Junior, O. d. L. C. \& Oliveira, L. L. d. (2018). CSD } \\
\text { Communication(Private Communication). }\end{array}$ \\
\hline YEZDEN & Lough, A. \& McKague, A. B. (2006). Synth.Commun. 36, 3387. \\
\hline YIDPUX & Poisot, M., Nather, C. \& Bensch, W. (2007). Acta Cryst. E63, m1751. \\
\hline YIZTOR & $\begin{array}{l}\text { Tatsuta, K., Furuyama, A., Yano, T., Suzuki, Y., Ogura, T. \& Hosokawa, S. } \\
\text { (2008). Tetrahedron Lett. 49, 4036. }\end{array}$ \\
\hline YOHKOX01 & $\begin{array}{l}\text { Bond, A. D., Cornett, C., Larsen, F. H., Qu, H., Raijada, D. \& Rantanen, J. } \\
\text { (2014). IUCrJ 1, 328. }\end{array}$ \\
\hline YOHKOX01 & $\begin{array}{l}\text { Bond, A. D., Cornett, C., Larsen, F. H., Qu, H., Raijada, D. \& Rantanen, J. } \\
\text { (2014). IUCrJ 1, 328. }\end{array}$ \\
\hline YUJGOZ & $\begin{array}{l}\text { Kromm, P., Allouchi, H., Bideau, J.-P., Cotrait, M. \& Nguyen, H. T. (1995). } \\
\text { Acta Cryst. C51, 1229. }\end{array}$ \\
\hline YUVLOS & $\begin{array}{l}\text { Kelly, N., Schulz, J., Gloe, K., Doert, T., Gloe, K., Wenzel, M., Acker, M. \& } \\
\text { Weigand, J. J. (2015). Z. Anorg. Allg. Chem. 641, 2215. }\end{array}$ \\
\hline $\begin{array}{l}\text { ZATLAJ } \\
\text { ZATLAJ01 } \\
\text { ZATLAJ03 }\end{array}$ & $\begin{array}{l}\text { Anderson, K. M., Goeta, A. E., Martin, J. E., Mason, S. A., McIntyre, G. J., } \\
\text { Sansam, B. C. R., Wilkinson, C. \& Steed, J. W. (2011). Cryst. Growth Des. } \\
\mathbf{1 1 , ~ 4 9 0 4 . ~}\end{array}$ \\
\hline ZITFIT & $\begin{array}{l}\text { Shen, C. -T., Liu, Y. -H., Peng, S. -M. \& Chiu, C. - W. (2013). Angew. } \\
\text { Chem., Int. Ed. 52, 13293. }\end{array}$ \\
\hline ZZZVCO04 & $\begin{array}{l}\text { Damay, F., Carretero-Genevrier, A., Cousson, A., Rodriguez-Carvajal, J., } \\
\text { Beek, W. V. \& Fillaux, F. (2006). Acta Cryst. B62, 627. } \\
\text { Struct. 213, 80. }\end{array}$ \\
\hline ZZZVCO05 & Palatinus, L. \& Damay, F. (2009). Acta Cryst. B65, 784. \\
\hline ZZZVCO06 & $\begin{array}{l}\text { Topic, F., Puttreddy, R., Rautiainen, J. M., Tuononen, H. M. \& Rissanen, K. } \\
\text { 2017). CrystEngComm 19, 4960. }\end{array}$ \\
\hline Dunand, A. \& Gerdil, R. (1982). Acta Cryst. B38, 570. \\
\hline ZZZVY12
\end{tabular}

